Aus der Abteilung Allgemein- und Viszeralchirurgie

(Prof. Dr. med. M. B. Ghadimi)

im Zentrum Chirurgie

der Medizinischen Fakultät der Universität Göttingen

\title{
Identifizierung potentieller Onkogene und therapeutischer Zielgene auf Chromosom 13q beim Kolonkarzinom
}

\author{
INAUGURAL-DISSERTATION \\ zur Erlangung des Doktorgrades \\ der Medizinischen Fakultät \\ der Georg-August-Universität zu Göttingen \\ vorgelegt von \\ Georg Emons \\ aus \\ Eutin
}

Göttingen 2013 
Dekan:

1. Berichterstatter:

2. Berichterstatter:

3. Berichterstatter:

Tag der mündlichen Prüfung:
Prof. Dr. med. M.P. Schön

Prof. Dr. med. Ghadimi

Prof. Dr. rer. nat. Burfeind

Prof. Dr. med. Oppermann 


\section{Inhaltsverzeichnis}

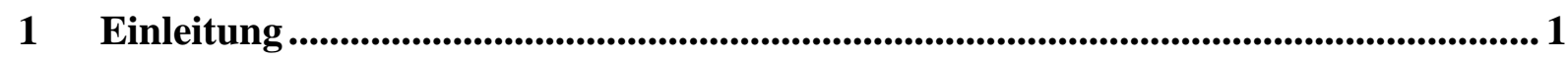

1.1 Epidemiologie kolorektaler Tumoren .............................................................. 1

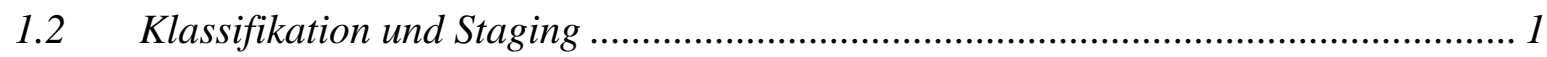

1.2.1 TNM-Klassifikation des kolorektalen Karzinoms........................................... 1

1.2.2 Stadieneinteilung des kolorektalen Karzinoms .............................................. 2

1.3 Lokalisation des kolorektalen Karzinoms ............................................................. 3

1.4 Therapie des kolorektalen Karzinoms................................................................. 3

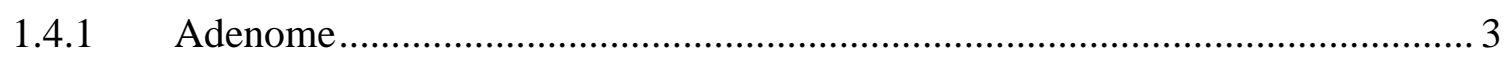

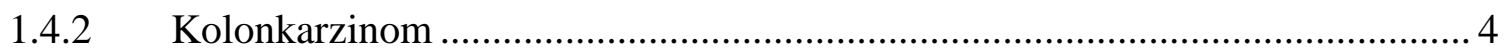

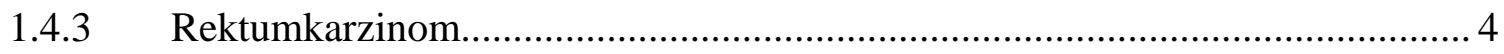

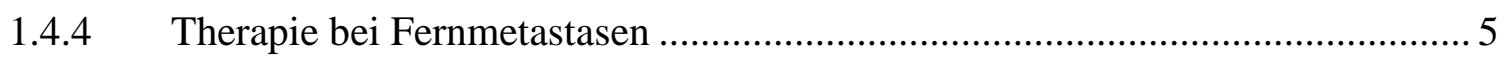

1.5 Genetische Grundlagen der kolorektalen Karzinogenese ....................................... 5

1.5.1 Genetisches Progressionsmodell des kolorektalen Karzinoms........................... 6

1.5.2 Ploidiestatus und genomische Instabilität................................................. 9

1.5.3 Chromosomales Progressionsmodell .......................................................... 11

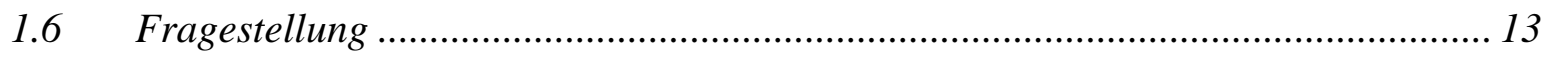

2 Material und Methoden ................................................................................................................ 14

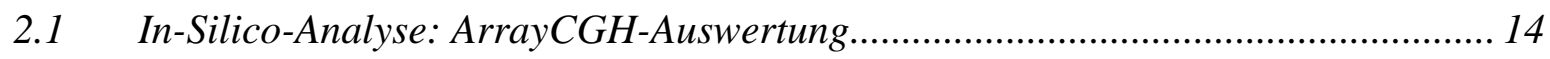

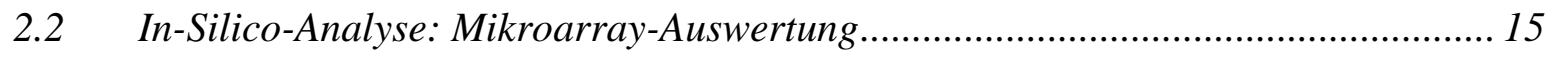

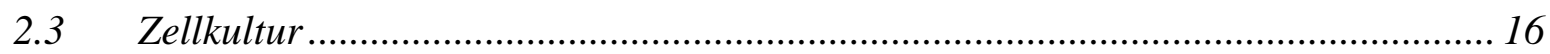

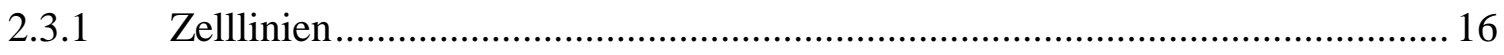

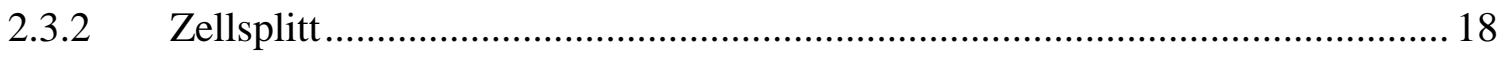

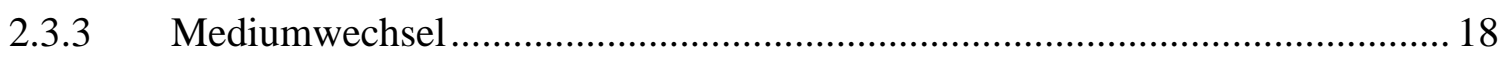

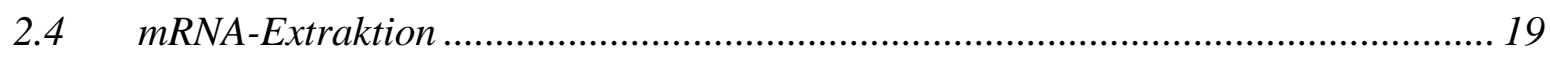

2.4.1 RNA-Isolation für Genexpressionsanalysen (Mikroarray-Validierung) .......... 19

2.4.2 RNA-Qualitäts- und Mengenmessung .................................................... 21 


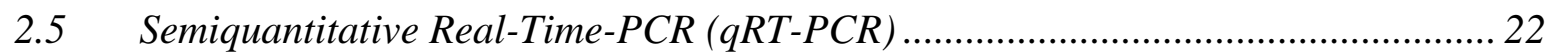

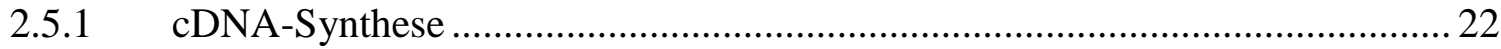

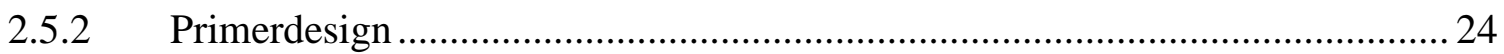

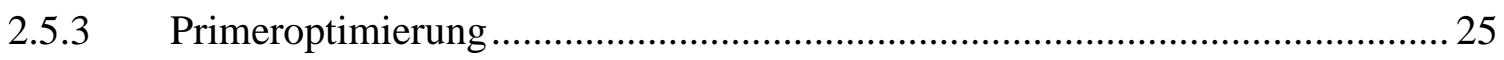

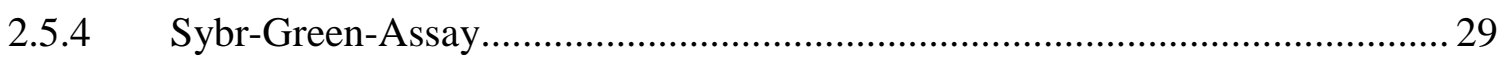

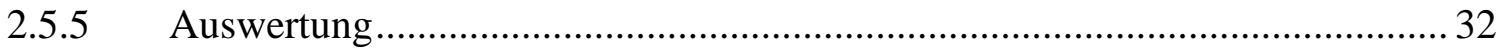

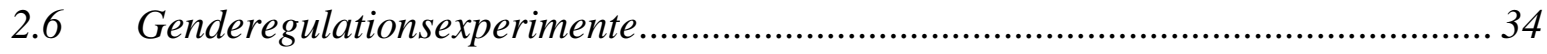

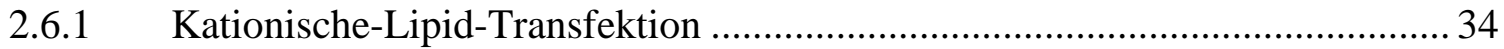

2.6.2 Genderegulation durch ,,Small-interfering-RNA“ (siRNA) ............................. 34

2.6.3 Viabilitätsassay (,Cell-Titer-Blue-Assay“).................................................. 38

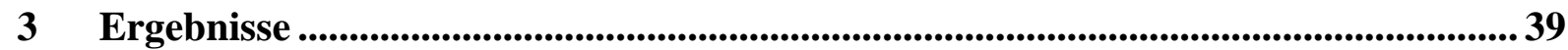

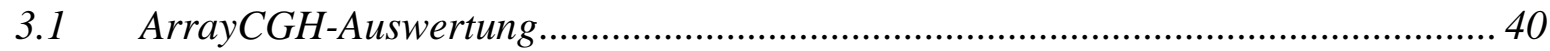

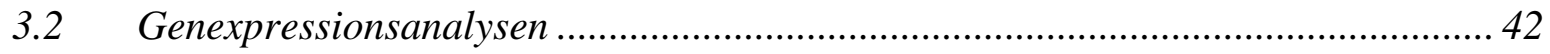

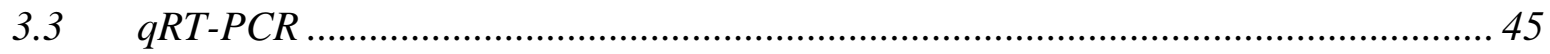

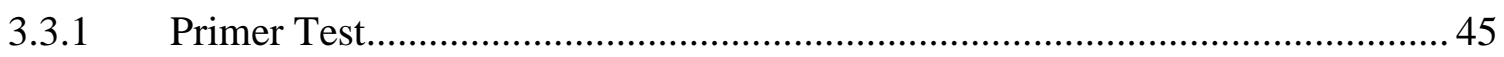

3.3.2 qRT-PCR der 25 Zelllinien zur Arrayvalidierung ....................................... 46

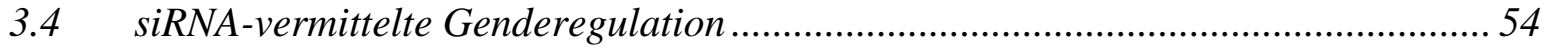

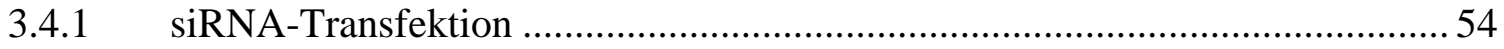

3.4.2 Viabilitätsassay und Knockdown-Validierung .............................................. 54

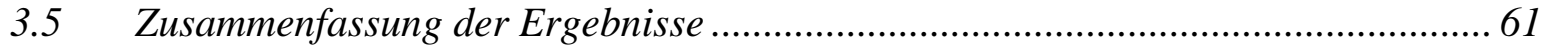

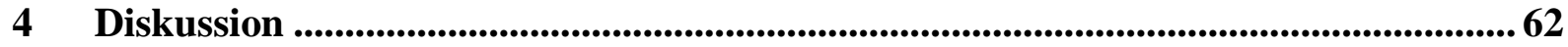

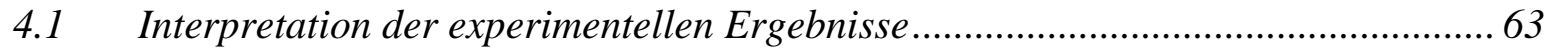

4.1.1 Identifikation zweier Regionen auf 13q mit regelmäßigen Zugewinnen ......... 63

4.1.2 Überexprimierte Gene in den beiden Regionen.............................................. 64

4.1.3 Genexpressionsprofil der Zelllinien und Mikroarray-Validierung .................... 64

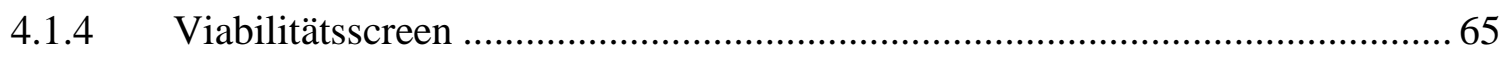

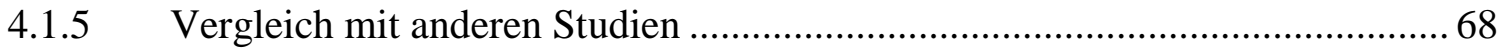

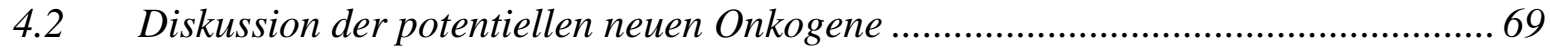

4.2.1 ATP7B (,ATPase, $\mathrm{Cu}^{2+}$ transporting, beta polypeptide $\left.{ }^{\star 6}\right)$.................................69 69

4.2.2 POMP (,proteasome maturation protein $\left.{ }^{\star \prime}\right)$......................................................... 70 
4.2.3 RFC3 (,,replication factor C (activator 1) 3 “) ............................................... 70

4.2.4 NUPL1 („,nucleoporin like 1“) ..................................................................... 71

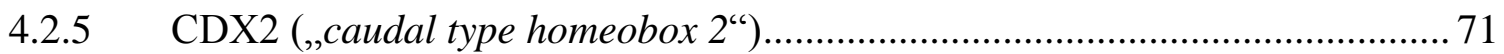

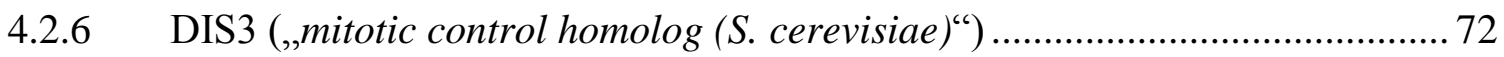

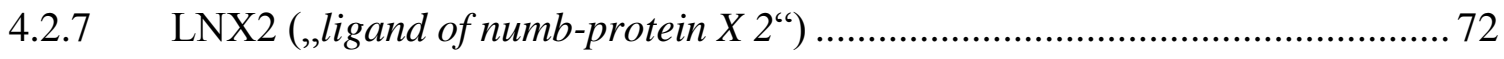

4.2.8 CKAP2 (, cytoskeleton associated protein 2“)/ TMAP (,,cytoskeleton

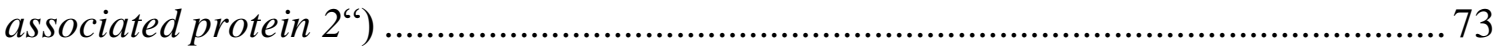

4.2.9 SLC7A1 (,solute carrier family 7 (cationic amino acid transporter, $y+$

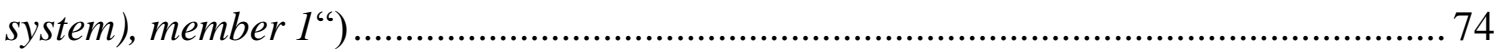

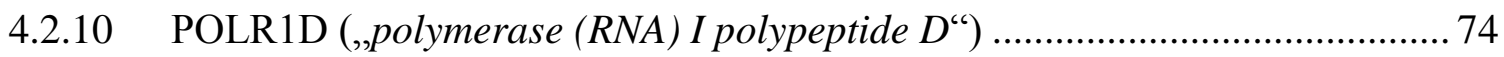

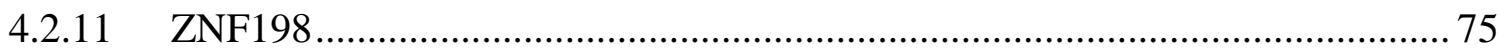

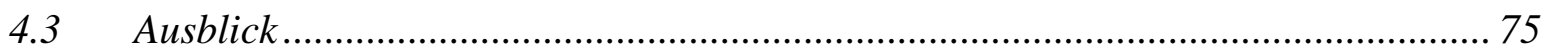

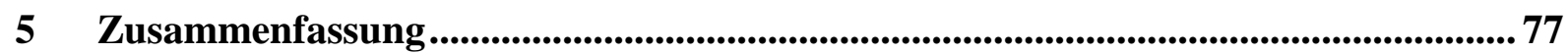

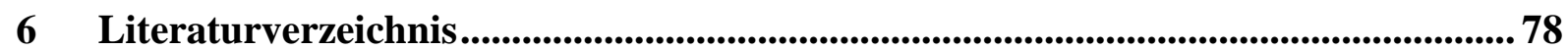

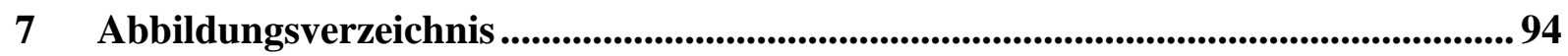

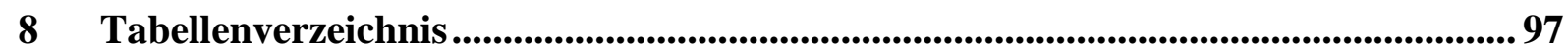

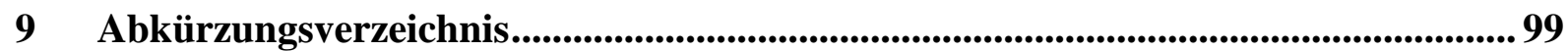




\section{$1 \quad$ Einleitung}

\subsection{Epidemiologie kolorektaler Tumoren}

Das kolorektale Karzinom ist mit mehr als 70000 Neuerkrankungsfällen pro Jahr noch vor dem Brustkrebs (ca. 46000) und dem Lungenkrebs (ca. 37000) die häufigste neoplastische Erkrankung in Deutschland (Robert-Koch-Institut 2010). Es tritt meistens sporadisch auf, nur in 5-10\% der Fälle gibt es eine hereditäre Ursache. Hierbei handelt es sich meistens um die familiäre adenomatöse Polyposis (FAP) oder das hereditäre nichtpolypöse kolorektale Karzinom (HNPCC). Darüber hinaus gibt es seltene hereditäre Erkrankungen, wie das PeutzJeghers oder das Juvenile Polyposis-Syndrom (US-Preventive-Services-Task-Force 2008). Das Hauptmanifestationsalter liegt zwischen dem 60. und 70. Lebensjahr, ab einem Alter von 50 Jahren steigt die Inzidenz dramatisch an. 5\% der Bevölkerung in Deutschland erkranken im Laufe ihres Lebens an einem kolorektalen Karzinom. Hauptrisikofaktoren sind neben dem Alter männliches Geschlecht, übermäßige Kalorien- und Alkoholzufuhr, der Verzehr von rotem Fleisch sowie verminderte körperliche Aktivität (Huxley et al. 2009).

\subsection{Klassifikation und Staging}

\subsubsection{TNM-Klassifikation des kolorektalen Karzinoms}

Das Staging des kolorektalen Karzinoms erfolgt anhand der von der „Union internationale contre le cancer" (UICC) herausgegebenen TNM-Klassifikation für solide Tumoren. T bezeichnet die Tiefeninvasion des Primärtumors, N gibt Informationen über das Vorliegen von Lymphknotenmetastasen, M über eventuell vorhandene Fernmetastasen. In Tabelle 1 sind die Kriterien der TNM-Klassifikation zusammengefasst. 


\begin{tabular}{|c|c|c|c|c|c|}
\hline T0 & Keine Infiltration & N0 & \begin{tabular}{|l|} 
Keine \\
Lympknotenmetastasen \\
\end{tabular} & M0 & $\begin{array}{l}\text { Keine } \\
\text { Fernmetastasen }\end{array}$ \\
\hline $\mathrm{T} 1$ & $\begin{array}{l}\text { Tumor infiltriert } \\
\text { Submukosa }\end{array}$ & N1 & $\begin{array}{l}<3 \text { perikolische/perirektale } \\
\text { Lympknotenmetastasen }\end{array}$ & M1 & Fernmetastasierung \\
\hline $\mathrm{T} 2$ & $\begin{array}{l}\text { Tumor infiltriert } \\
\text { Muscularis propria }\end{array}$ & $\mathrm{N} 2$ & $\begin{array}{l}\text { >3 perikolische/perirektale } \\
\text { Lympknotenmetastasen }\end{array}$ & & \\
\hline $\mathrm{T} 3$ & $\begin{array}{l}\text { Tumor infiltriert durch } \\
\text { die Muscularis propria in } \\
\text { die Subserosa oder in } \\
\text { nicht peritonealisiertes } \\
\text { perikolisches oder } \\
\text { perirektales Gewebe }\end{array}$ & & & & \\
\hline $\mathrm{T} 4$ & $\begin{array}{l}\text { Tumor infiltriert } \\
\text { Organe/Strukturen } \\
\text { und/oder perforiert das } \\
\text { viszerale Peritoneum }\end{array}$ & & & & \\
\hline
\end{tabular}

Tabelle 1: TNM-Klassifikation des kolorektalen Karzinoms (mod. nach Wittekind 2010, S. 67-70)

\subsubsection{Stadieneinteilung des kolorektalen Karzinoms}

Die Stadieneinteilung des kolorektalen Karzinoms erfolgt nach den Kriterien der UICC von I bis IV und ermöglicht eine Prognoseeinschätzung und eine Therapieempfehlung.

\begin{tabular}{|l|l|l|l|}
\hline Stadium Ia & T1 & N0 & M0 \\
\hline Stadium Ib & T2 & N0 & M0 \\
\hline Stadium II & T3, T4 & N0 & M0 \\
\hline Stadium III & Alle T & N1, N2 & M0 \\
\hline Stadium IV & Alle T & Alle N & M1 \\
\hline
\end{tabular}

Tabelle 2: Stadieneinteilung des kolorektalen Karzinoms nach der UICC (mod. nach Wittekind 2010, S. 67-70) 


\subsection{Lokalisation des kolorektalen Karzinoms}

Das kolorektale Karzinom entsteht zu über 60\% jenseits der linken Kolonflexur, 25\% liegen weiter oral. Ein Großteil der linksseitig gelegenen Tumore entfällt auf das Sigma und das Rektum (Eberl 2004).

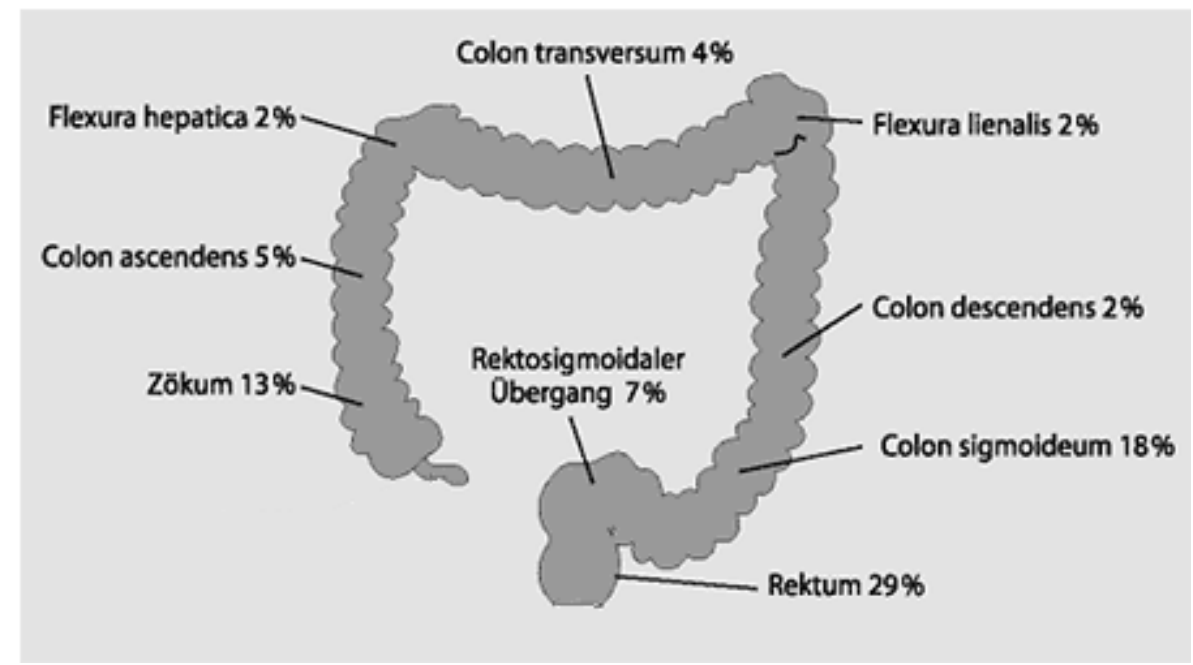

Abbildung 1: Verteilung und Lokalisation des kolorektalen Karzinoms (Schmoll et al. 2007)

\subsection{Therapie des kolorektalen Karzinoms}

Die Therapie des kolorektalen Karzinoms hat sich in den letzten Jahren zu einer multimodalen, interdisziplinären Behandlung entwickelt. Daher werden die aktuellen Therapiemöglichkeiten und Strategien hier nur kurz (und stark vereinfacht) dargestellt.

\subsubsection{Adenome}

Da die Mehrheit der kolorektalen Karzinome aus adenomatösen Polypen entsteht, besteht die Empfehlung, diese präventiv im Rahmen einer Koloskopie abzutragen. Eine solche Koloskopie wird ab dem 55. Lebensjahr empfohlen und auch von den Krankenkassen erstattet (Jass 2007). Das Risiko einer Entartung dieser Adenome hängt von ihrer Größe, Histologie und dem Grad der intraepithelialen Metaplasie ab. Dementsprechend sind auch die Empfehlungen für Kontrollkoloskopien: bei kleinen wenigen Adenomen reicht eine Koloskopie nach 6 Jahren, bei größeren nach 3 Jahren. Bei schwer abzutragenden serratierten Polypen sollte eine Kontrollkoloskopie bereits nach wenigen Monaten erfolgen (Jass 2007). 
Stellt sich bei der anschließenden pathologischen Aufarbeitung heraus, dass es sich bei einem Adenom bereits um einen T1-Tumor handelt, entscheidet sich das weitere therapeutische Vorgehen anhand des Gradings. Handelt es sich um einen gut differenzierten Tumor (G1 oder G2) und liegt keine Lymphgefäßinvasion vor (,low-risk“-Situation), kann bei gesicherter R0Resektion auf eine Nachresektion des Tumors verzichtet werden. In einer „high-risk“Situation (G3 oder G4, Lymphgefäßinvasion) sollte eine Nachresektion nach onkologischen Kriterien erfolgen (Schmiegel et al. 2008).

\subsubsection{Kolonkarzinom}

Das Kolonkarzinom wird in der Regel primär operiert, dabei sollte nach Möglichkeit eine R0Resektion erfolgen. Entscheidend für die weitere Therapie ist die postoperative, pathologische Aufarbeitung und Stadieneinteilung des Präparates. Idealerweise werden dabei mindestens 12 Lymphknoten untersucht (Schmiegel et al. 2008). Im UICC-Stadium I kann auf eine adjuvante Therapie verzichtet werden, im UICC-Stadium II hingegen ist eine adjuvante Therapie bei erhöhter Rezidivgefahr, T4-Stadium, intraoperativer Tumorperforation, Notfalloperation und weniger als 12 histopathatologisch aufgearbeiteten Lymphknoten, mit einem Fluoropyrimidin angebracht. Bei älteren Patienten ist eine Chemotherapie eher zurückhaltend anzuwenden. Im Stadium III sollte eine Therapie mit 5-FU und Oxaliplatin erfolgen (Schmiegel et al. 2008).

\subsubsection{Rektumkarzinom}

Aufgrund der lokalen anatomischen Bedingungen kommt es beim Rektumkarzinom häufiger als beim Kolonkarzinom zu Lokalrezidiven. Lediglich im UICC-Stadium I erfolgt die primäre Operation mit totaler mesorektaler Exzision. Im lokal fortgeschrittenen Stadium (UICC II und III) wird eine neoadjuvante Vorbehandlung durchgeführt. Diese kann aus einer alleinigen Bestrahlung oder aus einer kombinierten (Radio-)Chemotherapie mit 5-FU und gegebenenfalls Oxaliplatin oder Irinotecan bestehen. Ziel der neoadjuvanten Therapie ist es, das Tumorvolumen zu verkleinern, so dass bei lokal fortgeschrittenen Tumoren eine bessere Resektabilität (R0-Resektion) erreicht wird, oder bei sehr tief sitzenden Tumoren eine sphinktererhaltende Operation durchgeführt werden kann. Postoperativ wird eine adjuvante Chemotherapie mit 5-FU verabreicht, damit sollen disseminierte Tumorzellen vernichtet werden (Schmiegel et al. 2008). 


\subsubsection{Therapie bei Fernmetastasen}

Ab UICC IV erfolgt eine stark differenzierte Therapie unter Berücksichtigung des Gesamtkrankheitsbildes des Patienten. Hier soll daher nur kurz eine stark vereinfachte und gekürzte Version dargestellt werden. Ist eine R0-Resektion der gesamten Tumormasse bei einer singulären Leber- oder Lungenmetastase möglich und gibt es keine weitere Metastasierung oder Begleiterkrankungen, kann eine primäre Resektion des metastasierten Tumoranteiles erfolgen. Ist dies nicht der Fall, besteht die Möglichkeit einer neoadjuvanten Radiochemotherapie, um die Ergebnisse einer kurativen chirurgischen Intervention zu verbessern und eine R0-Resektion zu ermöglichen. Nach der Operation wird eine adjuvante Therapie empfohlen. Neben diesen kurativen Strategien gibt es bei nicht resektablen Tumoren/Metastasen oder bei weiteren schweren Begleiterkrankungen palliative Konzepte. Beispielsweise kann eine systemische Chemotherapie mit einem Fluoropyrimidin und Oxaliplatin oder Irinotecan erfolgen. Zusätzlich können Inhibitoren gegen den „Vascular Endothelial Growth Factor“ (VEGF) oder den „Epidermal Growth Factor Receptor“ (EGFR) angewand werden (Schmiegel et al. 2008).

\subsection{Genetische Grundlagen der kolorektalen Karzinogenese}

Krebs ist eine komplexe polygenetische, multifaktorielle Erkrankung und beruht auf einer genetisch determinierten Fehlsteuerung somatischer Zellen. Letztendlich werden die physiologischen Regelkreise gestört und es kommt $\mathrm{zu}$ folgenden Veränderungen der Zellphysiologie einer somatischen Zelle: Autonomie gegenüber externen Wachstumsfaktoren, Unempfindlichkeit gegenüber Wachstumsinhibitoren, Apoptoseresistenz, unlimitiertes Teilungspotential, Aufrechterhaltung der Angioneogenese und infiltratives Wachstum mit Metastasenbildung (Hanahan und Weinberg 2000; Hanahan und Weinberg 2011).

Kolorektale Karzinome entwickeln sich im Verlauf von Jahren aus Adenomen. Die AdenomKarzinom-Sequenz wurde erstmalig 1978 anhand morphologischer Veränderungen beschrieben (Day und Morson 1978). Hierauf basierend wurde ein genetisches Progressionsmodell entwickelt, welches die morphologischen Veränderungen mit genetischen Ursachen assoziiert (Vogelstein et al. 1988; Fearon und Vogelstein 1990; Fearon 2011).

Wesentlich für die Progression vom Adenom zum Karzinom sind hiernach vier Schlüsselgene: $A P C, K R A S, S M A D 4$ und $p 53$. Unterschieden wird in frühe und späte Veränderungen, allerdings ist die Reihenfolge der Veränderungen nicht starr, vielmehr kommt 
es im Verlauf der Tumorprogression zu einer Akkumulation von Mutationen. Dieses Progressionsmodell wird im Folgenden erläutert und ist in Abbildung 2 dargestellt.

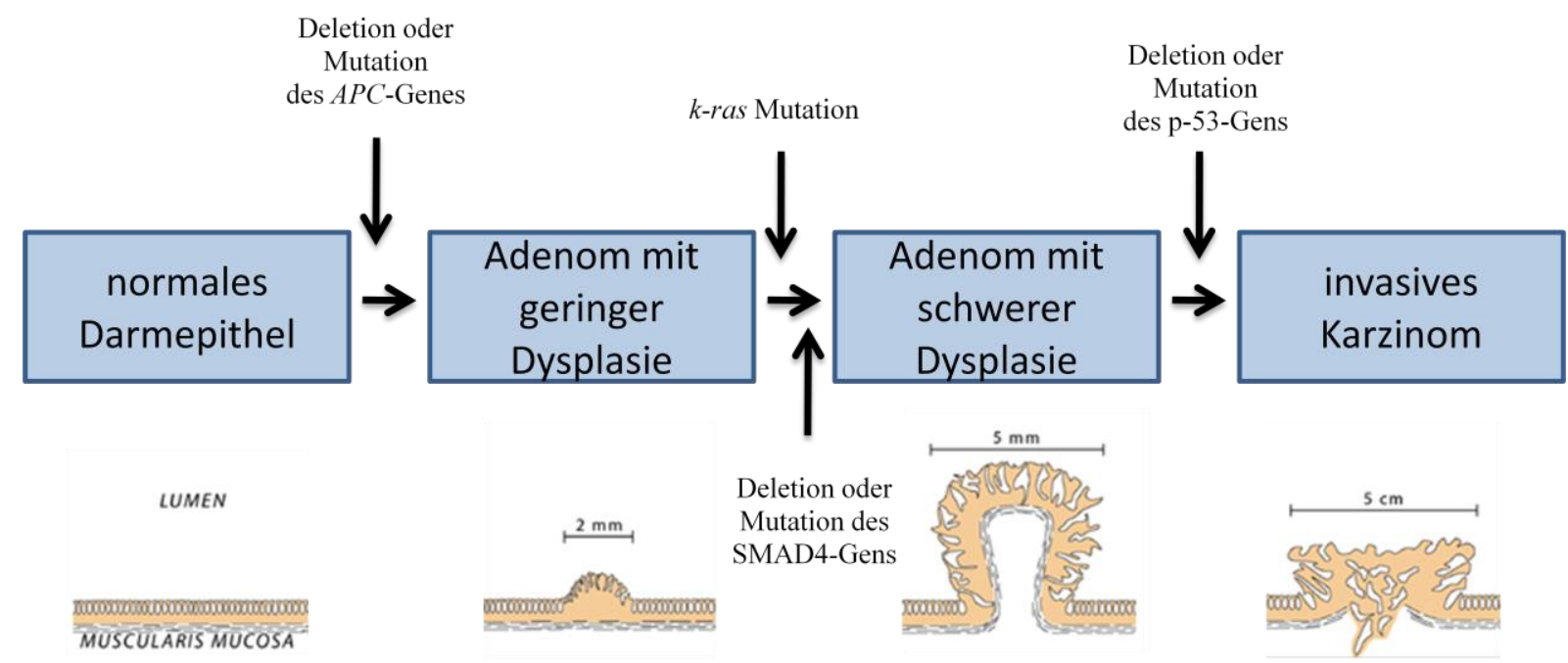

Abbildung 2: Genetisches Progressionsmodell der kolorektalen Karzinogenese (mod. nach Hanski und Itzkowitz 2000, S. 2)

\subsubsection{Genetisches Progressionsmodell des kolorektalen Karzinoms}

\subsubsection{Mutation und Deletion des $A P C$-Gens}

Das adenomatosus polyposis coli Gen (APC) liegt auf Chromosom 5q21 und wird in normaler Kolonmukosa konstitutiv zu einem Genprodukt von 310 kDa Größe exprimiert. Untersuchungen zeigten, dass das $A P C$-Gen bei DNA-Schäden durch p53 transkriptionell hochreguliert wird und damit induzierbar ist (Jaiswal und Narayan 2001). Physiologischerweise ist APC an der Zell-zu-Zell-Adhäsion, der Zellmigration, der chromosomalen Segregation sowie der Apoptoseinduktion in den Darmkrypten beteiligt (Stryker et al. 1987).

„Loss-of-function“-Mutationen im APC-Gen sind verantwortlich für die Entstehung der familiären adenomatösen Polyposis (FAP). Bei dieser Erkrankung kommt es zu multiplen (mehreren hundert) Adenomen im Kolon und Rektum des Patienten. Obwohl sich nur wenige Adenome zu einem Karzinom weiterentwickeln, ist die Lebenszeitinzidenz bei diesen Patienten 100\% (Galiatsatos und Foulkes 2006), daher empfiehlt sich bei diesen Patienten, je nach Mutationstyp und Ausprägung des Befalles, eine prophylaktische (Prokto-)Kolektomie (Galiatsatos und Foulkes 2006).

Neben ihrer Rolle in der FAP ist eine inaktivierende Mutation oder eine Deletion von APC auch in sporadischen Karzinomen wichtig. 70-80\% der sporadischen Adenome und Karzinome zeigen eine inaktivierende Mutation (Fearon 2011). Diese Mutationen treten 
bereits in den kleinsten Adenomen auf (Stryker et al. 1987) und gehören damit zu den frühen Mutationen in dem genetischen Progressionsmodell von Vogelstein et al. (Hanahan und Weinberg 2000; Hanahan und Weinberg 2011).

APC ist ein Regulator von B-Catenin im kanonischen Wnt-Pathway. In der Abwesenheit von Wnt-Liganten bindet APC an Axin, dies führt zu einer Phosphorylierung von ß-Catenin und damit zu seiner proteasomischen Degradation (Polakis 2007). Ein Verlust oder eine inaktivierende Mutation von $A P C$ führt daher zu einer Steigerung der ß-Catenin-Menge im Zytoplasma. B-Catenin bindet an TCF4 / LEF und transloziert in den Zellkern. Dort aktiviert dieser Komplex die Transkription diverser Gene, darunter Onkogene wie cMYC und Cyclin D1 sowie Wachstumsfaktoren wie FGF20 und FGF9 (Polakis 2007).

Auch die Aktin-Zytoskelett-Integrität sowie die Zell-Zell-Adhäsion und Zellmigration werden von APC beeinflusst. Über eine Interaktion mit $\beta$-Catenin, und dadurch mit Mitgliedern der Cadherin-Proteine, kommt es zu einer Verminderung der E-Cadherin vermittelten Zell-ZellAdhäsion, und damit zu einer Proliferation der Zellen (Hajra und Fearon 2002).

Eine Mutation oder ein Verlust von APC führt zur Bildung von Polypen, da Zellen der Kolonschleimhaut, welche normalerweise aus den unteren 2 Dritteln der Krypten Richtung Lumen wandern und dort abgeschilfert werden, zum Grund der Krypte migrieren und sich dort ansammeln (Moss et al. 1996).

\subsubsection{Mutation des $K R A S$-Gens}

Die RAS-Familie besteht aus drei Genen: KRAS, HRAS und NRAS. Diese kodieren für plasmamembranständige, monomerische Guanin-Nukleotid-bindende Proteine (G-Proteine, p21) mit intrinsischer GTPase-Aktivität (Malumbres und Barbacid 2003). Physiologischerweise leiten RAS-Proteine Signale weiter, nachdem ein Ligand an einen Rezeptor gebunden hat. Im Ruhezustand haben sie GDP gebunden und sind inaktiv. Hat nun ein Ligand gebunden, wird zusammen mit Guanin-Nukleotid-Austauschfaktoren das GDP durch DTP ersetzt und die Signaltransduktion aktiviert. RAS-Proteine liegen in verschiedenen Signalkaskaden unterhalb von diversen Rezeptor-Thyrosin-Kinasen, wie zum Beispiel dem „epidermal-growth-factor-receptor“ (EGFR) und leiten damit Signale weiter, welche die Zellproliferation, Motilität, Morphogenese und Apoptose regulieren (Seiden-Long et al. 2006).

Durch verschiedene Punktmutationen kommt es zu einer verminderten GTPase-Aktivität der RAS-Proteine, die zu einer verstärkten Bindung von GTP führt. Dadurch kommt es zu einer 
Verstärkung der Signaltransduktion, wodurch das onkogene Potential der RAS-Gene erklärt werden kann (Campbell et al. 1998). 48\% der Patienten mit einem Rektumkarzinom haben eine Mutation im KRAS Gen, meistens ist im Exon1 das Codon 12 (64\%) oder seltener das Codon 13 (22\%) betroffen (Gaedcke et al. 2010). Weitere seltene Mutationen finden sich in den Codons 61 und 146 (Gaedcke et al. 2010). Ähnliche Beobachtungen gibt es beim Kolonkarzinom, 43\% der Tumoren zeigen eine KRAS-Mutation (Lievre et al. 2006). Die Aktivierung von RAS führt im weiteren Verlauf der Signalkette zur Transkription diverser pro-onkotischer Gene und der Aktivierung des PI3K und MAP-Kinase-Signalweges.

\subsubsection{Mutation und Deletion der DCC- und SMAD-Gene}

Das DCC-Gen (,,deleted in colon carcinoma“) liegt auf Chromosom 18q21.3 und ist 1,2 Mio. Basenpaare groß. Durch alternatives Spleißen entstehen mehrere Proteine mit Größen zwischen 175 und $190 \mathrm{kDa}$.

Die genomische Region, in der DCC liegt, ist in etwa $70 \%$ der kolorektalen Karzinome verloren, dies geht mit einer niedrigen oder fehlenden $D C C$-Expression einher (Fearon et al. 1990; Mehlen und Mazelin 2003). Daher wurde vermutet, dass es sich bei DCC um ein Tumorsuppressorgen handelt. DCC kodiert für einen Netrin-1-Rezeptor, der zur Gruppe der „,dependence“-Rezeptoren gehört. „Dependence“-Rezeptoren lösen, wenn kein Ligand an sie gebunden ist, Apoptose in der Zelle aus. Am Grund der Darmkrypte ist die Expression von Netrin-1 hoch, der DCC-Rezeptor löst keinen Zelltod aus. Wandert die Zelle weiter in Richtung Darmlumen, nimmt die Konzentration von Netrin-1 ab, die Zelle teilt sich nicht mehr, differenziert und schließlich löst der „dependence“-Rezeptor aufgrund des Fehlens von Netrin-1 Apoptose aus (Mazelin et al. 2004). Neben dem Verlust von DCC kann es auch in seltenen Fällen zu einer inaktivierenden Mutation des Genes kommen.

In der Region 18q21.1 und damit in unmittelbarer Nähe des DCC-Genes liegen zudem die Tumorsuppressorgene SMAD2 und SMAD4, die daher ebenfalls als Zielgene der Aberration gesehen werden. Beide Gene codieren für Proteine, die unterhalb des TGF- $\beta$ Rezeptorkomplexes in der Signalkaskade liegen. Nachdem ein Ligand an den TGF-ß3Rezeptor gebunden hat, werden SMAD2 und 3 phosphoryliert, wandern zum Nukleus und regulieren dort Gentranskription. Eine Mutation in SMAD-Genen oder in anderen Teilen des TGF-Signalweges führt zu dessen Inaktivierung und verhindert Apoptose (Fearon 2011). Beim juvenilen Polyposis-Syndrom (JPS) findet sich ebenfalls eine Mutation von SMAD4, die eine Inaktivierung des TGF-ß-Signalweges zur Folge hat (Chow und Macrae 2005). 


\subsubsection{Mutation und Deletion des p53-Gens}

Das menschliche p53-Gen ist auf Chromosom 17p13 lokalisiert und kodiert für ein 43,7 kDa großes Protein. Physiologischerweise ist p53 instabil und wird abgebaut, aber kontinuierlich nachgebildet. Erst bei Zellstress, wie zum Beispiel DNA-Schäden, Hypoxie oder Aktivierung eines Onkogens, wird p53 posttranslational stabilisiert und akkumuliert in der Zelle. Diese Akkumulation hat viele Effekte: p53 funktioniert als Transkriptionsfaktor, DNAReparaturmechanismen werden angeschaltet und durch die verstärkte Expression von p21 kommt es zu einem Zellzyklusarrest in G1. Dadurch hat die Zelle Zeit, Reparaturen vorzunehmen. Kommt es allerdings zu einer weiteren Anhäufung von p53, wird über BAX die Apoptose eingeleitet (Vousden und Prives 2009). Darüber hinaus hat p53 weitere tumorsupprimierende Eigenschaften, es wirkt antiangionetisch (Teodoro et al. 2007) und kann in Zellen Seneszenz auslösen (Deng et al. 2008; Halazonetis et al. 2008).

Ungefähr 70\% der sporadischen kolorektalen Karzinome zeigt einen Verlust von 17p, bei vielen Tumoren weist das verbleibende Allel eine somatische Mutation auf (Guimaraes und Hainaut 2002). Da die meisten Adenome noch keinen Verlust von 17q oder eine Mutation von p53 haben, scheint diese Inaktivierung eng mit dem Fortschreiten der AdenomKarzinomsequenz zusammenzuhängen (Baker et al. 1990).

\subsubsection{Ploidiestatus und genomische Instabilität}

Kolorektale Karzinome zeigen eine große Variabilität in der Zusammensetzung ihrer DNA. Für die Pathogenese des kolorektalen Karzinoms sind drei Wege der genomischen Instabilität beschrieben: chromosomale Instabilität (CIN), Mikrosatelliteninstabilität (MIN) und „CpG Island Methylator Phenotype“ (CIMP). Bei der CIN kommt es zu einer Änderung der Chromosomenanzahl (Aneuplodie), zu subchromosomalen Amplifikationen oder Deletionen und zu einer hohen Rate von Verlusten der Heterozygotie (LOH). Ein Defekt im „DNA mismatch repair System “ (MMR) führt zur Mikrosatelliteninstabilität. Diese Tumoren sind zwar noch diploid, zeigen aber Veränderungen im Bereich der Mikrosatelliten. Durch die verstärkte Methylierung der CpG-Inseln kommt es zur Unterdrückung der Expression von Tumorsuppressorgenen. Allerdings zeigen diese Wege in vielen Tumoren Überschneidungen, so weisen z.B. $25 \%$ der MIN-Tumoren chromosomale Aberrationen auf (Sinicrope et al. 2006). Diese Signalwege werden im Folgenden ausführlicher beschrieben. 


\subsubsection{Chromosomale Instabilität (CIN)}

Bei circa $65-70 \%$ der Tumore kommt es sehr früh in der Karzinogenese zu einer durch chromosomale Instabilität verursachten Aneuploidie. Ganze Chromosomen oder Teile davon gehen verloren oder werden hinzugewonnen. Die Verluste eines maternalen oder paternalen Allels werden durch die Verdoppelung des verbleibenden Allels in der Tumorzelle kompensiert, dies wird als Verlust der Heterozygotie bezeichnet (Pino und Chung 2011).

Ursache der CIN sind Fehler bei der Segregation und Replikation der Chromosomen während der Mitose. In der Prometaphase binden die Chromosomen an die Mitosespindel. Nicht oder falsch gebundene Chromosomen lösen über eine Signalkaskade einen Arrest in der Prometaphase aus. Die Genprodukte von MAD1, MAD2, BUBR1, BUB3 und CENP-E inhibieren den CDC20/APC-Komplex. Haben in der Metaphase alle Chromosomen gebunden, wird das Signal des Mitosecheckpoint-Komplexes abgeschaltet, der anaphaseinduzierende Komplex aus CDC20 und APC aktiviert die Separasen, welche die Chromatiden teilen (Pino et al. 2011).

Mutationen in BUBRl führen zu einem Fortschreiten der Mitose, selbst wenn noch nicht alle Chromosomen verteilt sind (Cahill et al. 1998). Auch Veränderungen in Kinetochor-Proteinen werden beim kolorektalen Karzinom beobachtet und führen zu Fehlsegregationen (Wang et al. 2004).

Durch Defekte in den Zentrosomen kann es auf Grund von Spindelbildungsfehlern zu einer ungleichmäßigen Verteilung der Chromosomen kommen. Aneuploide Zelllinien zeigen sowohl funktionelle Defizite als auch Amplifikationen der Zentrosome. Durch die zusätzlichen Zentrosome kommt es $\mathrm{zu}$ einer erhöhten Fehlerrate bei der Chromosomensegregation, es entstehen multiple Spindelapparate, die in einer hochungewöhnlichen Teilung zu mehreren aneuploiden Zellen führen (Ghadimi et al. 2000; Ganem et al. 2009). Gene, die zu der Gruppe der mitotischen Kinasen gehören (Aur-A, - B, - $C$, Plk1-4 und NIMA1-11), sind ebenfalls an der Regulation des Zentrosomenzyklus, der Mikrotubuli-Kinetochorbindung, dem Spindelaufbau und der Chromosomenkondensation beteiligt und können daher zur chromosomalen Instabilität beitragen (Pino et al. 2011).

\subsubsection{Mikrosatelliten-Instabilität (MIN)}

Weniger als 25\% der Tumoren zeigen einen diploiden Chromosomensatz mit Veränderungen in kurzen, repetitiven Nukleotidsequenzen, den Mikrosatelliten. Wie bei dem seltenen, hereditären, nicht polypösen Kolonkarzinom (Lynch-Syndrom) liegen diesen Tumoren 
Defekte in den Genen des DNA-Mismatch-Reparatur-Systems zugrunde (MMR) (Iacopetta et al. 2010). Meistens sind die Gene MSH2 (31\%) und MLH1 (33\%) betroffen. Selten gibt es Veränderungen von PMS1 (2\%), PMS2 (4\%), MSH6 und MLH3. Durch den Ausfall dieser MMR-Gene werden Basenfehlpaarungen bei der Verdoppelung der DNA nicht mehr korrigiert. Dies hat zur Folge, dass es zu Deletionen und Insertionen von Nukleotiden im Bereich der Mikrosatelliten kommt. Diese Veränderungen können zu einer Leserasterverschiebung und damit $\mathrm{zu}$ einem Funktionsverlust von Genen führen. $\mathrm{Zu}$ den Genen, die von Alterationen in den Mikrosatelliten betroffen sind, gehören DNAReparations-Gene wie MSH3 (mutiert in 38\% der Fälle), MSH6, RAD50 und BLM. Ebenfalls sind apoptoseassoziierte Gene betroffen (APAF1, BAX (45\%), BCL10, Caspase-5 (48\%)), Signaltransduktionsgene (TGFßRIII (81\%), ACTRII, IGFIIR, WISP-3), Zellzyklusgene (PTEN, RIZ) und der Transkriptionsfaktor TCF4 (Iacopetta et al. 2010). MIN-Tumoren sind meistens im proximalen Kolon lokalisiert und werden mithilfe des Bethesda-Panels, bestehend aus 5 Mikrosatellitenmarkern, diagnostiziert und in weitere Subgruppen unterteilt. Bei einem Nachweis von 2 der 5 oder mehr veränderten Markern wird der Tumor als MSI-H (high) klassifiziert, bei nur einem als MSI-L (low) (Boland et al. 1998). Diese Unterscheidung ist wichtig, da Patienten mit einem Kolontumor und MSI-L oder MSS von einer 5-FUbasierten adjuvanten Chemotherapie profitieren, jene mit einer hohen Rate an Mikrosatellitenfehlern hingegen nicht (Ribic et al. 2003).

\subsubsection{CpG-Insel-Mutator-Phänotyp}

Die transkriptionale Inaktivierung von Tumorsuppressorgenen durch die Methylierung ihrer Promotorregionen (CpG-Inseln) ist ein relativ neu beschriebener Signalweg, der für die Entstehung des kolorektalen Karzinomes in einer Subgruppe der Tumoren verantwortlich gemacht wird (Laird 2005; Issa 2004). CDKN2A, MGMT, MLH1 und weitere Gene der Zellzykluskontrolle, des DNA-Reparatursystemes sowie andere Tumorsuppressorgene werden durch vermehrte Methylierung (Hypermethylierung) von CpG-Inseln inaktiviert (Issa 2004). Die CpG-Insel-Hypermethylierung findet sich bereits in Adenomen und wird deshalb zu den frühen Veränderungen in der Progression der kolorektalen Karzinogenese gezählt (Park et al. 2003).

\subsubsection{Chromosomales Progressionsmodell}

Die genomische Instabilität auf chromosomaler Ebene ist durch das Auftreten von numerischen und strukturellen Aberrationen geprägt. Neben Inversionen und Translokationen 
gibt es Veränderungen, die mit dem Verlust von chromosomalem Material (Deletionen/Verluste) oder Sequenzzugewinnen (Amplifikationen/Zugewinne) einhergehen. 1996 wurde von Ried et al. mittels vergleichender genomischer Hybridisierung (CGH) erstmals gezeigt, dass bei der Progression von normaler Darmschleimhaut zu einem invasiven Karzinom spezifische genomische Verluste und Zugewinne auftreten.

Ried und seine Forschergruppe untersuchten sowohl normale Darmschleimhaut als auch Tumoren aus verschiedenen Stadien der Karzinogenese auf chromosomale Aberrationen. Alle 14 untersuchten Proben aus normalem Darmgewebe waren diploid und zeigten keinerlei genomische Aberrationen. Von den 14 untersuchten „low-grade“-Adenomen zeigte lediglich eine Probe einen Zugewinn von Chromosom 7, die restlichen wiesen keine Veränderungen auf. Bei den 12 untersuchten ,high-grade“-Adenomen war bereits bei 30\% der Proben ein Zugewinn von Chromosom 7 und Chromosom 20 nachweisbar. Die Transition vom Adenom zum Kolonkarzinom war durch das Auftreten multipler chromosomaler Veränderungen gekennzeichnet. Die Chromosomen 1, 13 und 20 sowie die Chromosomenarme 7p und 8q zeigten Zugewinne, während Chromosom 4 und die Chromosomenarme 8p und 18q Verluste aufwiesen (Ried et al. 1996).

Verschiedene Untersuchungen konnten die Funde von Ried et al. bestätigen (Meijer et al. 1998; Hawkins et al. 2000; Hermsen et al. 2002; Tsafrir et al. 2006; Lips et al. 2007; Lips et al. 2008). Diese Zugewinne und Verluste scheinen also nicht zufällig zu sein, die kolorektale Karzinogenese folgt dementsprechend also nicht nur einem Muster von genetischen Veränderungen, sondern auch einem von chromosomalen Aberrationen. Daher wurde ein chromosomales Progressionsmodell analog zum genetischen Progressionsmodell von Fearon und Vogelstein et al. vorgeschlagen (Grade et al. 2006). Dieses ist in Abbildung 3 dargestellt.

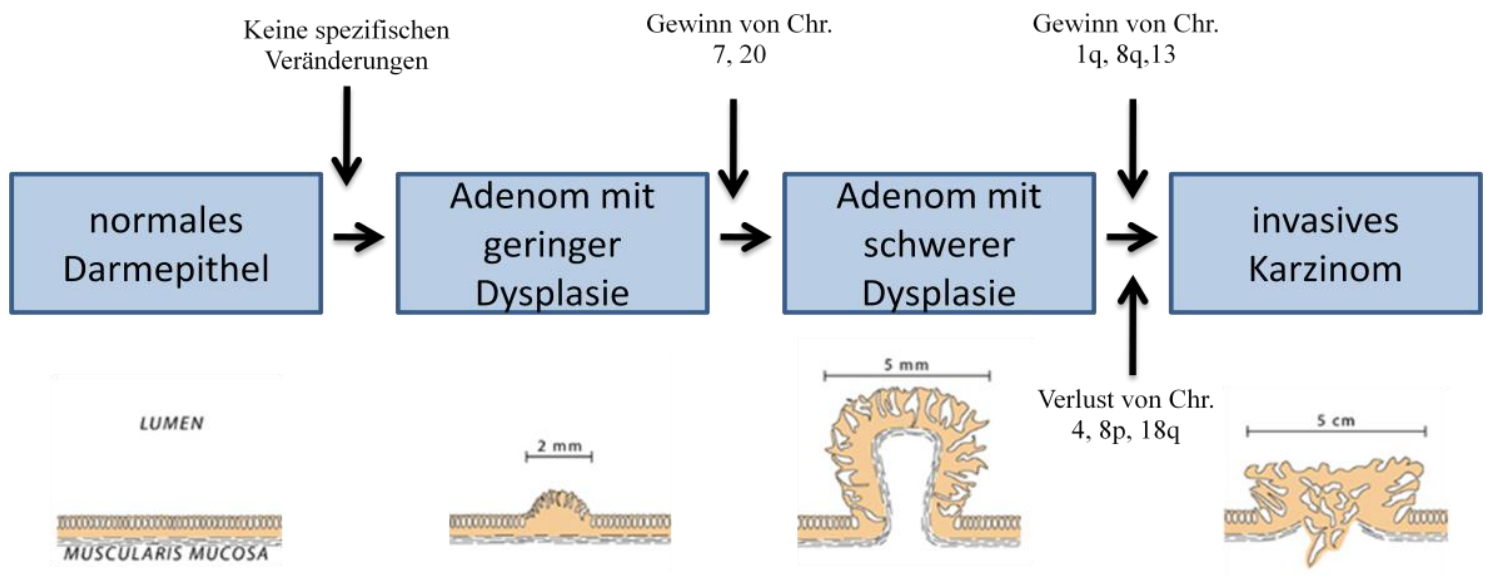

Abbildung 3: Chromosomales Progressionsmodell der kolorektalen Karzinogenese (mod. nach Grade et al. 2006) 


\subsection{Fragestellung}

Eine der häufigsten chromosomalen Aberrationen beim kolorektalen Karzinom ist der Zugewinn von Chromosom 13q (Hughes et al. 2006; Leslie et al. 2003). Doch auch wenn bereits gezeigt wurde, dass eine erhöhte Kopie-Anzahl mit einer erhöhten Expression der in diesen Bereichen liegenden Gene einhergeht (Leslie et al. 2006), sind die Zielgene dieser Aberration völlig unklar.

Ziel dieser Studie war daher:

- Regionen mit rekurrenten genomischen Zugewinnen auf 13q einzugrenzen.

- Gene zu identifizieren, die in diesen Regionen liegen und im Tumor gegenüber Normalgewebe hochreguliert sind.

- Die funktionelle Relevanz dieser Gene in einem „Loss-of-Funktion-Screen“ zu überprüfen. 


\section{$2 \quad$ Material und Methoden}

\subsection{In-Silico-Analyse: ArrayCGH-Auswertung}

Zur Identifikation von Regionen mit regelmäßigen Zugewinnen auf Chromosom 13 wurden zunächst ArrayCGH-Daten (Agilent 185K) von 31 primären Karzinomen (UICC-II/III) und 15 kolorektalen Zelllinien erneut ausgewertet. Der experimentelle Teil der ArrayCGHAnalysen wurde von Dr. Jordi Camps, aus dem Labor von Dr. Thomas Ried am NCI, durchgeführt und ist daher nicht Teil der vorliegenden Dissertation. Die Experimente sollen jedoch zum Verständnis der folgenden Analysen hier kurz beschrieben werden. Die Tumorproben sowie entsprechendes Normalgewebe wurden in der Abteilung für Allgemeinund Viszeralchirurgie an der Universitätsmedizin Göttingen entnommen, RNA und DNA wurden mittels TRIzol ${ }^{\circledR}$ (Invitrogen, Carlsbad, USA) isoliert (siehe unten). $3 \mu \mathrm{g}$ genomische DNA wurden mithilfe der Enzyme ALUI und RsaI (Promega, Madison, USA) verdaut und anschließend mittels DNA-Säulen (Qiagen, Valencia, USA) aufgereinigt. Die DNA wurde mit dem „Bioprime-ArrayCGH-Genomic-Labeling-Module“ (Invitrogen) umgeschrieben, die Tumor-DNA dabei mit Cy3-dUTP und die Referenz-DNA mit Cy5-dUTP markiert. Nach einer erneuten Aufreinigung der DNA über „Microcon-YM-30“-Säulen (Milipore, Bedford, USA) wurde die Menge der markierten DNA mittels des Nanodrops (siehe unten) bestimmt. Jeweils gleiche Mengen Cy3-markierter Proben-DNA und Cy5-markierter Referenz-DNA wurden auf einen ,, 185k-Human-Genome-Microarray-G4411A“ (Agilent Technologies, Santa Clara, USA) hybridisiert und anschließend gewaschen. Mit einem „Agilent-DNA-MicroarrayScanner“, Modell G2565BA wurden die Arrays eingelesen und die Bilder durch die „Agilent Feature Extraction“-Software analysiert. Mithilfe der „,Agilent CGH-Analytics 3.4“-Software wurden die Daten graphisch dargestellt.

Alle ArrayCGH-Profile der Tumoren und Zelllinien wurden im Rahmen dieser Arbeit nebeneinander gedruckt, Regionen, die in den Tumoren Verluste aufwiesen, wurden für weitere Analysen ausgeschlossen. Zusätzlich wurde eine Summationsdarstellung von Chromosom 13q erstellt (Abbildung 11, im Ergebnisteil), dazu wurden alle ArrayCGHProbenwerte (Zugewinne positiv, Verluste negativ) einer Arrayprobe addiert und die so entstehenden Werte schließlich grafisch dargestellt. 


\subsection{In-Silico-Analyse: Mikroarray-Auswertung}

Mikroarrays ermöglichen die gleichzeitige Messung von Genexpressionsprofilen vieler tausend Gene in einem einzigen Experiment. Dazu wird RNA zunächst in cDNA umgeschrieben, im Anschluss erfolgt eine erneute Umschreibung in Fluoreszenz-markierte cRNA. Diese wird aufgereinigt und auf Qualität und Menge überprüft. Nach einer Fragmentierung wird die cRNA auf den Mikroarray hybridisiert. Dieser verfügt über genspezifische Bindungsstellen, wobei mehrere gleiche Bindungsstellen zu einem Spot auf den Array gedruckt sind. Je mehr RNA eines Gens mit Bindungsstellen für diesen Spot zugegeben wird, desto mehr Bindungsstellen dieses Spots werden durch Fluoreszenz-tragende RNA besetzt. Dadurch ist die von einem Spot emittierte Fluoreszenz proportional zu der an ihn gebundenen cRNA-Menge und damit ebenfalls proportional zur Menge der Ziel-mRNA in der Probe. Ein Scanner liest den Array aus und speichert für jeden Spot einen Fluoreszenzwert. Im Anschluss wird der Array gegen die Gesamtfluoreszenz normalisiert und kann dann ausgewertet werden.

Die Anfertigung der Genexpressionsmikroarrays wurde ebenfalls von Dr. Jordi Camps, NCI, vorgenommen und wird daher hier nur kurz beschrieben. RNA wurde sowohl aus den primären Tumoren als auch aus 15 kolorektalen Zelllinien isoliert (siehe unten). $800 \mathrm{ng}$ totale RNA wurden mittels einer MMLV-Reversen-Transkriptase (Agilent) in cDNA umgeschrieben und die entstandene cDNA dann durch eine RNA-Polymerase (Agilent) in cRNA umgeschrieben. In dieser Reaktion wurde ein mit einem Fluoreszenzfarbstoff markiertes Nukleotid (Cyanine 3-CTP) zugegeben, welches von der RNA-Polymerase in die cRNA integriert wurde. Anschließend wurde die Fluoreszenz-markierte cRNA über „RNeasy mini"-Säulen (Qiagen) aufgereinigt, und mithilfe des Nanodrops (siehe unten) die Gesamtmenge an entstandener cRNA sowie die Konzentration an Cyanin-3-Farbstoff bestimmt. Durch den Quotienten aus cRNA-Menge und Cyanin-3-Konzentration konnte der

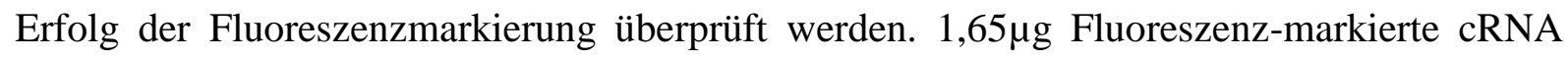
wurden fragmentiert und anschließend für $17 \mathrm{~h}$ bei $65^{\circ} \mathrm{C}$ auf einen $4 \mathrm{x} 44 \mathrm{~K}$ Oligonukleotidbasierten „Whole Human Genome Microarray G4112F“ (Agilent) hybridisiert. Nach mehreren Waschschritten wurden die Arrays in einem G2565BA-Scanner (Agilent) eingelesen. Vermittels der Agilent Feature Extraction Software (Version 9.5.3) wurde das gescannte Bild analysiert und für jede der 44000 Proben auf jedem Array eine Fluoreszenz- 
Intensität bestimmt. Anschließend erfolgte die biostatistische Auswertung der Genexpressionsarrays. Dafür war es zunächst notwendig, unter Verwendung der Programmiersprache „R“ (Bolstad et al. 2003) eine Quantilennormalisierung der einzelnen Arrays durchzuführen, um eine Vergleichbarkeit der einzelnen Arrays untereinander zu ermöglichen. Unterschiede in der Expression von Genen wurden mit einem modifizierten Bayes T-Test unter Zuhilfenahme des „Limma“-Paketes für „,R“ (Smyth 2005) bestimmt. Unterschiede in der Expression von Genen zwischen Tumor und Mukosa mit einem p-Wert $<0,05$ wurden als signifikant angesehen. Die hierarchischen Clusteranalysen wurden mittels des JMP-Programmes (Version 8, SAS, Cary, USA) durchgeführt.

Für dieses Projekt wurden dann sämtliche Gene auf Chromosom 13 unter Zuhilfenahme des „Excel“-Programmes (Microsoft, Redmound, USA) nach der Größe der differentiellen Expression zwischen Tumor und Mukosa sortiert. Gene, die nicht signifikant dereguliert waren $(p>0,05)$, wurden ausgeschlossen. Gene, die sowohl in den per ArrayCGH identifizierten Amplikonen lagen und zusätzlich signifikant überexprimiert waren, wurden als Kandidatengene in Betracht gezogen.

\subsection{Zellkultur}

\subsubsection{Zelllinien}

24 Zelllinien wurden von der „American Type Culture Collection“ (ATCC) bezogen (siehe Tabelle 3), die Zelllinie p53HCT116 (Bunz et al. 1998) wurde von Dr. Curtis C. Harris, NCI, zur Verfügung gestellt. Die gefrorenen Zellen wurden im Wasserbad bei $37^{\circ} \mathrm{C}$ angetaut und anschließend in ein 15-ml-Röhrchen (Corning, New York, USA) mit $10 \mathrm{ml}$ Medium (Invitrogen) überführt und für $8 \mathrm{~min}$ bei $800 \mathrm{u} / \mathrm{min}$ zentrifugiert. Das entstandene Pellet wurde in $5 \mathrm{ml}$ Medium resuspendiert und in eine T25-Flasche (Corning) überführt. Diese wurde bei $37,5^{\circ} \mathrm{C}$ und unter Zugabe von $5 \% \mathrm{CO}_{2}$ inkubiert. Bei Zelllinien, die ohne $\mathrm{CO}_{2}$ kultiviert werden mussten, wurden Flaschen mit luftdichten Deckeln verwendet. Hatten die Kulturen eine Konfluenz von $>70 \%$ erreicht, wurden sie in eine T75-Flasche (Corning) überführt. Eine Übersicht über die verwendeten Zelllinien und Kultivierungen gibt Tabelle 3. 


\begin{tabular}{|c|c|c|c|c|c|}
\hline Zelllinie & $\delta / 0$ & Medium & Wachstum & $\mathrm{CO} 2$ & ATCC Nr. \\
\hline SW837 & $\hat{0}$ & Leibovitz's L-15 & adhärent & $0 \% \mathrm{CO}_{2}$ & $\underline{\text { CCL-235 }}$ \\
\hline SW48 & ㅇ & Leibovitz's L-15 & adhärent & $0 \% \mathrm{CO}_{2}$ & $\underline{\text { CCL-231 }}$ \\
\hline LS174T & 우 & Minimum essential medium (Eagle) & adhärent & $5 \% \mathrm{CO}_{2}$ & $\underline{\text { CL-188 }}$ \\
\hline LS513 & $\hat{0}$ & RPMI 1640 Custom & adhärent & $5 \% \mathrm{CO}_{2}$ & CRL-2134 \\
\hline SW1463 & 우 & Leibovitz's L-15 & adhärent & $0 \% \mathrm{CO}_{2}$ & $\underline{\text { CCL-234 }}$ \\
\hline HT-29 & q & McCoy's 5a & adhärent & $5 \% \mathrm{CO}_{2}$ & $\underline{\text { HTB-38 }}$ \\
\hline SW1116 & 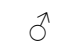 & Leibovitz's L-15 & adhärent & $0 \% \mathrm{CO}_{2}$ & $\underline{\text { CCL-233 }}$ \\
\hline LS411N & $\hat{0}$ & RPMI 1640 Custom & adhärent & $5 \% \mathrm{CO}_{2}$ & $\underline{\text { CRL-2159 }}$ \\
\hline NCI-H716 & $\sigma^{\lambda}$ & RPMI 1640 Custom & adhärent/Suspension & $5 \% \mathrm{CO}_{2}$ & $\underline{\text { CCL-251 }}$ \\
\hline Lovo & $\hat{0}$ & Ham's F12K medium & adhärent & $5 \% \mathrm{CO}_{2}$ & $\underline{\text { CCL-229 }}$ \\
\hline Caco-2 & $\sigma^{\lambda}$ & Minimum essential medium (Eagle) & adhärent & $5 \% \mathrm{CO}_{2}$ & $\underline{\mathrm{HTB}-37}$ \\
\hline NCI-H508 & $\hat{0}$ & RPMI 1640 Custom & adhärent/Suspension & $5 \% \mathrm{CO}_{2}$ & CCL-253 \\
\hline RKO & $?$ & Minimum essential medium (Eagle) & adhärent & $5 \% \mathrm{CO}_{2}$ & CRL-2577 \\
\hline SW480 & $\hat{\sigma}$ & Leibovitz's L-15 & adhärent & $0 \% \mathrm{CO}_{2}$ & CCL-228 \\
\hline COLO 320DM & 우 & RPMI 1640 Custom & adhärent/Suspension & $5 \% \mathrm{CO}_{2}$ & $\underline{\text { CCL-220 }}$ \\
\hline LS123 & q & Minimum essential medium (Eagle) & adhärent & $5 \% \mathrm{CO}_{2}$ & CCL-255 \\
\hline $\mathrm{T} 84$ & $\hat{0}$ & 1:1 Eagle's and Ham's F12 & adhärent & $5 \% \mathrm{CO}_{2}$ & CCL-248 \\
\hline DLD-1 & $\hat{0}$ & RPMI 1640 & adhärent & $5 \% \mathrm{CO}_{2}$ & CCL-221 \\
\hline p53HCT116 & $\hat{0}$ & McCoy's medium & adhärent & $5 \% \mathrm{CO}_{2}$ & \\
\hline HCT 116 & $\hat{0}$ & McCoy's 5a & adhärent & $5 \% \mathrm{CO}_{2}$ & CCL-247 \\
\hline LS1034 & $\hat{0}$ & RPMI 1640 Custom & adhärent & $5 \% \mathrm{CO}_{2}$ & $\underline{\text { CRL-2134 }}$ \\
\hline SK-CO-1 & $\hat{0}$ & Minimum essential medium (Eagle) & adhärent & $5 \% \mathrm{CO}_{2}$ & $\underline{\text { HTB-39 }}$ \\
\hline Colo 201 & 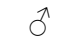 & RPMI 1640 Custom & adhärent/Suspension & $5 \% \mathrm{CO}_{2}$ & $\underline{\text { CCL-224 }}$ \\
\hline SW403 & 우 & Leibovitz's L-15 & adhärent & $0 \% \mathrm{CO}_{2}$ & CCL-230 \\
\hline SW620 & $\hat{0}$ & Leibovitz's 1-15 & adhärent & $0 \% \mathrm{CO}_{2}$ & $\underline{\text { CCL-227 }}$ \\
\hline
\end{tabular}

Tabelle 3: Auflistung aller verwendeten Zelllinien mit Angaben über Wachstumsbedürfnisse und Herkunft 


\subsubsection{Zellsplitt}

Haben Zellen eine gewisse Dichte in einer Flasche erreicht, verlangsamt sich ihr Wachstum aufgrund von Konkurrenz um Platz und Nährstoffe oder durch direkte Zellkontaktinhibition. Die Zellen werden geteilt und nur ein Teil wird wieder in die Flasche überführt. Der Rest kann entweder für ein Experiment verwendet werden, in eine zweite Flasche überführt oder verworfen werden.

Zellmedium (Invitrogen), PBS (Invitrogen) und Trypsin (Invitrogen) wurden auf $37^{\circ} \mathrm{C}$ erwärmt. In Suspension wachsende Zellen wurden direkt in ein 15-ml-Röhrchen (Corning) überführt und für 7 min bei $800 \mathrm{u} / \mathrm{min}$ zentrifugiert. Der Überstand wurde abgesaugt und das Zellpellet in $5 \mathrm{ml}$ Medium resuspendiert. Die gewünschte Menge an Zellen wurde zurück in die Flasche überführt und das Volumen an Medium auf $5 \mathrm{ml}$ (T25) bzw. $10 \mathrm{ml}$ (T75) ergänzt. Unter dem Mikroskop wurde schließlich kontrolliert, ob sich Zellen in der Flasche befinden. Adhärent wachsende Zellen wurden nach Absaugen des Mediums einmal mit 5 ml (T25) bzw. $10 \mathrm{ml}$ (T75) PBS gewaschen. Die Zellen wurden mit $1 \mathrm{ml}$ (T25) bzw. $2 \mathrm{ml}$ (T75) Trypsin überschichtet und für maximal 7 min bei $37^{\circ} \mathrm{C}$ inkubiert. Unter einem Zellkulturmikroskop wurde kontrolliert, ob alle Zellen vom Flaschenboden gelöst sind. War dies nicht der Fall, wurden die Zellen durch vorsichtiges Schütteln oder weitere Inkubation gelöst. Die Zellen wurden in $10 \mathrm{ml}$ Medium aufgenommen und, wie weiter oben bei in Suspension wachsenden Zellen beschrieben, behandelt.

\subsubsection{Mediumwechsel}

Durch den Stoffwechsel der Zellen werden die im Medium enthaltenen Nährstoffe verbraucht und Stoffwechselprodukte reichern sich an. Ein im Medium enthaltener Indikator zeigt diesen Prozess an und gibt vor, wann das Medium gewechselt werden muss.

In Suspension wachsende Zellen wurden durch Zentrifugieren für 7 min bei $800 \mathrm{u} / \mathrm{min}$ pelletiert. Das Pellet wurde in $5 \mathrm{ml}$ (T25) bzw. $10 \mathrm{ml}$ (T75) neuem Medium resuspendiert und wieder in die Flasche überführt.

Bei adhärent wachsenden Zellen wurde das Medium abgesaugt und $5 \mathrm{ml}$ (T25) bzw. $10 \mathrm{ml}$ (T75) neues zugegeben. 


\section{$2.4 \quad$ mRNA-Extraktion}

\subsubsection{RNA-Isolation für Genexpressionsanalysen (Mikroarray-Validierung)}

Um RNA aus Zellen gewinnen zu können, müssen diese lysiert und alle anderen Zellbestandteile entfernt werden. Durch die Zugabe von TRIzol ${ }^{\circledR}$ (Invitrogen) und durch die mechanische Zerstörung der Zellmembranen erreicht man die Lyse der Zellen. Da sich TRIzol $^{\circledR}$ durch Zugabe von Chloroform und Zentrifugation in eine wässrige und eine organische Phase aufteilt, erhält man eine erste Aufreinigung. Die hydrophile RNA löst sich in der wässrigen Phase, während Proteine und andere hydrophobe Moleküle zum Großteil in der organischen Phase zurückbleiben. In einem zweiten Schritt wird die RNA in „RNeasy“Säulen (Qiagen) weiter gereinigt. Eine silikatische Gelmembran bindet die RNA in Gegenwart von Ethanol. RNA-Stücke kleiner als 200 bp werden genau wie alle anderen Zellbestandteile nicht gebunden und bei den Waschungen mit verschiedenen Puffern eliminiert.

Das Zellkulturmedium wurde aus einer T75-Flasche komplett entfernt, anschließend wurden die Zellen mit $20 \mathrm{ml}$ PBS gewaschen. Je nach Zelllinie wurden zwischen 8 und 15 Millionen Zellen verwendet. Die Zellen wurden mit $10 \mathrm{ml} \mathrm{TRIzol}{ }^{\circledR}$ überschichtet, mit einem Zellschaber (Corning) suspendiert, in ein 15-ml-Röhrchen überführt und mithilfe einer Pipette homogenisiert. Die in $10 \mathrm{ml} \mathrm{TRIzol}{ }^{\circledR}$ gelösten Zellen wurden durch manuelles Schütteln für 15 sek, anschließende Zugabe von $2 \mathrm{ml}$ Chloroform (EMD Chemicals, USA) und erneutes Schütteln für 15 sek lysiert. Anschließend wurde für 10 min bei Raumtemperatur inkubiert. Nach 15 sek Zentrifugation mit $8000 \mathrm{u} / \mathrm{min}$ und bei $4^{\circ} \mathrm{C}$ bildeten sich zwei Phasen. Die obere Phase wurde in ein 15-ml-Röhrchen überführt und 2 ml 100\%iges Ethanol (Warner-GrahamCompany, Cockeysville, USA) tropfenweise unter Vortexen hinzugegeben. Die so entstandene Lösung wurde gleichmäßig auf zwei „RNeasy“-Midi-Säulen (Qiagen Inc., Valencia, USA) verteilt. Die Säulen wurden für $10 \mathrm{~min}$ bei $5500 \mathrm{u} / \mathrm{min}$ zentrifugiert, das Filtrat entnommen und wieder auf die Säule geladen. Die Lösung wurde insgesamt vier Mal auf diese Weise mit derselben Säule gefiltert und anschließend verworfen. Als nächstes folgten die Waschungen der RNA. Um Proteine aus der Säule zu entfernen, wurde diese insgesamt zwei Mal mit 2,5 ml ,RW1 “-Puffer (Qiagen) beladen und bei 5000u/min für $5 \mathrm{~min}$ zentrifugiert, das dabei entstehende Filtrat verworfen. Es folgten zwei Waschungen mit 2,5 ml „RPE“‘-Puffer (Qiagen), die Säulen wurden mit dem Puffer beladen und im ersten Durchgang 
für $5 \mathrm{~min}$, im zweiten für $10 \mathrm{~min}$ zentrifugiert und das Filtrat ebenfalls verworfen. Um die RNA zu eluieren, wurde die Säule auf ein neues 15-ml-Röhrchen gesetzt und insgesamt 4 Mal mit $500 \mu \mathrm{l}$ DEPC Wasser (Invitrogen) beladen, für 1 min bei Raumtemperatur inkubiert und bei $5500 \mathrm{u} / \mathrm{min}$ für 5 min zentrifugiert. Um die RNA zu fällen, wurde die entstandene Lösung unter Vortexen mit $4 \mathrm{ml}$ 100\%igem Ethanol (Warner-Graham-Company) und mit $200 \mu 13 \mathrm{M}$ Natrium-Acetatlösung (pH6) (Quality Biological Inc., Gaithersburg, USA) versetzt und für 2h bei $-80^{\circ} \mathrm{C}$ inkubiert. Um ein RNA-Pellet zu erhalten, wurde 30 sek mit $8000 \mathrm{u} / \mathrm{min}$ bei $4^{\circ} \mathrm{C}$ zentrifugiert. Der Überstand wurde verworfen, das Pellet in $1 \mathrm{ml} 70 \%$ igem Ethanol resuspendiert und in ein 1,5-ml-Röhrchen (Corning) überführt. Durch 15 minütige Zentrifugation mit $14000 \mathrm{u} / \mathrm{min}$ bei $4^{\circ} \mathrm{C}$ wurde die RNA erneut pelletiert. Der Überstand wurde verworfen und das Pellet luftgetrocknet. Schließlich wurde es, je nach Größe, mit 80$200 \mu 1$ DECP-Wasser versetzt und für $5 \mathrm{~min}$ bei $65^{\circ} \mathrm{C}$ unter Schütteln resuspendiert.

\subsubsection{RNA- Isolation zur Validierung der siRNA-vermittelten Geninhibierung mit „Capture-Plates ${ }^{66}$}

Da bei dem unten beschriebenen siRNA-Screen sehr viele Proben anfielen, aus denen RNA isoliert und anschließend cDNA synthetisiert werden sollte, musste hier ein anderes, schnelleres und einfacheres Verfahren als bei der Array-Validierung gewählt werden. „Capture-Plates“ sind 96-well-Platten, die mit Oligo-dTs beschichtet sind. Füllt man ein Zelllysat in ein Well, so binden die Poly-A-Schwänze der mRNAs an die Oligo-dTs der „Capture-Plate“. Diese können gereinigt werden, und es kann gleich in der Platte eine cDNA-Synthese erfolgen (siehe unten). Anders als bei der vorher beschriebenen Methode können hier nur mRNA-Moleküle isoliert werden, alle anderen RNAs ohne Poly-A-Schwanz gehen verloren.

Nach der Entnahme der 96-well-Platten (Corning) aus dem Inkubator wurde das Medium entfernt und die Zellen jeweils mit $100 \mu$ l PBS gewaschen. Anschließend wurden $45 \mu 1$ des B-mercaptoethanolhaltigen Puffers „TCL“ (Qiagen) dazugegeben und für $5 \mathrm{~min}$ bei Raumtemperatur inkubiert, um die Zellen zu lysieren. Das Lysat wurde in „,Turbo-Capture96-Platten “ (Qiagen) überführt und bei $100 \mathrm{u} / \mathrm{min}$ für 90 Minuten bei Raumtemperatur auf einer Mischplatte inkubiert. Nach der Inkubation wurde die Platte drei Mal mit $100 \mu 1$ „TCW“-Lösung (Qiagen) gewaschen, danach erfolgte direkt in der „Capture-Plate“ die cDNA-Synthese (siehe unten). 


\subsubsection{RNA-Qualitäts- und Mengenmessung}

\subsubsection{Konzentrationsmessung}

Mit einem „NanoDrop1000 ${ }^{\circledR}$ Spectrophotometer“ (NanoDrop Technologies, Wilmington, USA) wurde die Konzentration an RNA in der Lösung und deren Reinheit bestimmt. Dieses Photometer misst gleichzeitig die Absorptionsintensität bei $260 \mathrm{~nm}$ und $280 \mathrm{~nm}$ als Extinktion. Nach dem Lambert-Beer'schen Gesetz ist die Extinktion sowohl proportional zum molaren Extinktionskoeffizienten (40 für RNA) als auch zu der Konzentration des gelösten Stoffes und der durchstrahlten Schichtdicke. Der Quotient der Extinktionen bei $260 \mathrm{~nm}$, dem Absorptionsmaximum von Nukleinsäuren, und der bei $280 \mathrm{~nm}$, dem Absorptionsmaximum von Proteinen, ist ein Index für die Verunreinigung der Probe mit Proteinen. Er sollte für RNA und DNA zwischen 1,8 und 2,0 liegen. Alle Proben erfüllten dieses Kriterium, sie lagen zwischen 1,98 und 2,01.

\subsubsection{RNA-Gelelektrophorese}

Zur Prüfung der RNA-Integrität dient eine RNA-Gelelektrophorese. Die negativ geladene RNA wandert im Gel zur Anode, abhängig von ihrer Größe, unterschiedlich schnell. Bei nicht-degenerierter RNA bilden die ribosomalen 18s- und 28s-RNAs klare Banden, die ein indirekter Marker für die Güte der RNA sind. Sind diese Banden nicht oder nur verkleinert zu erkennen, ist die RNA degradiert. Damit die RNA keine Sekundärstrukturen ausbilden kann, muss ein denaturierendes, formaldehydhaltiges Gel verwendet werden.

$36 \mathrm{ml}$ DECP Wasser (Invitrogen) wurden mit 0,6 g Agarose (Invitrogen) vermischt und aufgekocht. Nach dem Abkühlen der Lösung wurden 5 ml 10x MOPS (200 mM MOPS, 50 mM Natriumacetat, 10 mM EDTA pH7 in DEPC- $\mathrm{H}_{2} \mathrm{O}$ (Quality Biological Inc, Gaithersburg, USA)), $9 \mathrm{ml}$ Formaldehyd und $5 \mu \mathrm{l}$ GelRed (Biotium, Hayward, USA) zugegeben und vermischt. Das Gel wurde gegossen und 20 min bei Raumtemperatur inkubiert. Nach dem Erstarren des Gels wurde es in eine Elektrophoresekammer eingespannt, die mit 1x MOPS Puffer gefüllt war, und für 25 min bei $70 \mathrm{~V}$ präkonditioniert. $1 \mu \mathrm{g}$ der RNA Proben wurden mit $10 \mu 1$ 4x DB Puffer (500 $\mu 1$ deionisiertes Formamid, $180 \mu$ l Formaldehyd, $100 \mu 1$ 10x MOPS, $100 \mu 1$ 10x DYE, $2 \mu$ Ethidiumbromid (10 mg/ml) vermischt und auf das Gel aufgetragen. Das Gel lief bei $70 \mathrm{~V}$ für 2,5h, anschließend wurde es unter UV-Licht fotografiert. 


\subsubsection{RNA-Integritätsbestimmung mittels Bioanalyzer}

Der Bioanalyzer benutzt die Gelelektrophorese in Kombination mit einem Farbstoff-Assay zur Bestimmung der RNA-Qualität. Dazu werden die Proben in einen Chip gegeben, dort elektrophoretisch aufgetrennt und anschließend mit einem Farbstoff versetzt. Ein Laser misst die entstandene Fluoreszenz. Anhand des Verhältnisses von 18s-rRNA und 28s-rRNA, der Fläche unter der Elektrophoresekurve, sowie weiterer Parameter, lässt sich die „,RNAIntegrität-Nummer" (RIN) errechnen. Diese hat eine Skala von 1 bis 10, wobei 1 stark degradiert bedeutet, und 10 die bestmögliche RNA Qualität beschreibt (Imbeaud et al. 2005; Schroeder et al. 2006).

$1 \mu 1$ hitzedenaturierte, homogenisierte Gesamt-RNA wurde in einen „RNA Serie II Kit Chip ${ }^{\circledR “}$ (Agilent Technologies, USA) gegeben, die Analyse erfolgte auf einem „Agilent 2100 Bioanalyzer® “. Proben mit einem RIN unter 8 wurden verworfen.

\subsection{Semiquantitative Real-Time-PCR (qRT-PCR)}

Die qRT-PCR basiert auf der konventionellen PCR. Während diese allerdings nur eine qualitative Aussage machen kann, ermöglicht die qRT-PCR eine quantitative Abschätzung der Genexpression (Pfaffl 2004). Genau wie bei der konventionellen PCR wird bei einem quantitativen Assay eine spezifische Nukleotidsequenz amplifiziert. Da sich die Menge dieser Sequenzen, solange diese Reaktion mit 100\%iger Effizienz abläuft, in jedem Durchlauf der PCR verdoppelt, verhält sich die Menge der gebildeten Sequenzen zum Zeitpunkt $\mathrm{x}$ proportional zu der Menge an Ausganssequenzen. Dies ermöglicht den relativen Vergleich von Sequenzmengen in verschiedenen Proben.

\subsection{1 cDNA-Synthese}

Da RNA von der DNA-synthetisierenden Taq-Polymerase während der Real-Time-PCR nur unzureichend als Matrize erkannt wird und darüber hinaus noch durch ubiquitär vorkommende RNasen degradiert wird, ist es erforderlich, sie in stabilere, komplementäre DNA, die so genannte cDNA, umzuschreiben. Hierzu wird eine reverse Transkriptase eingesetzt, die als RNA-abhängige DNA-Polymerase einen komplementären DNA-Strang an den vorhandenen RNA-Strang synthetisiert. Den Startpunkt für die reverse Transkription setzen die Random-Primer, das sind einzelsträngige DNA-Hexamere, die an alle 
einzelsträngigen Nukleinsäurestränge binden. So entsteht durch die reverse Transkription ein Gemisch aus cDNA, welches die Gesamtheit der Proben-RNA darstellt.

\subsubsection{1 cDNA-Synthese zur Microarray-Validierung}

$10 \mu \mathrm{g}$ RNA wurden mit $\mathrm{H}_{2} \mathrm{O}$ auf ein Volumen von $16 \mu \mathrm{l}$ verdünnt und zur Aufhebung von Sekundärstrukturen für $10 \mathrm{~min}$ bei $65^{\circ} \mathrm{C}$ inkubiert. Nach dem Abkühlen auf Eis wurden $6 \mu 1$ Random-Primer (Invitrogen) und $2 \mu 1 \quad 10$ mM dNTP-Mix (Amersham Biosciences, Buckinghamshire, UK) zugegeben, gevortext und erneut für $5 \mathrm{~min}$ bei $65^{\circ} \mathrm{C}$ inkubiert, wieder um Sekundärstrukturen zu eliminieren. Nach erneutem Abkühlen auf Eis wurden $8 \mu \mathrm{l} 5 \mathrm{x}$ First-Strand-Puffer (Invitrogen), $4 \mu \mathrm{l}$ 0,1 M DTT (Invitrogen) und $2 \mu 1$ „RNAseOut“ (Invitrogen) hinzugegeben. Damit die Random-Primer binden können, wurde für 2 min bei $25^{\circ} \mathrm{C}$ inkubiert. $2 \mu 1$,SuperScript II Reverse Transkriptase ${ }^{\circledR}$ “ (Invitrogen) wurden dem Reaktionsansatz zugegeben, es folgte ein einstündiger Elongationsschritt bei $42^{\circ} \mathrm{C}$, in dem die reverse Transkriptase den cDNA-Strang an die RNA-Matrize synthetisiert. Zur Deaktivierung aller Enzyme wurde für 17 min bei $72^{\circ} \mathrm{C}$ inkubiert. Die cDNA-Lösung wurde mit $360 \mu 1 \mathrm{H}_{2} \mathrm{O}$ verdünnt. Pro Probe wurden an verschiedenen Tagen insgesamt drei separate cDNASynthesen durchgeführt. Damit für die qRT-PCR-Experimente der gleiche cDNA-Pool zur Verfügung steht, wurden die Proben vereinigt und erneut qualitativ und quantitativ gemessen.

\subsubsection{2 cDNA-Synthese zur Validierung siRNA-vermittelter Genderegulation aus}

$$
\text { „Capture-Plate“-RNA }
$$

Für die Validierung des Knockdowns der einzelnen siRNA-Versuche waren sehr viele cDNASynthesen notwendig. Durch den Einsatz sogenannter „Capture-Plates“ konnte die RNAIsolation und die cDNA-Synthese schneller durchgeführt werden.

In den „Capture-Plates“ wird mRNA an Oligo-dTs gebunden, welche an der Platte fixiert sind. Daher besteht die Möglichkeit, nach erfolgter RNA-Isolation (siehe oben) direkt in der Platte eine cDNA Synthese durchzuführen. Obwohl es möglich gewesen wäre, entschieden wir uns dagegen, die Capture-Plate-Oligo-dTs zu nutzen, und verwendeten wieder RandomHexameres, da diese eine homogenere RNA-Transkription ermöglichen. Abbildung 4 zeigt schematisch die RNA-Isolation und cDNA-Synthese in einem 96-Well-Capture-Plate. 
Platte

A

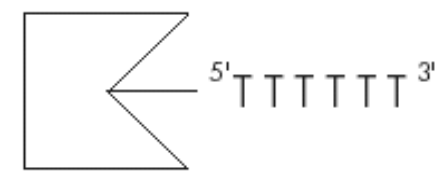

AAAAAA U U U U U mRNA

B

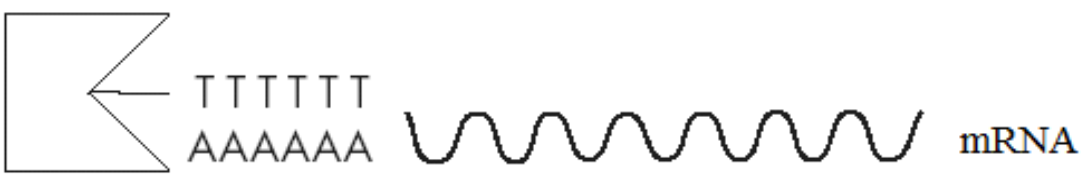

$\mathrm{C}$
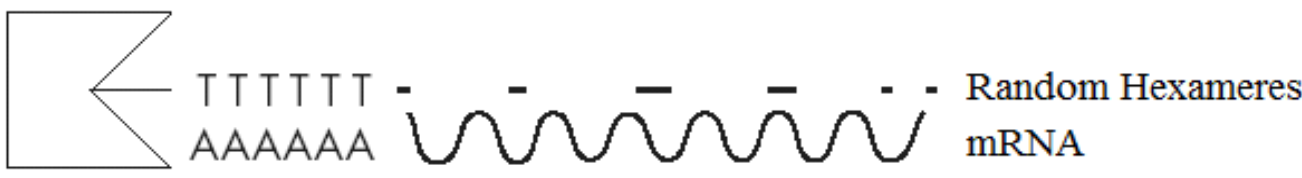

$\mathrm{D}$

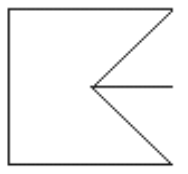

T T T T T T

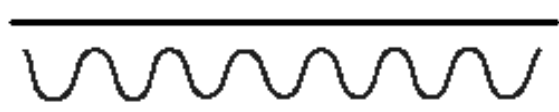

cDNA AAAAAA $\cup \cup \cup \cup U \cup U$ mRNA

Abbildung 4: Schematische Darstellung der RNA-Isolation und cDNA-Synthese in einer Capture-Plate. Der Poly-A-Tail einer mRNA bindet an ein Oligo-dT der Platte (A, B). Random Hexameres werden zugegeben und binden an die mRNA (C). Fertige cDNA (D) (mod. nach Qiagen 2008 S. 8 ).

Die mit mRNA beladenen Capture-Plates wurden direkt nach dem Waschen mit einem cDNA-Synthese-Mix, bestehend aus $8 \mu 1$ 5x-Puffer (Invitrogen), $4 \mu 1$ DTT (Invitrogen), $2 \mu 1$ dNTPs (Invitrogen), 0,5 $\mu 1$ Random Hexameres (Invitrogen) sowie 20,5 $\mu 1$ Wasser beladen. Anschließend wurde für 5 min bei $65^{\circ} \mathrm{C}$ inkubiert, die Platte auf Eis abgekühlt, ein Mix aus 1 $\mu 1$ Superscript III (Invitrogen), 0,5 $\mu$ l RNase-Out (Invitrogen) sowie 3,5 $\mu$ l Wasser dazugegeben, 5 min bei $25^{\circ} \mathrm{C}$ und dann für $1 \mathrm{~h}$ bei $50^{\circ} \mathrm{C}$ inkubiert. Durch ein Erhitzen auf $75^{\circ} \mathrm{C}$ für 15 min wurde die Reaktion inaktiviert. Die cDNA wurde bei $-20^{\circ} \mathrm{C}$ bis zur Verwendung in der PCR gelagert.

\subsubsection{Primerdesign}

Das Primerdesign bestimmt die Spezifität, Sensitivität und Reproduzierbarkeit einer qRTPCR. Dafür ist es wichtig, dass die Sequenz des Amplikons in allen Spleiß-Varianten des Gens vorkommt. Das Primerpaar sollte ein Intron umschließen, damit keine genomische DNA mitamplifiziert werden kann. Die Primer dürfen keine Sekundärstrukturen, wie zum Beispiel 
Primerdimere, bilden können und müssen so gewählt sein, dass eine der Primersequenzen einzigartig für die Zielsequenz des zu untersuchenden Gens ist (Bustin 2000).

Mithilfe der Ensembl-Datenbank (http://www.ensembl.org/index.html; Stand 2007) wurden für jedes Zielgen zwei Exone ausgewählt, die in jeder Spleißvariante dieses Gens vorkommen und ein mindestens 1000 bp großes Intron umschließen.

Mit der Primer3-Software (Rozen und Skaletsky 2000) wurden die Primerpaare erstellt. Die Standardeinstellungen von Primer3 wurden abgeändert, um die Primer an den Power-SybrGreen-Assay (siehe unten) anzupassen. Schmelztemperatur der Primer: $59^{\circ} \mathrm{C}$ bis $61^{\circ} \mathrm{C}$, maximal drei Mononukleotid-Wiederholungen, Amplikon-Länge zwischen 100 und 250 Basenpaaren. Sequenzen mit „CG-Clamps“ wurden nach Möglichkeit vermieden.

Alle so gefundenen Primersequenzen wurden mithilfe der NCBI-Software „,blast“ (Altschul et al. 1997) auf ihre Einzigartigkeit im Genom überprüft. Es wurde die Funktion ,nucloeotide Blast“ verwendet, welche die Algorithmen „blastn“, „megablast“ und „discontiguous megablast “ umfasst. Tabelle 4 gibt eine Übersicht über die verwendeten Primerpaare, ihre Sequenzen und Lokalisationen im Genom. Synthetisiert wurden die Primer bei Eurofins MWG Operon (Huntsville, USA). Die Spezifität aller Primerpaare wurde an einem cDNAMix aus allen Zelllinien getestet. Nach der Amplifikation wurde per Gelelektrophorese und Schmelzkurvenanalyse (siehe unten) überprüft, ob nur ein PCR-Produkt entstanden ist und ob es die vorher errechnete Größe oder Schmelztemperatur hat.

\subsubsection{Primeroptimierung}

Damit eine qRT-PCR auswertbar ist, muss die Effizienz, mit der die PCR-Reaktion abläuft, bekannt sein und möglichst nah an 100\% liegen. Neben der Effizienz der Taq-Polymerase hängt die Effizienz der Reaktion im Wesentlichen von der Bindungsfähigkeit der Primer an die cDNA ab. Diese wird maßgeblich durch die Konzentration der Primer und die Temperatur in diesem Schritt beeinflusst. Um die optimale Menge an Primern zu finden, bei der es eine hohe Bindungsfähigkeit aber noch keine Primerdimere gibt, wurden jeweils drei verschiedene Primer-Mengen getestet: $50 \mathrm{nM}, 150 \mathrm{nM}$ und $300 \mathrm{nM}$. Die Konzentrationen, in der die Primer eingesetzt wurden, gehen aus Tabelle 4 hervor. Mithilfe des Programmes „LinRegPCR ${ }^{\circledR \text { “ }}$ (Ramakers et al. 2003) wurde die Effizienz der Reaktion bestimmt. Nur Primer, die keine Sekundärstrukturen bildeten und eine Effizienz von $100 \% \pm 2 \%$ aufwiesen, wurden verwendet. 


\begin{tabular}{|c|c|c|c|c|c|c|c|}
\hline Genname & $\begin{array}{l}\text { Referenz } \\
\text { Sequenz }\end{array}$ & $\begin{array}{l}\text { Spleiß- } \\
\text { Varianten }\end{array}$ & $\begin{array}{l}\text { Vorwärts } \\
\text { Primer Lage }\end{array}$ & Vorwärts Primer Sequenz & $\begin{array}{l}\text { Rückwärts } \\
\text { Primer Lage }\end{array}$ & Rückwärts Primer Sequenz & $\begin{array}{l}\text { Primer } \\
\text { Konzentration }\end{array}$ \\
\hline \multicolumn{8}{|c|}{ Gene in der Region 13q12.1-q12.3 } \\
\hline GPR12 & NM 005288.1 & 1 & Exon1 438-457 & GACGTACCATTCGGAGAGGA & Exon1 620-601 & AGGAAGGACACCGAGAGGAT & $150 / 150$ \\
\hline USP12 & NM_182488.1 & 1 & Exon1 227-246 & GCTGTGATTGGGTGGAAGAT & Exon2 380-358 & AATCCAAAATAGTGCTCATTGAC & $300 / 300$ \\
\hline RASL11A & NM 206827.1 & 1 & Exon3 802-821 & AAGCTGTATTCACGGCTGGT & Exon4 923-904 & CATTTGGACAGGGAATCGAC & $300 / 300$ \\
\hline MTIF3 & NM_152912.3 & 1 & Exon2 88-108 & GAGCTTCTCCTCATCAACTGG & Exon3 249-230 & GACAACTGTGCTGGTGCTGT & $300 / 300$ \\
\hline LNX2 & NM 153371.2 & 2 & Exon2 508- 527 & ATGCAACGTTGTGATCTGGA & Exon3 682-663 & CCAAACAGTCTGCTTCTGGA & $150 / 150$ \\
\hline POLR1D Spl.Var.1 & NM 152705.1 & 2 & Exon1 89-108 & CCACCTGAGGATCCAGAAAC & Exon2 232-212 & CCTCGTGCAATACAAATGTCA & $300 / 300$ \\
\hline POLR1D Spl.Var.2 & NM_152705.1 & 2 & Exon3 156-177 & AAGAACTGCTTAAGGAGGCAAA & Exon4 341-322 & TCTTCGCTGGTTCCTTATCG & $300 / 300$ \\
\hline GSH1 & NM 145657.1 & 1 & Exon2 481-498 & CCCAGCAGCAAGAGGATG & Exon2 616-597 & GCTTCTCGGACAGATTCAGG & $300 / 300$ \\
\hline IPF1/PDX1 & NM 000209.1 & 1 & Exon 1241-1258 & CGTTGTTTGTGGCTGTTG & Exon $1380-1362$ & TTCCCCGCTGTGTGTGTTA & $300 / 300$ \\
\hline $\mathrm{CDX} 2$ & NM_001265.2 & 1 & Exon1 663-681 & GAACCTGTGCGAGTGGATG & Exon2 820-801 & TCCTCCGGATGGTGATGTAG & $150 / 150$ \\
\hline PAN3 & $\underline{\text { NM } 175854.5}$ & 1 & Exon2 2-22 & TGGATGGAGGTGCTTTAACTG & Exon3 176-157 & GCTGAATATGGCTTGGCACT & $150 / 150$ \\
\hline POMP Set 2 & NM 015932.2 & 2 & Exon5 343-363 & CAGCGTCTTCCATTTCTTTCA & Exon5 523-504 & GGTTTCCATGAACAGCACAC & $300 / 300$ \\
\hline SLC46A3/FKSG16 & NM_181785.1 & 2 & Exon2 405-424 & ACTTTGACCGGTCCACTGAC & Exon3 554-533 & TTTCTGAACTTCCTCCTGGAAT & $300 / 300$ \\
\hline \multicolumn{8}{|c|}{ Gene in der Region 13q34 } \\
\hline EFNB2 & NM_004093.2 & 2 & Exon1 44-63 & TCCGTGTGGAAGTACTGCTG & Exon2 201-179 & TCCAATTTGTCTCCTATCTGTGG & $300 / 300$ \\
\hline LIG4 & NM_002312.3 & 2 & Exon2 170-190 & CAGGAAACCATCAAGATCTCA & Exon3 319-300 & AAGGAACGTGAGATGCAACA & $300 / 300$ \\
\hline ABHD13/c13orf6 & NM 032859.2 & 1 & Exon1 492-511 & TTTATGTTCCCATGCCCACT & Exon2 649-630 & ACCTATGTTGCCTGCATTCC & $300 / 300$ \\
\hline IRS2 & NM 003749.2 & 1 & Exon1 4469-4488 & ACCTACGCCAGCATTGACTT & Exon2 4654-4634 & CACAGTCATTGCTCAGATCCA & $300 / 300$ \\
\hline COL4A1 & NM_001845.3 & 1 & Exon23 1241-1260 & TCCCTGGTGAAAGAGGAGAA & Exon24 1391-1372 & GGCTGACATTCCACAATTCC & $300 / 300$ \\
\hline COL4A2 & NM 001846.1 & 1 & Exon24 2946-2965 & TGGTGACAGAGGAGATGCTG & Exon25 3165-3146 & ACCCTTCAGACCGGGTATTC & $300 / 300$ \\
\hline FLJ10769 & NM 018210.1 & 1 & Exon4 320-339 & CTTGTCCCACGTGTTCTGTG & Exon5 472-453 & CCAGGTCCTACGACAAGAGC & $300 / 300$ \\
\hline FLJ12118/CARS2 & NM 024537.1 & 1 & Exon14 1561-1580 & GGCAGCAGCTCCTAGAAAGG & Exon15 1756-1738 & CGTCTTGTCGTGAGCAGGT & $300 / 300$ \\
\hline ING1 & NM_005537.3 & 4 & Exon2 1008-1028 & GGAGCTAGACGAGTGCTACGA & Exon2 1139-1119 & CTCACGATCTGGATCTTCTCG & $300 / 300$ \\
\hline LOC283487/c13orf29 & NM 178514.3 & 1 & Exon1 480-499 & AGGTTCGGGAAGAAAGGAAA & Exon1 606-587 & GGAAACATGCCTCGTAAGGA & $300 / 300$ \\
\hline ANKRD10 & NM_017664.2 & 3 & Exon7 894- 913 & CGTTGATAGGGAGTTTGCTG & Exon8 1028-1009 & CTGCTTTCCATCCCACTGAG & $300 / 300$ \\
\hline
\end{tabular}




\begin{tabular}{|c|c|c|c|c|c|c|c|}
\hline C13orf16 & NM 152324.1 & 2 & Exon3 122-141 & CTGCAGCAATGGAATACGTG & Exon4 296-277 & GGAACCGCTTTCTTGTAGCA & $300 / 300$ \\
\hline TUBGCP3 & NM_006322.3 & 3 & Exon17 2196-2213 & GCGAAGCGGATGGAATAC & Exon18 2352-2327 & TGTAATACTGCATCTGATGAATGAAA & $300 / 300$ \\
\hline ATP11A & $\underline{\mathrm{NM} \quad 032189.2}$ & 3 & Exon17 1872-1891 & GAGCCAGAGTGGAGCGTAAC & Exon18 2075-2056 & CCTCAACAGCTGTAGCACCA & $150 / 150$ \\
\hline PCID2 & NM_018386.1 & 10 & Exon2 79-98 & AAGCCATCGACAGCAGAGAT & Exon3 229-209 & TGAGCTGCAAACATTTCATCA & $300 / 300$ \\
\hline CUL4A & NM 003589.2 & 4 & Exon12 1094-1113 & AGAATGAGCGGTTCGTCAAC & Exon13 1232-1213 & TCCTCGTCTGTGGCTTCTTT & $300 / 300$ \\
\hline LAMP1 & NM_005561.2 & 2 & Exon4 713-732 & CAGGCGTACCTTTCCAACAG & Exon6 864-845 & CCGCTCACGTTGTACTTGTC & $300 / 300$ \\
\hline GRTP1 & NM 024719.1 & 2 & Exon4 179-198 & CATAACCAGGGAGTGGGCTA & Exon5 289-268 & TCCAACAAGAGCATCTAACAGC & $150 / 150$ \\
\hline ADPRHL1 & $\underline{\text { NM } 199162.1}$ & 3 & Exon2 106-125 & AGCGCATTATCACCAAGTCA & Exon3 417-398 & TAGCTGAGCACAGCCTTCAA & $300 / 300$ \\
\hline DCUN1D2 & NM_018185.2 & 4 & Exon5 452-471 & AGGCTCTTCTGCCAAGACTG & Exon5 553- 534 & CTTTCTGCCCTGGGTTCTTA & $300 / 300$ \\
\hline TFDP1 & NM_007111.3 & 2 & Exon 3 495-514 & TCCGACTCCTCACCTTGGTC & Exon 5 562-544 & CGTAGGCCCTTGCCATTCT & $300 / 300$ \\
\hline GRK1 & NM 002929.2 & 1 & Exon2 844-863 & CACAGCAGGTTCATCGTGTC & Exon3 1010-991 & ATCTGCGCCGTGTAGAAGAG & $300 / 300$ \\
\hline GAS6 & NM 000820.1 & 3 & Exon6 636-655 & CTCCAGATCTGCCACAACAA & Exon7 836-817 & СTTCTCCTGGGAGCTGTACG & $300 / 300$ \\
\hline CDC16 & NM_003903.2 & 7 & Exon14 1453-1472 & TGGTTTCTTGATGCTTTGGA & Exon15 1546-1527 & AGACATGCCCCAAGTTGTTC & $300 / 300$ \\
\hline \multicolumn{8}{|c|}{ Gene außerhalb der beiden Regionen } \\
\hline GPC5 & NM_004466.3 & 1 & Exon6 1559-1580 & GCCTTCGACTGTACAGGTCATT & Exon6 1707-1688 & GGCTTTGATTCCATTTCCAA & $300 / 300$ \\
\hline MYCBP2 & $\underline{\text { NM } 015057.2}$ & 3 & Exon 28 3833-3852 & GGTCCTGATGGAGGAGATCA & Exon29 4003-3984 & ACTGCTGGGTCCTGACACTC & $300 / 300$ \\
\hline DLEU2 & $\underline{\text { NR } 002612.1}$ & 1 & Exon2 309-330 & TGCATTGGAACATGACATGAGA & Exon4 452-429 & TGTTCCTTGCAGTACACCTTTCAA & $300 / 300$ \\
\hline NUPL1 & $\underline{\text { NM } 014089.3}$ & 6 & Exon5 714-733 & TGGGACAACAGCCACAACTA & Exon6 887-868 & TCATTGCCTGCAGTTGAAGT & $300 / 300$ \\
\hline KLF5 & NM_001730.3 & 1 & Exon3 1591-1610 & CACTACCGGAAGCACACAGG & Exon4 1700-1681 & GCTCAGTTCTGGTGCCTCTT & $150 / 150$ \\
\hline BRCA2 & NM 000059.2 & 1 & Exon9 2077-2096 & CAGCCCAGTTTGAAGCAAAT & Exon10 2233-2213 & TTCCTCAGAATTGTCCCAAAA & $300 / 300$ \\
\hline FABP7 & NM_001446.3 & 2 & Exon2 489-508 & CCAGCTGGGAGAAGAGTTTG & Exon3 598-579 & СТTTGCСАТСССАТTTСТGT & $300 / 300$ \\
\hline EBPL & $\underline{\text { NM } \quad 032565.1}$ & 7 & Exon7 464-483 & GAGCTGTATGGCTGCTGGAT & Exon7 564-545 & TCAGAACCCACACACCGTTA & $300 / 300$ \\
\hline CENPJ & NM_018451.2 & 1 & Exon7 2786-2805 & GTCCTCCTACATCGGAGCTG & Exon8 2924-2906 & ACCTGGGATCGAGCATTGT & $300 / 300$ \\
\hline GTF2F2 & $\underline{\mathrm{NM} \quad 004128.1}$ & 2 & Exon10 714-736 & СTTAAGGACTTGGTGGACATCAC & Exon11 828-809 & GCTTCAGCTCCCATGTGTTT & $300 / 300$ \\
\hline TMTC4 & NM_032813.1 & 4 & Exon18 1363-1383 & TCCTCAAGGCAATTAAAGCAA & Exon19 1485-1466 & CAAGCTGCAAGGAGATTTCA & $300 / 300$ \\
\hline SLC7A1 & $\underline{\mathrm{NM} \quad 003045.3}$ & 2 & Exon9 1522-1541 & GCACTCTCCTGGCTTACTCG & Exon10 1664-1645 & ATTGGTGCTTGCCAATTCAT & $300 / 300$ \\
\hline C13orf23 & $\underline{\text { NM } 170719.1}$ & 3 & Exon5 1077-1096 & TGAGAAGAAACGGTGCAAGA & Exon6 1211-1192 & TCCATTTATGCGGCTAGGTC & $300 / 300$ \\
\hline ZDHHC20 & $\underline{\text { NM_153251.2 }}$ & 3 & Exon3 333-350 & TTCACATCTCCCGCTTCC & Exon4 453-433 & AAGCTCTTGCTGCTCTTCTCA & $300 / 300$ \\
\hline
\end{tabular}




\begin{tabular}{|c|c|c|c|c|c|c|c|}
\hline NEK3 & NM 152720.1 & 3 & Exon14 1499-1518 & GCTGATCTCAGCTTGGCTTT & Exon15 1616-1597 & CGTGACCTCCATCAACACTG & $300 / 300$ \\
\hline ATP7B & NM_001005918.1 & 2 & Exon1 1418-1437 & GGATTTGAGGCTTCAGTCGT & Exon2 1538-1519 & GAGCCACTTCCTGCACAGAT & $150 / 150$ \\
\hline CKAP2 & NM 018204.2 & 3 & Exon5 1310-1330 & TTTGGACTACCATGGCAGAAG & Exon6 1443-1422 & CAGGTCATTCAGTGTGACCAGT & $300 / 300$ \\
\hline TBC1D4 & NM_014832.1 & 3 & Exon12 2126-2145 & ACGGTCCAACAGTCTTGCTT & Exon13 2246-2228 & GGAGTCGGAATCCTCTTCG & $150 / 150$ \\
\hline MIPEP & NM 005932.1 & 2 & Exon13 1498-1517 & CCCGTTCCTCAAGGAGTTCT & Exon14 1638-1619 & AATCAGTAGGGCACCTGGTC & $300 / 300$ \\
\hline ZMYM2 & NM_197968.1 & 6 & Exon29 4137-4156 & ACAGCCAATCCTTCCAGATG & Exon30 4250-4228 & ACTAGAGCATTCTGGTTGCAAAT & $300 / 300$ \\
\hline FLJ22624/c13orf34 & $\underline{\mathrm{NM} \quad 024808.2}$ & 3 & Exon11 1619-1638 & TACGCAGAATTGTGGAAGCA & Exon12 1759-1739 & САACACСТCTGTGTTGTGTGG & $300 / 300$ \\
\hline XPO4 & NM 022459.3 & 2 & Exon18 2168- 2188 & CTGTGCAGAGGACATTGATGA & Exon19 2282-2263 & AAGAATCGCTGCTGAAGTGG & $150 / 150$ \\
\hline C13orf3 & NM_145061.3 & 2 & Exon5 898- 917 & CATCATCCAGCAGTTGGAAA & Exon6 1005-982 & GCTATGCTGTTCTTTGTAGATGGA & $150 / 150$ \\
\hline $\mathrm{RFC} 3$ & NM_181558.1 & 2 & Exon1 171-190 & TGCAGTGTGGTGACTTTCCT & Exon2 349-328 & ACTTGCAATGGTGCTAATTTCA & $300 / 300$ \\
\hline CKAP2 & $\underline{\mathrm{NM} 018204.2}$ & 3 & Exon5 1310-1330 & TTTGGACTACCATGGCAGAAG & Exon6 1443-1422 & CAGGTCATTCAGTGTGACCAGT & $300 / 300$ \\
\hline AKAP11 & NM_144490.1 & 3 & Exon6 397-418 & AGCTGCAGTTTCTTTGGAACTT & Exon7 549- 529 & CAAAGCATTCCAGAAGGATGA & $150 / 150$ \\
\hline DIAPH3 & NM_030932.2 & 3 & Exon 1582-1601 & GAAACACGGTTGGCAGAGTC & Exon 1708-1689 & CCACAAACTGCTCAGGTTCA & $150 / 150$ \\
\hline GPR180 & NM 180989.4 & 1 & Exon6 912-931 & TCTCCAGTGGGATTCTACGC & Exon7 1051-1032 & GGATCCCTGCTAAGTTGTGG & $300 / 300$ \\
\hline C13orf18 & NM_025113.1 & 2 & Exon6 740-759 & GAGCCTTCCCATCTGACATC & Exon7 848-829 & CATCAACAGGCAGCACAAAT & $150 / 150$ \\
\hline Sox 1 & NM 005986.2 & 2 & Exon1 2152-2171 & GGAATGGGAGGACAGGATTT & Exon1 2283-2264 & AACAGCCGGAGCAGAAGATA & $150 / 150$ \\
\hline DIS3/KIA1008 & NM_014953.2 & 5 & Exon16 2111-2130 & CTGCTCСАССТССАТСАААТ & Exon17 2219-2200 & GCCTGATCCAAAGACTCAGC & $300 / 300$ \\
\hline \multicolumn{8}{|c|}{ Normalisierungsgene des siRNA Screens } \\
\hline YWHAZ & NM_003406.2 & 2 & Exon 5 1091-1114 & ACTTTTGGTACATTGTGGCTTCAA & Exon5 1184-1165 & CCGCCAGGACAAACCAGTAT & $150 / 150$ \\
\hline HPRT1 & NM 000194.1 & 2 & Exon5 496-516 & TGACACTGGCAAAACAATGCA & Exon6 589-569 & GGTCCTTTTCACCAGCAAGCT & $300 / 300$ \\
\hline B-ACTIN & $\underline{\text { NM_001101.2 }}$ & 1 & Exon1 23-39 & AGCCTCGCCTTTGCCGA & Exon2 123-109 & CTGGTGCCTGGGGCG & $300 / 300$ \\
\hline \multicolumn{8}{|c|}{ Normalisierung der Zelllinienversuche } \\
\hline FBXL12 & NM_017703.1 & 1 & Exon1 378-397 & CATGTCGACCTGACGCTCTA & Exon2 496-477 & TGGGAGCCAGAGAACAGGTA & $300 / 300$ \\
\hline RAB35 & NM 006861.4 & 1 & Exon1 567-586 & AGATGGGCATCCAGTTGTTC & Exon2 675-656 & GCCAGGTTGTCTTTCTTTGC & $300 / 300$ \\
\hline OTUB1 & NM_017670.1 & 2 & Exon3 165-184 & ATTGCTGTGCAGAACCCTCT & Exon4 299-280 & GGTCTTGCGGATGTACGAGT & $300 / 300$ \\
\hline
\end{tabular}

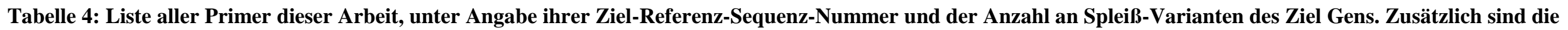
Primersequenzen der Paare sowie ihre Lokalisation im Transkript aufgeführt. Die eingesetzte Primerkonzentration ist ebenfalls aufgeführt 


\subsubsection{Sybr-Green-Assay}

Sybr-Green interkaliert mit dsDNA und emittiert dabei Licht. Dabei ist die Menge der emittierten Fluoreszenz proportional zu der Menge des gebundenen Sybr-Greens und damit ebenfalls proportional zu der Menge an dsDNA. Dieses Prinzip macht man sich bei der semiquantitativen-Real-Time-PCR zunutze. In einer PCR-Reaktion verdoppeln sich die Anzahl der amplifizierten DNA-Moleküle in jedem Zyklus. Dieses Prinzip ist in Abbildung 5 dargestellt. Misst man nach jedem Zyklus der PCR die Menge an emittierter Fluoreszenz und trägt in einem Diagramm den Zyklus gegen die logarithmische Fluoreszenz auf, so erhält man eine S-förmige Kurve. Eigentlich würde man bei einer Verdopplung der DNA-Menge in jedem Zyklus einen exponentiellen Anstieg der Fluoreszenz erwarten, allerdings reicht die Leuchtkraft in den ersten Zyklen noch nicht aus, um das unspezifische Hintergrundleuchten $\mathrm{zu}$ übertreffen. In den letzten Zyklen flacht die Kurve wieder ab, es ist keine exponentielle Amplifikation mehr möglich, da die Substrate zur Neige gehen.

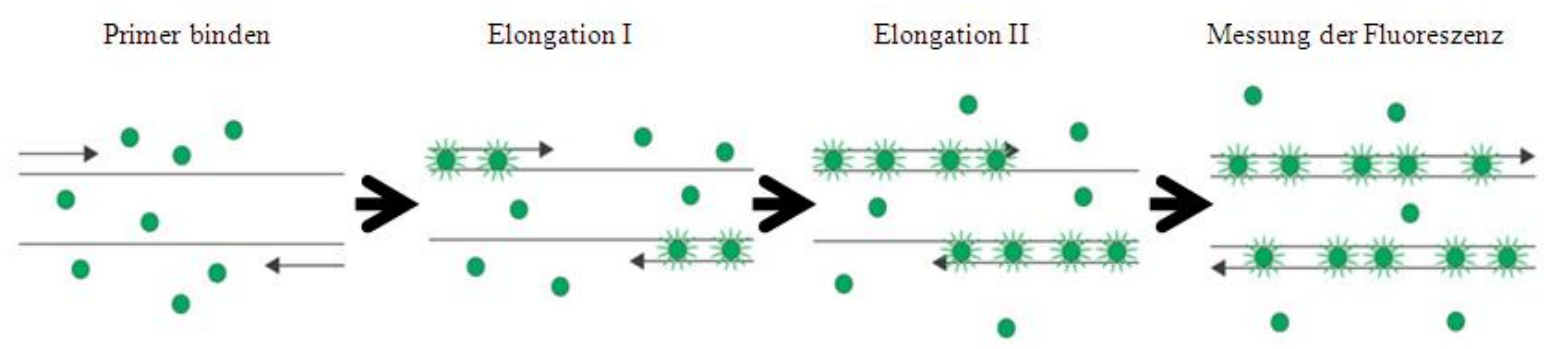

Abbildung 5: Prinzip des Sybr Green Assays (mod. nach van der Velden et al. 2003 S. 1015)

Zunächst wurde ein Mastermix hergestellt (siehe Tabelle 5), dieser wurde in eine „MicroAmp96-Well-Reaction-Plate“ (Applied Biosystems) gegeben. Die gesamte Verarbeitung erfolgte auf Eis. Tabelle 6 gibt einen Überblick über das Platesetup der qRT-PCR im Zelllinienscreen inklusive aller Kontrollen.

\begin{tabular}{l|c|l} 
Zutat & Menge in $\boldsymbol{\mu l} \mathbf{1 x}$ & Hersteller \\
\hline „Power Sybr Green PCR & 12,5 & Applied Biosystems \\
Mastermix” & & \\
Primer Mix (Vorwärts und & 6 & Operon \\
Rückwärtsprimer) & & \\
Wasser & 4,5 & Sigma
\end{tabular}

Tabelle 5: PCR-Mastermix 
In jedes Well der Platte wurden zu dem Mastermix jeweils $3 \mu$ cDNA gegeben und die Platte mit einem „Optical Adhensive Cover“ (Applied Biosystems) verschlossen.

\begin{tabular}{|c|c|c|c|c|c|c|c|c|c|c|c|}
\hline 1 & 2 & 3 & 4 & 5 & 6 & 7 & 8 & 9 & 10 & 11 & 12 \\
\hline A & & Ref. & SW1463 & SW1463 & SW1463 & DLD1 & DLD1 & DLD1 & Ref. & & \\
\hline Colo-320 & Colo-320 & Colo-320 & SW480 & SW480 & SW480 & SW1116 & SW1116 & SW1116 & LOVO & LOVO & LOVO \\
\hline LS-174t & LS-174t & LS-174t & HT-29 & HT-29 & HT-29 & NCI-H508 & NCI-H508 & NCI-H508 & Rektum & Rektum & Rektum \\
\hline SK-CO-1 & SK-CO-1 & SK-CO-1 & SW48 & SW48 & SW48 & Kolon & Kolon & Kolon & SW403 & SW403 & SW403 \\
\hline CACO-2 & CACO-2 & CACO-2 & RKO & RKO & RKO & COLO-201 & COLO-201 & COLO-201 & LS-411N & LS-411N & LS-411N \\
\hline SW620 & SW620 & SW620 & SW837 & SW837 & SW837 & $\mathrm{T}-84$ & $\mathrm{~T}-84$ & $\mathrm{~T}-84$ & HTC 116 & HTC 116 & HTC 116 \\
\hline LS-123 & LS-123 & LS-123 & LS-1034 & LS-1034 & LS-1034 & Normal & Normal & Normal & $\begin{array}{c}\text { p53- } \\
\text { HTC116 }\end{array}$ & $\begin{array}{c}\text { p53- } \\
\text { HTC116 }\end{array}$ & $\begin{array}{c}\text { p53- } \\
\text { HTC116 }\end{array}$ \\
\hline NTC & NTC & NTC & NCI-H716 & NCI-H716 & NCI-H716 & LS-513 & LS-513 & LS-513 & Ref. & & \\
\hline
\end{tabular}

Tabelle 6: Beispiel eines Platesetups im Zelllinienscreen zur Bestimmung des Expressionsmusters eines Gens. Jede Reaktion wurde in Triplikaten durchgeführt, um eventuelle Ausreißer zu vermeiden. Zusätzlich zu den 25 Zelllinien sind eine Wasserkontrolle (NTC), 3 verschiedene Normalgewebepoole (Kolon, Normal, Rektum) und ein Referenz-cDNA-Pool mitgeführt worden.

Anschließend wurde der Inhalt der PCR-Platte kurz auf einer Rüttelplatte bei sehr niedriger Drehzahl, um die Taq-Polymerase nicht zu schädigen, gemixt und danach kurz zentrifugiert. Die eigentliche PCR-Reaktion wurde in einem „Applied Biosystems PRISM 7000“Thermozykler durchgeführt. Nach zwei minütigem Vorwärmen bei $50^{\circ} \mathrm{C}$ erfolgte die Aktivierung der Taq-Polymerase durch Erhitzen für $10 \mathrm{~min}$. bei $95^{\circ} \mathrm{C}$. Im Anschluss daran wurden 40 PCR-Zyklen gefahren (siehe Tabelle 7). Nach jedem Zyklus maß die Maschine die emittierte Fluoreszenz.

\begin{tabular}{|c|c|c|}
\hline Vorwärmen & $50^{\circ} \mathrm{C}$ & $2 \mathrm{~min}$. \\
\hline Taq-Aktivierung & $95^{\circ} \mathrm{C}$ & $10 \mathrm{~min}$. \\
\hline Denaturierung & $95^{\circ} \mathrm{C}$ & 15 sek. \\
\hline $\begin{array}{c}\text { Annealing und } \\
\text { Elongation }\end{array}$ & $60^{\circ} \mathrm{C}$ & $1 \mathrm{~min}$. \\
\hline Fluoreszenzdetektion & & \\
\hline
\end{tabular}

Tabelle 7: PCR Protokoll, die ersten beiden Schritte wurden jeweils ein Mal durchgeführt, nach Schritt 5 wurde zu Schritt 3 zurückgegangen und dieser insgesamt 40x wiederholt. 


\subsubsection{Schmelzkurven-Analyse}

Jedes Amplifikationsprodukt hat eine spezifische Schmelztemperatur. Da Sybr-Green an alle dsDNA bindet und Fluoreszenz emittiert, muss sichergestellt werden, dass nur das gewünschte Produkt amplifiziert wurde und es kein zweites Produkt aufgrund unspezifischer Bindungen oder Primerdimeren gibt. Dies geschieht mit der so genannten Schmelzkurvenanalyse. Nach der letzten Elongationsphase kühlt die PCR-Maschine die PCRProdukte auf $60^{\circ} \mathrm{C}$ ab und erhitzt sie in mehreren Schritten auf $95^{\circ} \mathrm{C}$, dabei wird bei jedem Schritt die Fluoreszenz gemessen. Jedes Amplifikationsprodukt hat einen spezifischen Schmelzpunkt, abhängig von der Länge und dem CG-Gehalt des Produktes. Ist dieser erreicht, denaturiert die dsDNA, Sybr-Green wird freigesetzt und es kommt zu einer schlagartigen Reduktion der Fluoreszenzintensität. In einer grafischen Darstellung der Fluoreszenzintensität gegen die Temperatur lässt sich nun die Schmelztemperatur der in der PCR entstandenen Produkte ablesen. Die Schmelzkurvenanalyse erlaubt eine wesentlich genauere Analyse als ein Elektrophoresegel, da nicht die Länge des Produktes, sondern seine spezifische Zusammensetzung die Schmelztemperatur beeinflusst. Abbildung 6 zeigt das Ergebnis einer Schmelzkurvenanalyse eines spezifischen und eines unspezifischen Amplifikationsproduktes. Die PCR-Produkte wurden direkt im Anschluss an die Amplifikation zunächst für 15 sek auf $95^{\circ} \mathrm{C}$ erhitzt, auf $60^{\circ} \mathrm{C}$ abgekühlt und dann erneut schrittweise in 20 min auf $95^{\circ} \mathrm{C}$ erhitzt. Während der 20 minütigen Erhitzungsphase wurde kontinuierlich die Fluoreszenz gemessen. Anschließend wurde die Fluoreszenzänderung als Funktion der Temperatur dargestellt. War mehr als ein Peak in dieser Funktion, wurde der Assay verworfen und mit neuen Primern wiederholt.
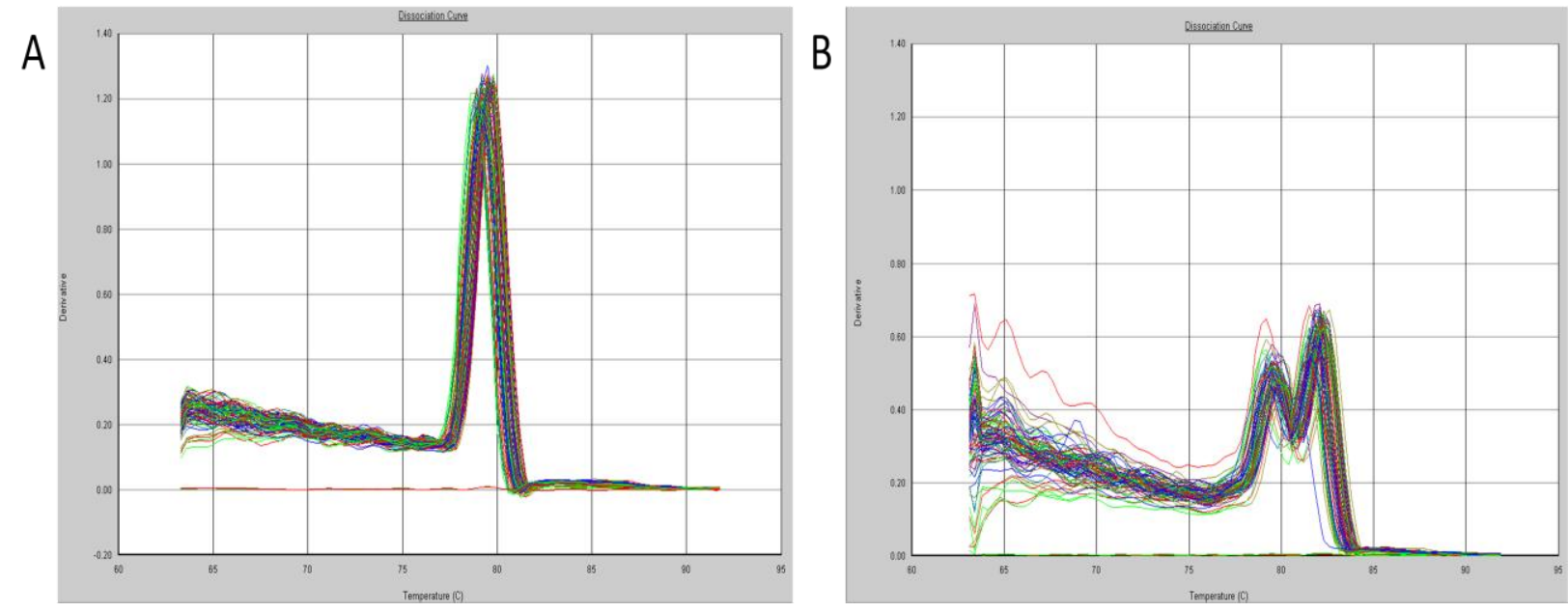

Abbildung 6: Zwei Schmelzkurvenanalysen, einmal mit einem spezifischen Produkt (A) und einmal mit zwei unspezifischen Produkten (B). Hier ist jeweils die erste Ableitung des emittierten Lichtes gegen die Temperatur dargestellt. 


\subsubsection{Auswertung}

Das Ziel der PCR-Auswertung ist eine semiquantitative Bestimmung der Ausgangsmenge einer bestimmten Nukleotidsequenz. Semiquantitativ bedeutet, dass die Menge einer bestimmten RNA/DNA-Sequenz nicht absolut, sondern im Verhältnis zu einer anderen Sequenz bestimmt wird. Bei dieser handelt es sich um eine Sequenz, die möglichst in allen Proben gleichstark exprimiert ist und durch die Behandlung nicht verändert wird. In den meisten Fällen wird daher ein sogenanntes „Housekeeping“-Gen verwendet. Bei der Genexpressionsanalyse in den Zelllinien war dies nicht möglich, da es kein einzelnes, über alle Zelllinien stabil exprimiertes Gen gab. In Anlehnung an die „MIQE-Guidelines“ (Bustin et al. 2009) entschieden wir uns dafür, aus unseren Genexpression-Mikroarray-Daten drei Gene auszuwählen, welche möglichst geringe Schwankungen über alle Proben aufwiesen. Es handelte sich um die Gene OTUB1, FBXL2 und RAB35. Für die Bestimmung des siRNA Knockdowns in SW480 konnten drei „Housekeeping“-Gene verwendet werden, die bereits ausführlich in der Literatur beschrieben sind, es handelt sich um die Gene YWHAZ, HPRT1 und $\beta$-ACTIN (Goossens et al. 2005; Pfaffl 2004). Alle Proben wurden auf den Mittelwert der drei Gene normalisiert, im Genexpressionsversuch auf OTUB1, FBXL2 und RAB35, bei der siRNA-Knockdown-Validierung auf YWHAZ, HPRT1 und $\beta$-ACTIN. Mithilfe der sogenannten $\Delta \Delta$ Ct-Methode wurde die Expression der einzelnen Gene in einer Probe im Verhältnis zu einer Referenz berechnet. Als Referenz dienten im Zelllinienscreen drei Kontrollgewebe, nämlich ein Pool aus normalem Kolongewebe, ein Pool aus normaler Rektummukosa sowie ein kommerziell erhältlicher RNA-Pool aus zehn verschiedenen humanen Zelllinien (,Stratagene Reference Pool“ (Agilent Technologies)). Bei der siRNAKnockdown-Validierung diente RNA aus zeitgleich mit „Allstar-Negative-Control-siRNA“ (siNEG) (Qiagen) transfizierten Zellen als Referenz.

Die Auswertung der qRT-PCR erfolgte mittels der „ABI Prism 7000 SDS Software“ (Version 1.2.3). Als erstes wurden die gemessenen Fluoreszenz-Werte des Sybr-Greens auf einen zweiten, passiven Farbstoff (ROX) normalisiert. Durch diese Normalisierung konnte erreicht werden, dass eventuelle Schwankungen in der Anregung oder Menge der Farbstoffe auf der Platte ausgeglichen werden. Danach wurde die sogenannte „Baseline-Substraction“ durchgeführt, dabei werden die unspezifischen Hintergrundsignale von den Fluoreszenzdaten abgezogen.

Die auf ROX normalisierten, hintergrundfreien Werte wurden nun logarithmisch grafisch dargestellt. Bei einer erfolgreichen Amplifikation zeigte sich eine S-förmige Kurve. Es wurde 
ein Schwellenwert gewählt, den alle Proben in der exponentiellen Phase der Amplifikation überschreiten. Für jede Probe wurde der sogenannte „Crossing Threshold“ (Ct)-Wert bestimmt, der den Zyklus der PCR angibt, bei dem die definierte Fluoreszenzintensität erreicht ist. Um eine Vergleichbarkeit zwischen den einzelnen Experimenten des Zelllinienscreens $\mathrm{zu}$ erreichen, wurde bei diesem Experiment mit einem fixierten Schwellenwert von 1 gerechnet. Die Ct-Werte wurden exportiert und mithilfe von Microsoft Excel $^{\circledR}$ (Version 2003) weiterverarbeitet.

Als Erstes wurde die relative Expression des Zielgens zu dem Mittelwert der drei stabil exprimierten Gene berechnet $(\Delta \mathrm{Ct})$ :

$$
\Delta C t=C t_{\text {Zielgen }^{-}}\left(C t_{\text {OTUB1 }}+C t_{R A B 35}+C t_{F B X L 2}\right) / 3
$$

Anschließend wurde die relative Expression des Zielgens in der Probe mit der relativen Expression des Zielgens in der Referenz verglichen $(\Delta \Delta \mathrm{Ct})$ :

$$
\Delta \Delta C t=\Delta C t_{\text {Zielgen }}(\text { Probe })-\Delta C t_{\text {Zielgen }}(\text { Referenz })
$$

Da sich die Menge an cDNA in jedem Zyklus bei 100\% Primereffizienz verdoppelt, gilt:

$$
\text { Ratio }=\left(\text { Effizienz }_{\text {Primer }}\right)^{-\Delta \Delta C}=2^{-\Delta \Delta C}
$$

Jede Messung wurde drei Mal durchgeführt und der Median der drei Ergebnisse gebildet. 


\subsection{Genderegulationsexperimente}

\subsubsection{Kationische-Lipid-Transfektion}

Durch die Transfektion soll eine Zelle dazu gebracht werden, DNA- oder RNA-Fragmente aufzunehmen und $\mathrm{zu}$ verarbeiten. Hierzu wird das negativ geladene DNA-Fragment von positiv geladenen Lipidmolekülen umhüllt, es entsteht ein Transfektionskomplex. Dieser Komplex kann nun ohne Probleme von der Zelle aufgenommen werden (siehe unten).

\subsubsection{Genderegulation durch „Small-interfering-RNA“(siRNA)}

Durch die Transfektion einer Zelle mit einer siRNA soll das Expressionsniveau eines Zielgens gesenkt werden. Ein in der Zelle natürlich vorkommender Mechanismus wird hierzu genutzt: Normalerweise werden regulative ,MikroRNAs“ (miRNAs) in der Zelle durch eine RNase namens „Dicer“ aus doppelsträngiger RNA herausgeschnitten. Die so entstandenen Bruchstücke werden in den ,RNA-induced silencing complex“ (RISC) integriert, welcher nun komplementär an die Ziel-RNA bindet. RISC besitzt eine RNA-Helicase- und NukleaseAktivität, welche zum Entwinden und Spalten der Ziel-mRNA führen. Die Reste der mRNA werden durch intrazelluläre Nukleasen abgebaut. In der Zelle dient dieser Mechanismus als Schutz vor Fremd-RNA wie z.B. Viren oder zur posttranskriptionellen, intrazellulären Regulation von RNAs (Caplen und Mousses 2003; Huppi et al. 2005)

Die regulativen RNAs können künstlich nachgeahmt werden. Ein zu einem Abschnitt der Zielsequenz komplementärer RNA-Strang und sein Gegenstrang werden künstlich synthetisiert. Dieses Nukleotid wird ,short-interfering-RNA“( (siRNA) genannt. In Abbildung 7A ist der schematische Aufbau einer siRNA dargestellt. Nach der Transfektion in die Zelle bindet die siRNA genau wie eine miRNA an RISC und führt zu einer Runterregulation der Ziel-mRNA (siehe Abbildung 7B) 

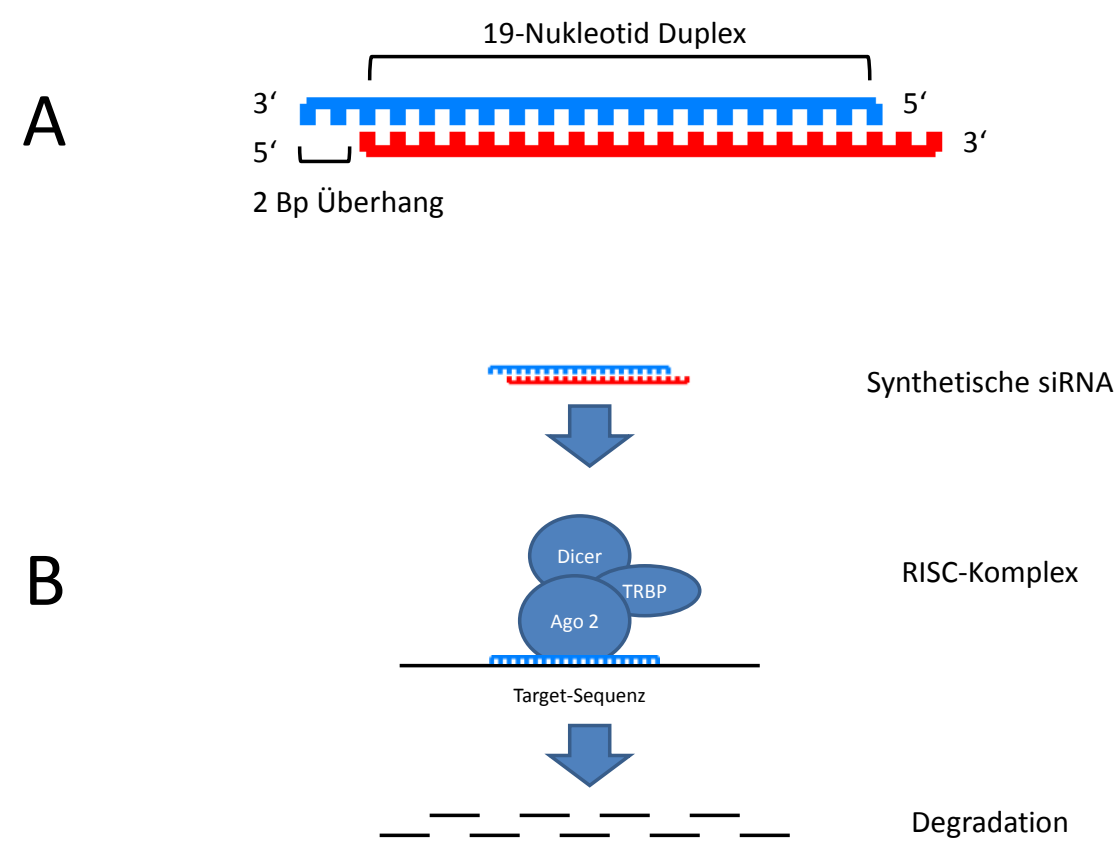

Abbildung 7 A: Schematischer Aufbau einer siRNA. Diese besteht aus einem 19 Nukleotid großen RNADuplex mit einem Überhang von 2 Basenpaaren (bp) pro Seite. B: Funktionsprinzip der siRNA vermittelten Genausschaltung. Eine synthetische siRNA wird in die Zelle gebracht, sie bindet an den RISC-Komplex. Der „Sense"-Strand wird degradiert, der Komplex aktiviert. Dieser kann nun an die Zielsequenz binden und diese denaturieren (mod. nach Martin und Caplen 2007 S. 81)

Jedes Zielgen wurde durch zwei verschiedene siRNAs dereguliert. Die siRNAs wurden nach Möglichkeit so gewählt, dass sie alle Spleiß-Varianten eines Gens abdecken. Eine siRNA lag in der Nähe der Mikroarray-Zielsequenz. Um eine höhere Varianz zu erreichen wurde die zweite siRNA so gewählt, dass sie in einem anderen Exon des Zielgens liegt als die erste. Aufgrund der hohen Zahl an siRNAs wurden „Flexi-Plates“ (Qiagen) verwendet. Alle in dieser Studie verwendeten siRNAs sind in Tabelle 8 aufgeführt. Hier wurde eine sogenannte reverse Transfektion durchgeführt, dies bedeutet, dass siRNAs und Transfektionsmedium vorgelegt und anschließend die Zellen zugegeben werden. Beim Absinken auf den Boden des Reaktionsgefäßes treffen die Zellen auf die Lipidkomplexe und werden transfiziert. Abbildung 8 zeigt den schematischen Ablauf der gesamten siRNA-Screens. 


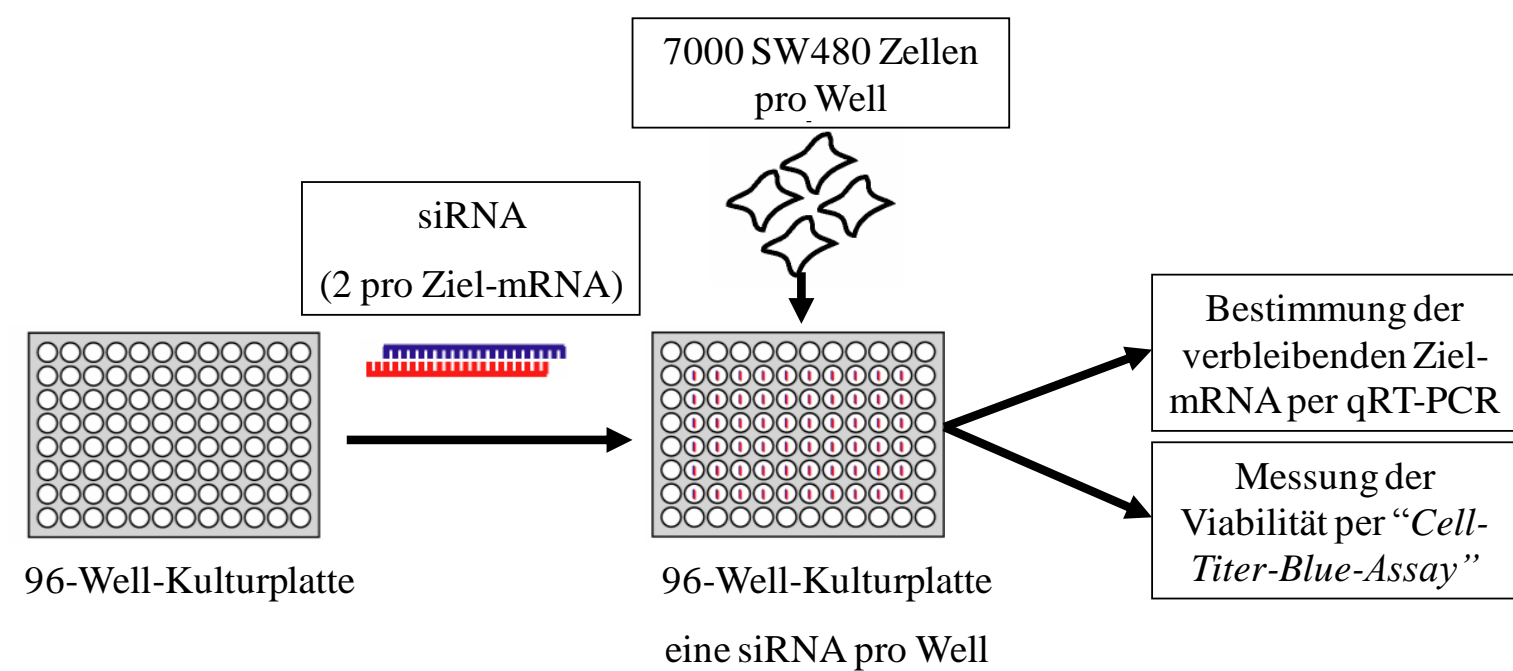

Abbildung 8: Schematische Darstellung des siRNA-Screens. Je 7000 SW480 Zellen wurden transfiziert und nach 48h wurde per qRT-PCR die Runterregulation der Zielsequenz bestimmt. Nach 72h und 96h wurde per „Cell-Titer-Blue-Assay“ die verbleibende Viabilität bestimmt.

In eine 96-well Kulturplatte wurden zunächst $25 \mu 1$ „Fetal Bovine Serum“ (FBS)-freies RPMI-Zellkulturmedium pro Well gegeben, anschließend wurden $20 \mathrm{nM}$ siRNA hinzugegeben und der Inhalt des Wells durch pipetieren gründlich gemischt. Danach wurden $25 \mu 1$ einer Mischung $0.6 \mu 1$,Oligofectamin ${ }^{\circledR}$ “ (Invitrogen) und 24,4 $\mu 1$ FBS-freiem Medium zugegeben und die Platten für $30 \mathrm{~min}$ bei Raumtemperatur inkubiert, damit sich Oligofectamin-siRNA-Komplexe bilden können. Anschließend wurden jeweils 7000 SW480 Zellen zusammen mit $50 \mu$ RPMI-Medium, das 20\% FBS (Invitrogen) enthielt, darüber geschichtet. Es wurde nicht gemischt, so dass die Zellen beim Absinken auf den Boden des Wells transfiziert wurden. Nach Zugabe der Zellen wurden die Platten $30 \mathrm{~min}$ bei Raumtemperatur inkubiert, anschließend wieder bei $37^{\circ} \mathrm{C}$ bebrütet. Um alle Folgeversuche durchführen zu können, wurden jeweils vier Platten nach dem in Abbildung 9 aufgeführten Schema erstellt. Nach 48h, 72h und 96h wurde jeweils eine Platte gestoppt und ein Viabilitätsscreen mit dem „Cell-titer-blue-Assay“ (siehe unten) durchgeführt. Die vierte Platte wurde nach $48 \mathrm{~h}$ gestoppt und zur RNA-Isolierung verwendet (siehe unten). 


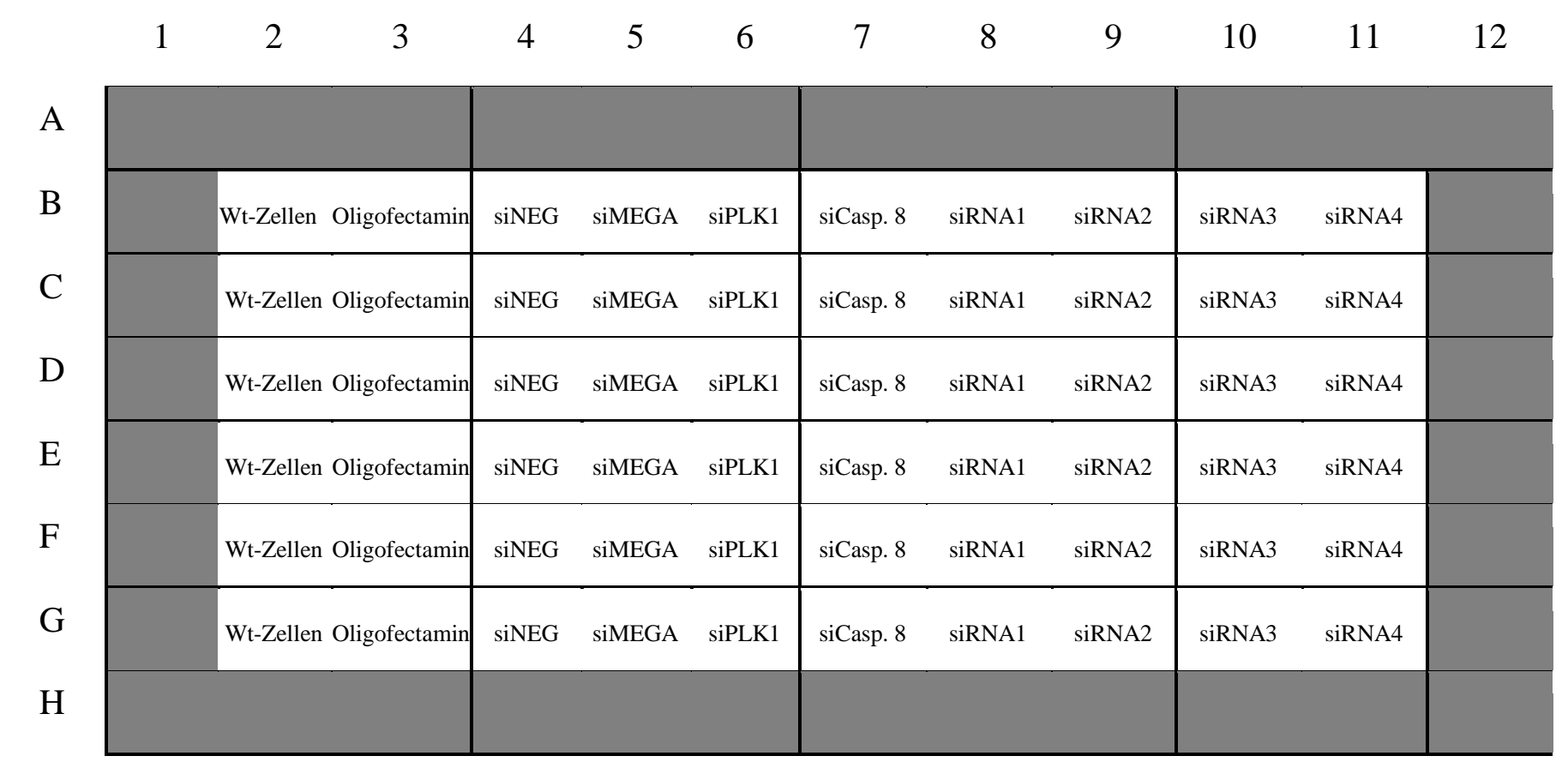

Abbildung 9: Beispielhaftes Plate-Setup einer siRNA-Transfektion zur Viabilitätsmessung mit Wildtyp (Wt)-Zellen, Toxizitätskontrolle (nur mit Oligofectamin behandelte Zellen), Negativkontrolle (siNEG), Positivkontrollen (siMEGA, siPLK1, siCaspase 8) und vier zu testenden siRNAs.

Die Randwells der Platten wurden jeweils nur mit Medium gefüllt, um Fehler durch Verdunstung im Inkubator zu verhindern. Als Negativkontrolle diente eine „nonsense“siRNA ( siNEG), dies ist eine siRNA, die im humanen Transkriptom keine komplementäre Zielsequenz besitzt. Darüber hinaus gab es auf den Platten zur Viabilitätsmessung jeweils Wells mit unbehandelten Zellen und Zellen nur mit Oligofectamin zur Abschätzung der Toxizität des Transfektionsmediums. Als Positivkontrollen wurden Zellen mit dem „Megakiller siRNA mix“ (Qiagen), eine Mischung aus siRNAs, die eine letale Wirkung auf Zellen haben, sowie siRNAs gegen PLK1 und Caspase 8 transfiziert. 


\begin{tabular}{|l|l|l|l|l|l|l|}
\hline siRNA Name & siRNA Name & siRNA Name & siRNA Name & siRNA Name & siRNA Name & siRNA Name \\
\hline ADPRHL1_2 & C13ORF23_1 & DIAPH3_1 & GPR12_3 & LOC283487_2 & SLC7A1_1 & GPR180_2 \\
\hline ADPRHL1_5 & C13ORF23_2 & DIAPH3_3 & GPR12_4 & LOC283487_5 & SLC7A1_4 & ITR_6 \\
\hline AKAP11_5 & C13ORF3_1 & EBPL_3 & GRTP1_2 & MIPEP_3 & SOX1_2 & ZMYM2_1 \\
\hline AKAP11_6 & C13ORF3_4 & EBPL_4 & GRTP1_5 & MIPEP_5 & SOX1_3 & ZNF198_1 \\
\hline ATP11A_1 & C13ORF6_1 & EFNB2_3 & GTF2F_1 & MYCBP2_1 & TBC1D4_1 & \\
\hline ATP11A_4 & C13ORF6_4 & EFNB2_4 & GTF2F2_3 & MYCBP2_3 & TBC1D4_2 & \\
\hline ATP7B_1 & CDX2_1 & FLJ11305_2 & IPF1_2 & NEK3_10 & TUBGCP3_4 & \\
\hline ATP7B_4 & CDX2_8 & FLJ11305_3 & IPF1_4 & NEK3_9 & TUBGCP3_6 & \\
\hline BRCA2_6 & CENPJ_2 & FLJ12118_5 & KIAA1008_2 & NUPL1_1 & XPO4_2 & Kontrollen \\
\hline BRCA2_7 & CENPJ_4 & FLJ12118_7 & KIAA1008_4 & NUPL1_3 & XPO4_4 & siNEG \\
\hline C13ORF12_2 & CKAP2_5 & FLJ14624_2 & KLF5_1 & PAN3_5 & ZDHHC20_1 & siMEGA \\
\hline C13ORF12_3 & CKAP2_6 & FLJ14624_4 & KLF5_2 & PAN3_6 & FLJ25952_3 & siPLK1_7 \\
\hline C13ORF18_1 & DCUN1D2_1 & FLJ22624_1 & LNX2_5 & RFC3_4 & POLR1D_1 & CASP8AP2_3 \\
\hline C13ORF18_4 & DCUN1D2_3 & FLJ22624_4 & LNX2_7 & RFC3_6 & MGC9850_1 & CASP8AP2_6 \\
\hline
\end{tabular}

Tabelle 8: Liste aller verwendeten siRNAs, jeweils zwei pro Targetgen sowie der Kontrollen. Dabei ist zu beachten, dass einige siRNAs, obwohl gegen dasselbe Targetgen gerichtet, unterschiedliche Namen tragen.

\subsubsection{Viabilitätsassay (,Cell-Titer-Blue-Assay“)}

Der „Cell-Titer-Blue-Assay“ dient der Bestimmung der Viabilität, sprich der Stoffwechselaktivität, einer Zellpopulation. Dem Zellkulturmedium wird Resazurin zugesetzt, dieses wird von metabolisch aktiven Zellen zu Resorufin reduziert. Resazurin ist dunkelblau und emittiert nur wenig Fluoreszenz, Resorufin hingegen ist pink und fluoresziert stark. Die emittierte Fluoreszenz ist daher proportional zu der Stoffwechselaktivität der Zellen in einem Well.

$25 \mu \mathrm{l}$ Cell-Titer-Blue-Reagenz (Promega, Madison, USA) wurden zu jedem Well einer 96Well-Platte hinzugegeben, hierbei handelte es sich um spezielle Analyseplatte (Corning), bei der die Well-Zwischenräume geschwärzt sind, um eine Fluoreszenzüberstrahlung von einem Well in ein anderes, zu verhindern. Das Reagenz wurde vorsichtig durch leichtes Schütteln mit dem Zellmedium vermischt und anschließend für $1 \mathrm{~h}$ bei $37^{\circ} \mathrm{C}$ inkubiert. Nach der Inkubation wurde die Platte in ein "SpektraMax-ME2-Fotometer" (Molecular Devices, Sunnyvale, USA) überführt, welches nach erneutem Durchmischen des Mediums die emittierte Fluoreszenz in jedem Well maß. Um Messfehler zu verhindern, wurde die gesamte Platte automatisch 9x gemessen und anschließend ein Mittelwert der emittierten Fluoreszenz pro Well gebildet. Von dem Mittelwert wurde noch des Weiteren die Hintergrundfluoreszenz abgezogen. Dieser Leerwert wurde in einem Well ohne Zellen gemessen. 


\section{Ergebnisse}

Ziel dieser Arbeit war die Identifizierung potentieller Onkogene auf Chromosom 13q. Dazu wurden zunächst ArrayCGH-Daten von 31 Primärtumoren und 15 Zelllinien ausgewertet, um die chromosomalen Regionen auf Chromosom 13q näher einzugrenzen. Anschließend wurde mittels Mikroarrays ein Genexpressionsprofil von einem Teil dieser Tumoren sowie von 15 Zelllinien erstellt, um Gene zu identifizieren, die zusätzlich hochreguliert waren. Mithilfe der qRT-PCR wurde in 25 Zelllinien überprüft, ob sich die durch Genexpressions-Arrays identifizierten hochregulierten Gene auch hier wiederfinden.

Gene, die sich in den Primärtumoren und Zelllinien sowohl mittels Array als auch per PCR als hochreguliert erwiesen, wurden daraufhin per siRNA in der Zelllinie SW480 herunterreguliert. Der Erfolg des Knockdowns wurde anschließend wieder per qRT-PCR kontrolliert. Mit einem „Cell-Titer-Blue-Assay“ wurde nach dem Knockdown die Viabilität der Zellen als Surrogat-Parameter für Onkogene bestimmt. Abbildung 10 zeigt den Ablauf der Experimente.

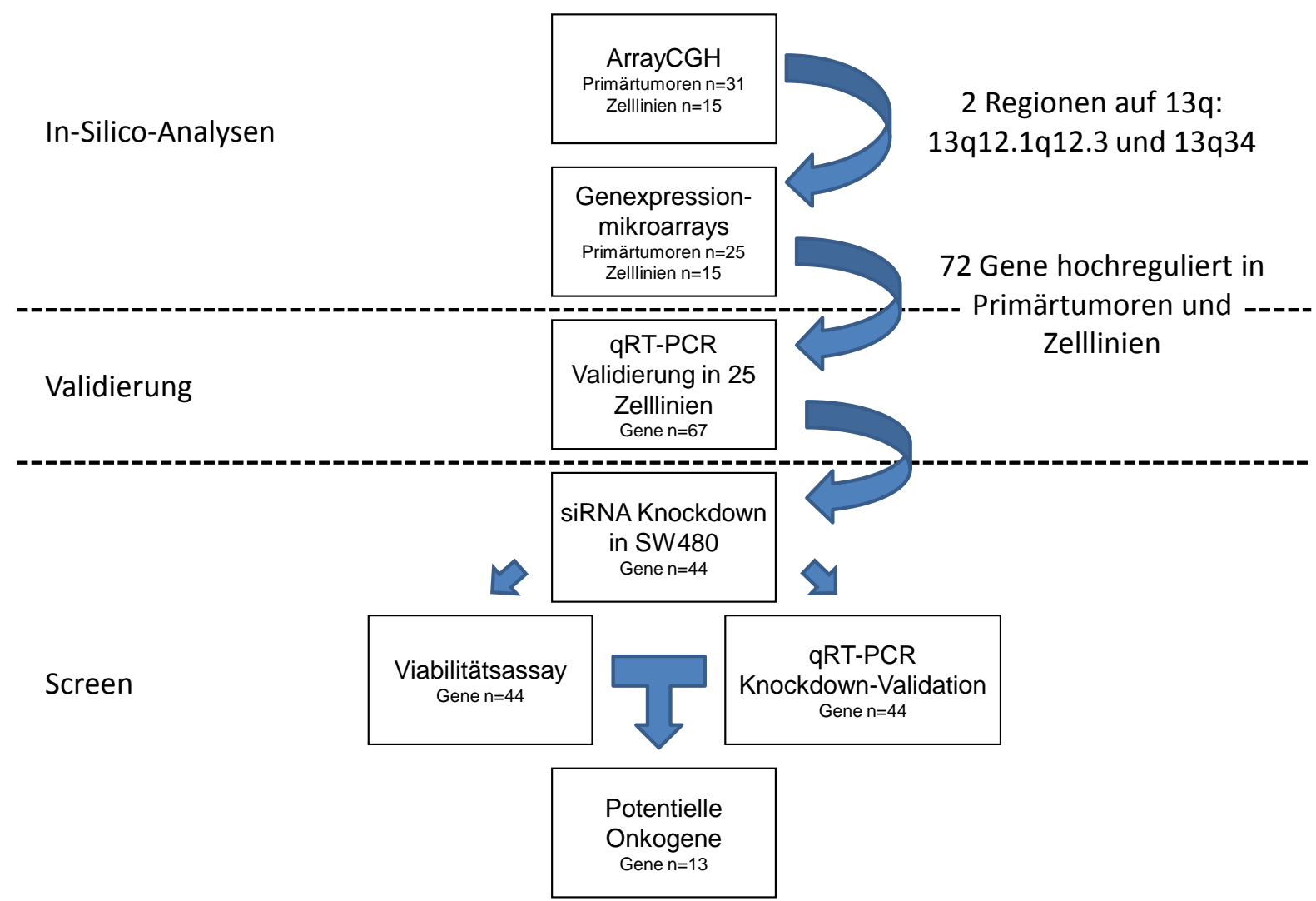

Abbildung 10: Schematischer Ablauf der Experimente 


\subsection{ArrayCGH-Auswertung}

Die ArrayCGH-Experimente sind nicht Bestandteil der vorliegenden Dissertation. Sie wurden von Dr. Jordi Camps aus der Arbeitsgruppe von Dr. Thomas Ried am National Cancer Institut durchgeführt. Deren Ergebnis wurde jedoch verwendet, um die entsprechenden Regionen näher $\mathrm{zu}$ charakterisieren. Insgesamt wurden 31 primäre Kolontumore (UICC II/III) untersucht, davon zeigten 19 (61\%) einen Zugewinn von Chromosom 13q. Von den 15 Zelllinien wiesen 8 (53\%) einen Zugewinn von 13q auf. Ein Teil dieser Daten wurde von Dr. Jordi Camps bereits publiziert (Camps et al. 2008).

Oft zeigte sich ein Zugewinn des gesamten Chromosoms 13, in vielen Fällen waren allerdings nur subchromosomale Regionen verändert. Insgesamt konnten zwei Regionen auf Chromosom 13q identifiziert werden, welche in einem Großteil der Tumoren Zugewinne oder sogar Amplifikationen aufwiesen und in keinem Verluste.

Diese beiden Regionen liegen im Bereich der Banden 13q12.1q12.3 und 13q34 (chr13:26,222,778-28,886,810 und chr13:109,376,185-111,647,042). Um auch Gene im Umfeld der minimal amplifizierten Regionen zu identifizieren, wurden die Regionen erweitert zu chr13:20,856,880-29,466,246 und chr13:103,927,403-114,125,347. Sie sind in Abbildungen 11 und 12 anhand eines Summationsplots aller Kolontumoren und Zelllinien sowie beispielhaft an einer Zelllinie und einem Tumor dargestellt. 


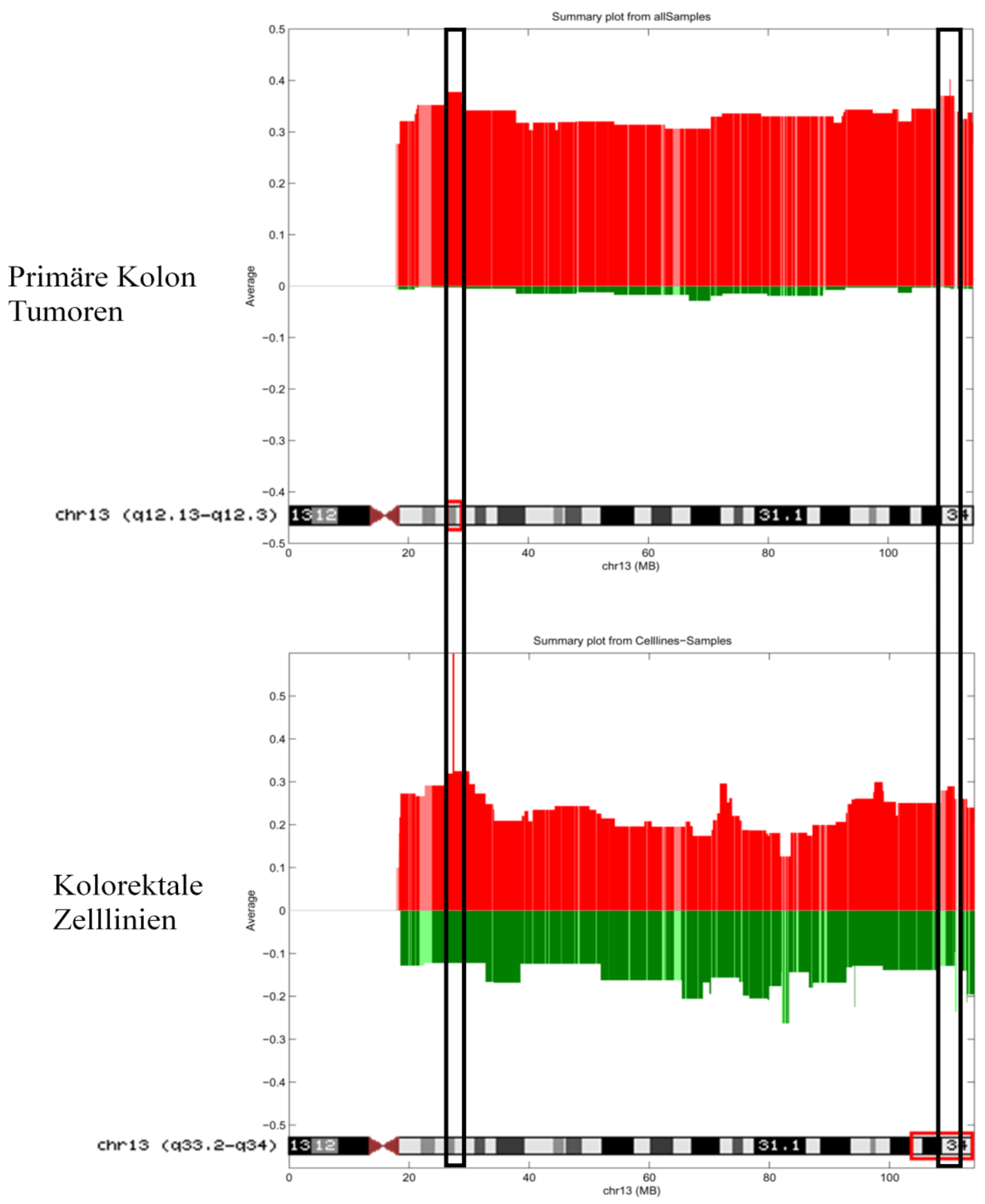

Abbildung 11: Zusammenfassung der Array-CGH-Analyse von 31 Patienten für Chromosom 13q und der 15 Zelllinien. Verluste sind in Grün dargestellt, Zugewinne in Rot. Die Regionen 13q12.1q12.3 und 13q34 sind zusätzlich markiert. 


\section{Primärer \\ Kolontumor \\ Kolorektale Zelllinie \\ (Colo 320)}

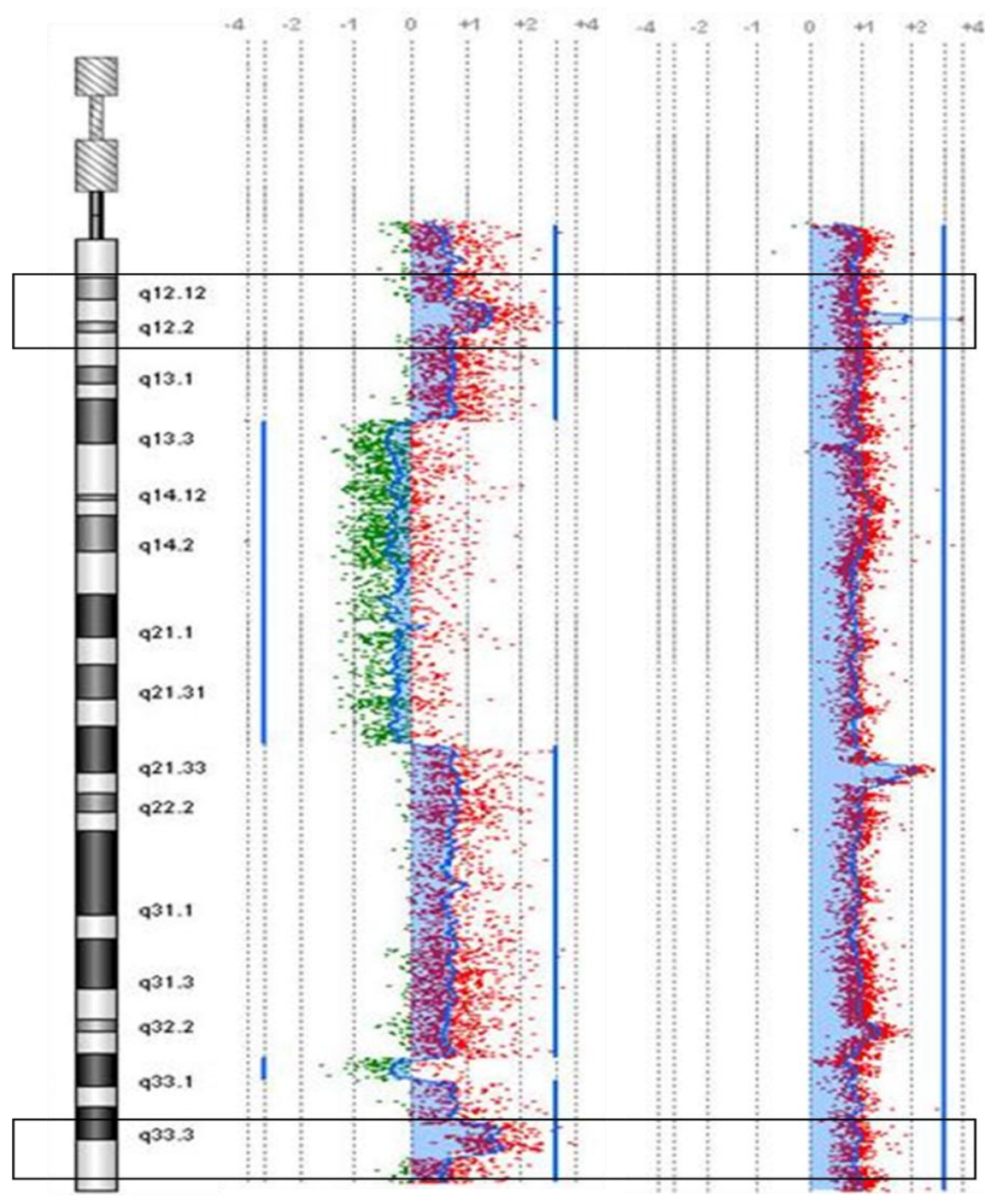

Abbildung 12: Beispielhafte Darstellung zweier Array-CGH Experimente (Primärtumor und Zelllinie) Zugewinne hier rot, Verluste grün. Die Regionen mit regelmäßigen Zugewinnen/Amplifikationen sind markiert.

\subsection{Genexpressionsanalysen}

Mithilfe der Genexpressions-Mikroarrays sollte festgestellt werden, welche Gene in diesen beiden Regionen dereguliert sind. Dazu waren bereits im Vorfeld von Dr. Jordi Camps Genexpressionsarrays von 25 der 31 primären Kolontumoren angefertigt worden, bei den 6 fehlenden Tumoren erwies sich die RNA-Qualität als nicht ausreichend. 17 der 25 Tumoren wiesen einen Zugewinn von Chromosom 13q auf. Es wurde gezielt nach Genen gesucht, die im Tumor und in der Mukosa unterschiedlich exprimiert waren. Zusätzlich wurden für 15 Zelllinien ebenfalls Mikroarrays angefertigt. Da es zu den Zelllinien keine passende Mukosa 
gibt, wurde hier, abweichend von den vorangegangenen Experimenten, die Veränderung der Genexpression im Vergleich zu einem Referenz-RNA-Pool gemessen.

Insgesamt waren in den Tumoren auf Chromosom 13q 579 Proben gegenüber der zugehörigen Mukosa dereguliert $(\mathrm{p}<0,0005)$. In den beiden Regionen auf Chromosom 13 liegen 72 annotierte Gene, von denen 48 (66\%) im Tumor gegenüber der normalen Mukosa signifikant hochreguliert waren $(\mathrm{p}<0,05)$. Einen Überblick über die Expressionsmuster dieser Gene sowie weiterer Proben auf den Mikroarrays in den beiden Regionen liefern die Abbildungen 13, 14 und 15.

Für die weiteren Analysen wurden auch Gene außerhalb der beiden Regionen verwendet, die im Mikroarray deutlich hochreguliert waren und deren Funktion interessant erschien.

\section{Deregulierte Gene in der Region 13q12.1q12.3 in 15 Zelllinien}

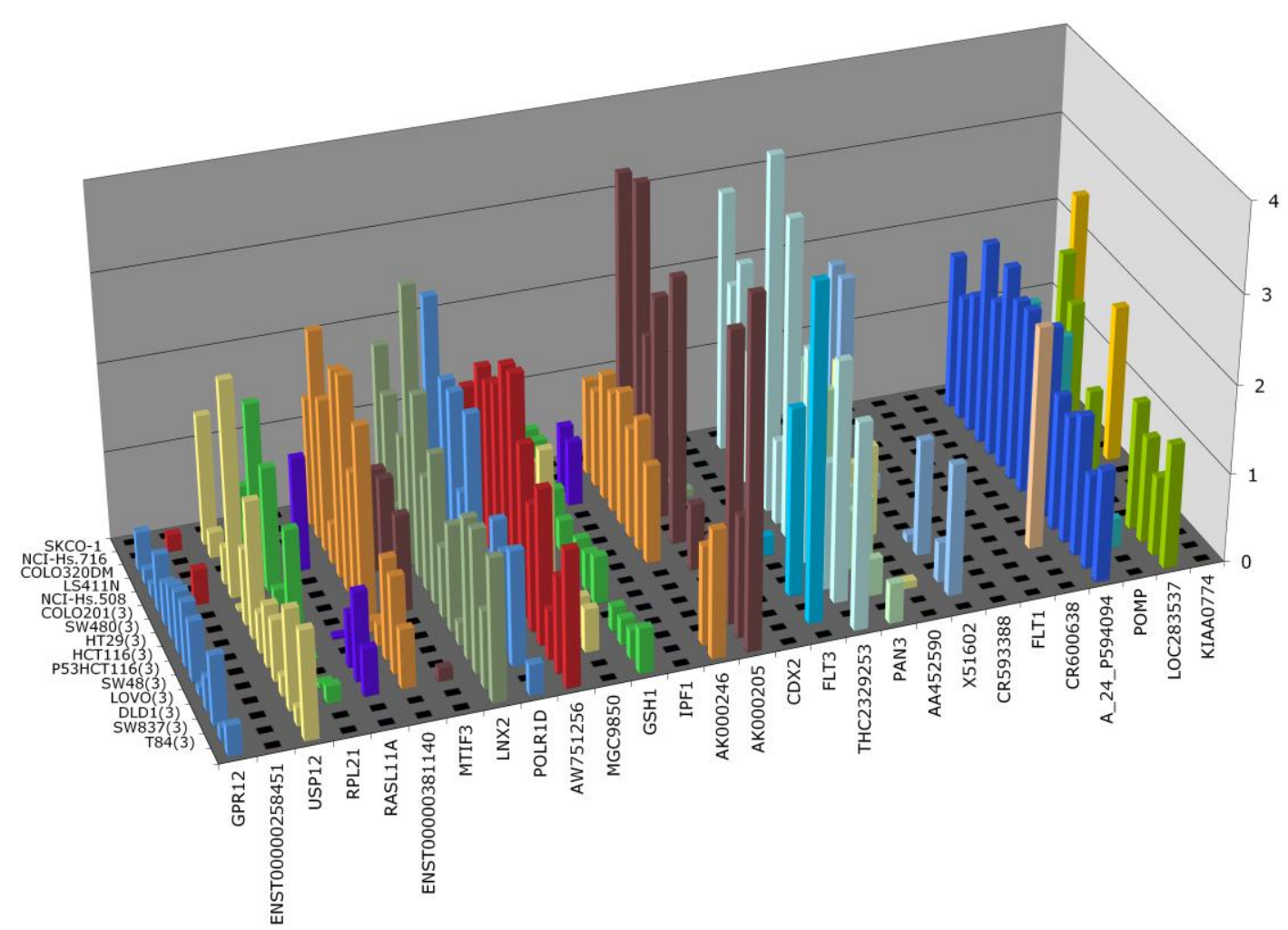

\footnotetext{
Abbildung 13: Expressionsmuster von 28 deregulierten Proben in der Region 13q12.1-12.3 im Vergleich zwischen Zelllinien und RNA-Referenz-Pool. Eine Expression von 1 bedeutet gleiche mRNA-Level in Zelllinie und Referenz.
} 


\section{Deregulierte Gene in der Region $13 q 34$ in 15 Zelllinien Teil 1}

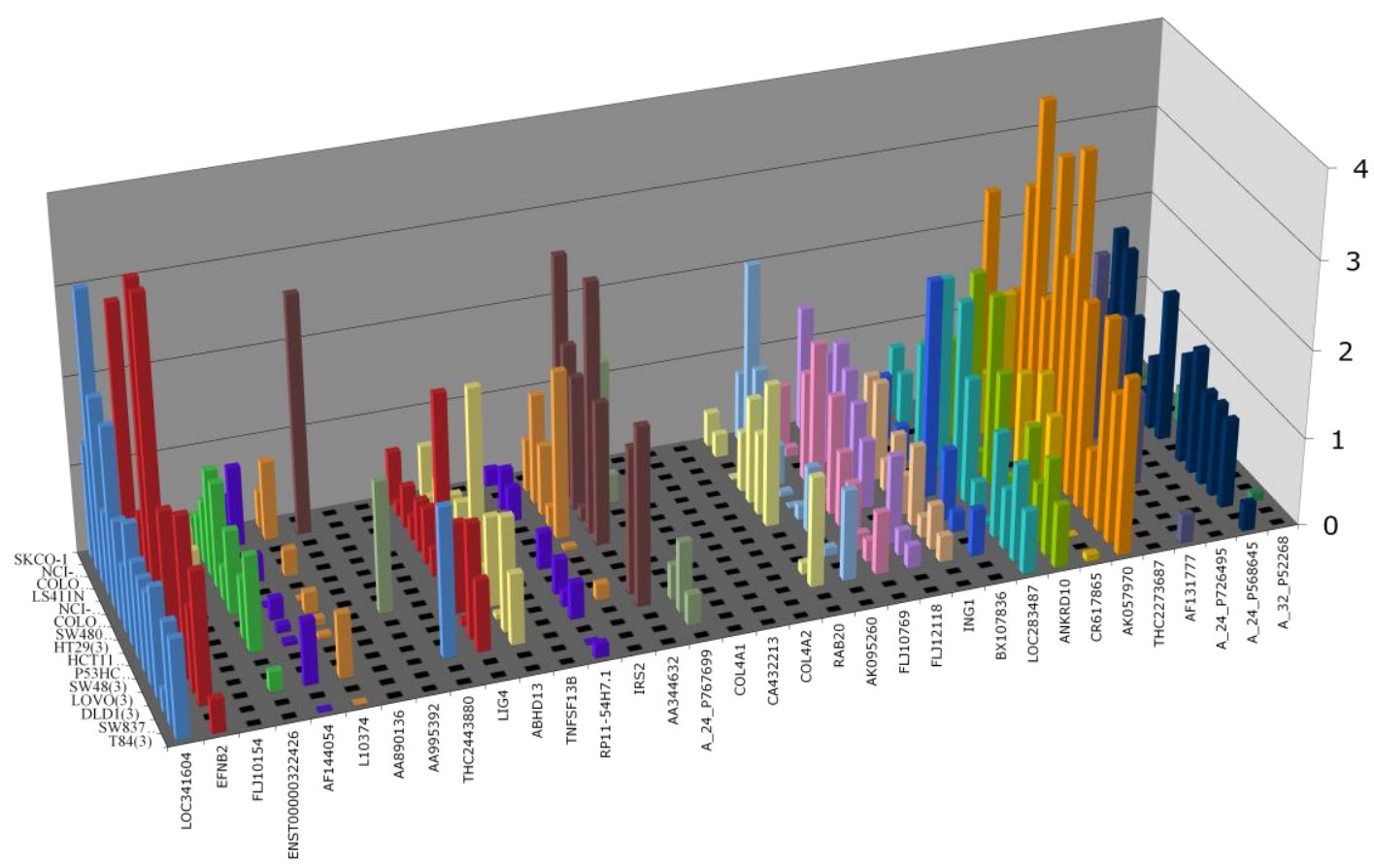

Abbildung 14: Expressionsmuster von den ersten 34 deregulierten Proben in der Region 13q12.1-12.3 im Vergleich zwischen Zelllinien und RNA-Referenz-Pool. Eine Expression von 1 bedeutet gleiche mRNAExpressions-Level in Zellinie und Referenz.

\section{Deregulierte Gene in der Region $13 q 34$ in 15 Zelllinien Teil 2}

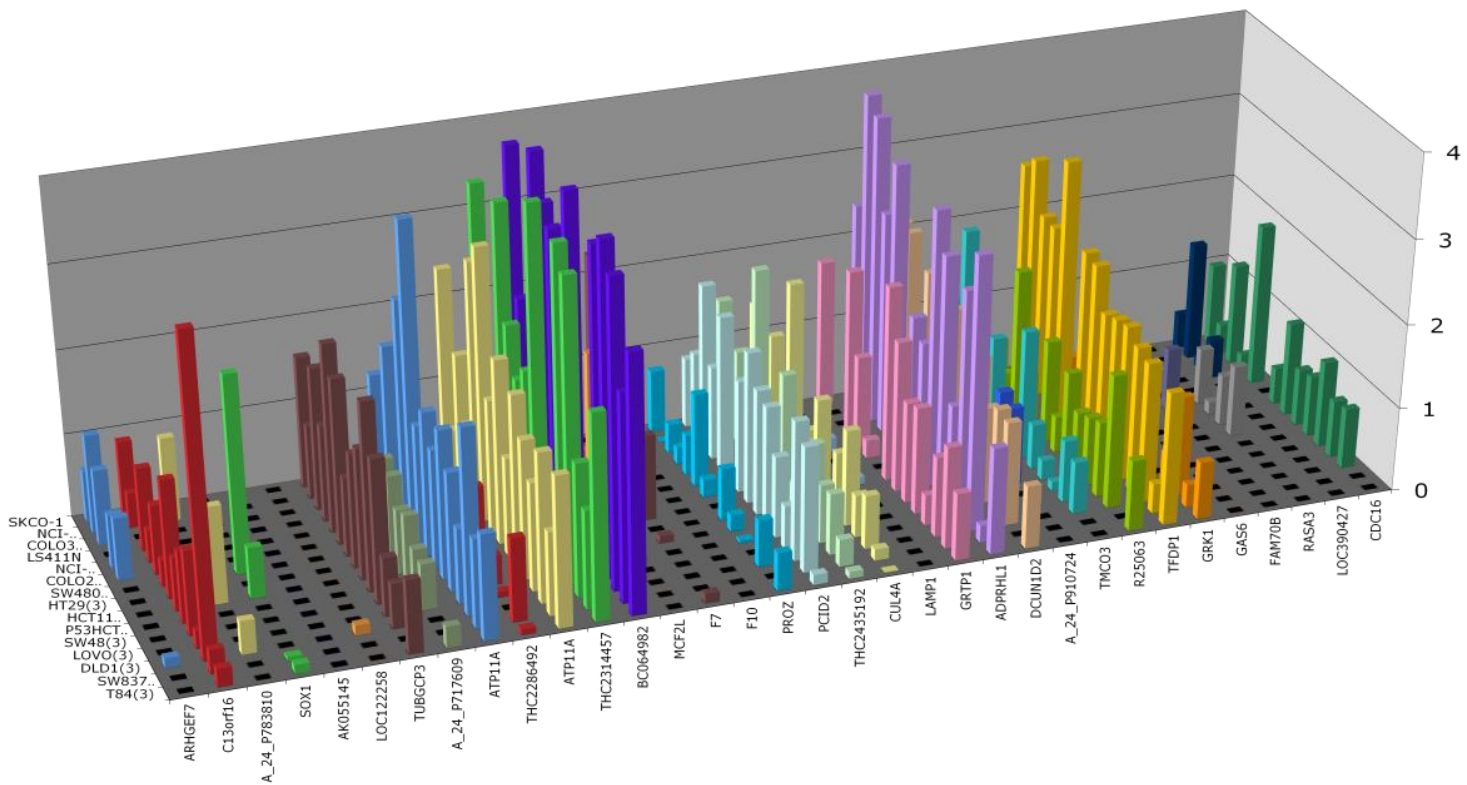

Abbildung 15: Expressionsmuster von weiteren 34 deregulierten Proben in der Region 13q12.1-12.3 im Vergleich zwischen Zelllinien und RNA-Referenz-Pool. Eine Expression von 1 bedeutet gleiche mRNALevel in Zelllinie und Referenz. 


\section{3 qRT-PCR}

Die mittels Mikroarray in den Patientenproben und Zelllinien identifizierten Gene sollten nun in 25 kolorektalen Zelllinien per qRT-PCR validiert werden. Es handelt sich hierbei um die 48 Gene in den beiden beschriebenen Regionen sowie um 19 zusätzliche Gene von Chromosom 13, die ebenfalls in Tumoren gegenüber normaler Mukosa überexprimiert waren, jedoch nicht in den beiden Regionen lokalisiert sind. Für jedes Gen wurde ein spezifisches Primerpaar erstellt.

\subsubsection{Primer Test}

Per Gelelektrophorese wurde sichergestellt, dass alle Primer nur jeweils ein Produkt der berechneten Größe haben. Beispielhaft sind in Abbildung 16 die PCR Produkte von 47 der 67 Primerpaare aufgetragen. Alle Primerpaare zeigen nur jeweils ein Produkt, welches zwischen 90 und 240 bp groß ist. Zusätzlich wurde durch Dissoziationskurven des PCR-Produktes im Anschluss an jeden qRT-PCR-Lauf die Bildung nur eines spezifischen PCR-Produktes überprüft.
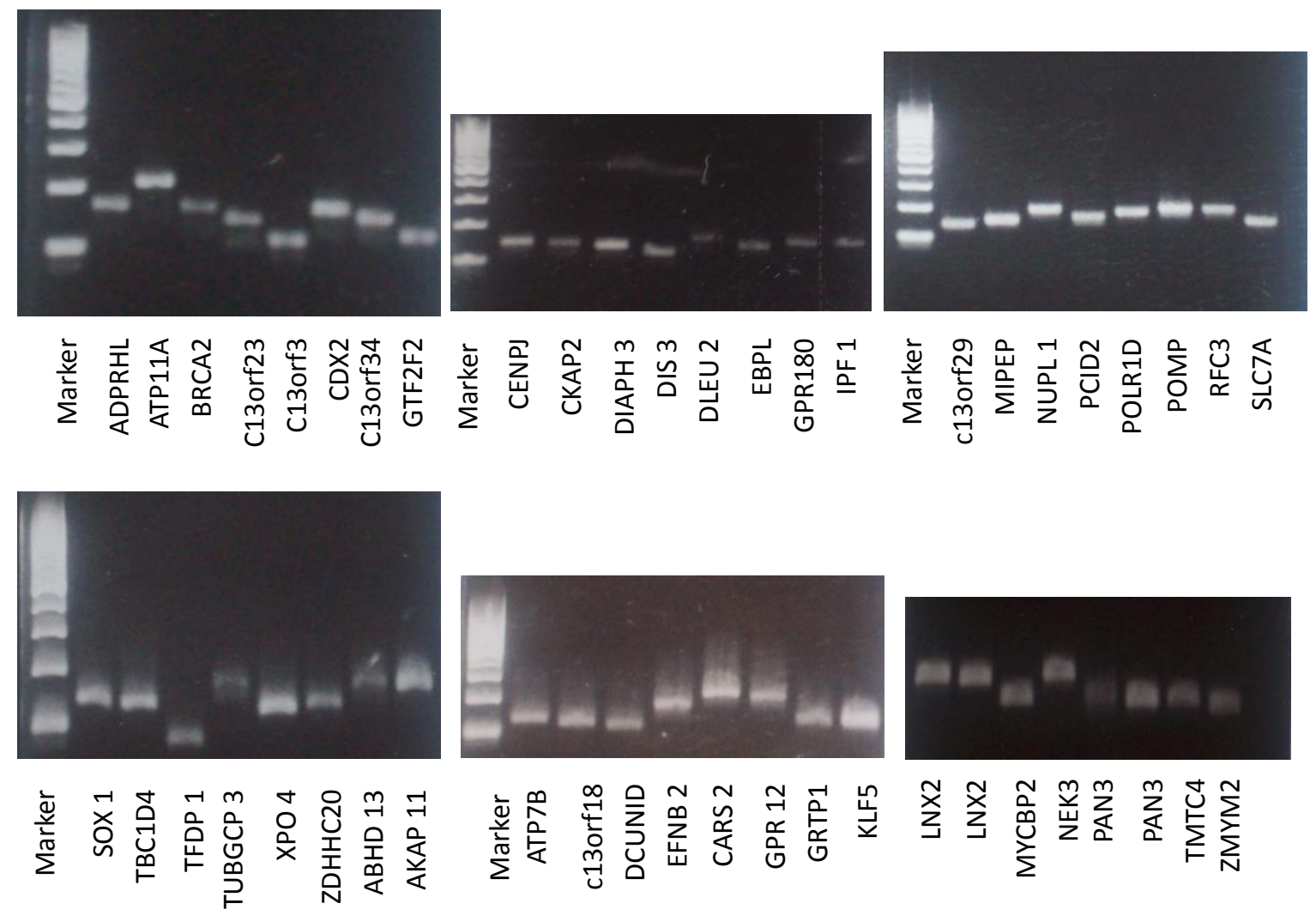

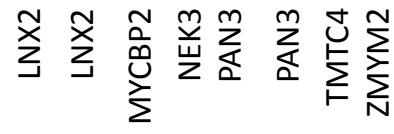

Abbildung 16: Gelelektrophorese der Produkte von 47 der 67 in dieser Arbeit verwendeten Primer. LNX2 und PAN3 wurden jeweils aus 2 Reaktionsreplikaten aufgetragen, um eine Reproduzierbarkeit zu zeigen. 


\subsection{2 qRT-PCR der 25 Zelllinien zur Arrayvalidierung}

Mit der Real-Time-PCR sollten zwei Ziele erreicht werden: Einerseits sollte das Ergebnis der Mikroarrays aus den 15 Zelllinien mit einer unabhängigen Methode validiert werden, andererseits sollten die Genexpressionsprofile der $48+19$ Gene in weiteren 10 Zelllinien bestimmt werden.

Im Folgenden sind die Ergebnisse der qRT-PCR tabellarisch dargestellt. Tabelle 10 zeigt die Genexpression der 67 Gene als „Foldchange“ im Vergleich zu einem Pool aus normaler Rektummukosa, Tabelle $11 \mathrm{im}$ Vergleich zu normaler Kolonmukosa und Tabelle $12 \mathrm{im}$ Vergleich zu der „Stratagen-Referenz“-RNA. Die mittels PCR gemessenen Expressionsdaten korrelierten sehr gut mit den Ergebnissen des Arrays. Verglichen wurde jeweils, ob die per Array identifizierte Hochregulation eines Gens in einer Zelllinie ebenfalls per PCR detektiert wurde. Für SW480 stimmten 58\% der untersuchten Gene überein (bei HT29 (71\%), bei SW837 (68\%), bei HTC116 (71\%), bei DLD1 (81\%), bei P53-HCT116 (62\%), bei SW48 (70\%), bei LS411N (83\%), bei NCI-H716 (76\%), bei NCI-H508 (89\%), bei COLO320DM (76\%), T-84 (65\%), bei SK-CO-1 (65\%), bei COLO 201 (86\%) und bei LOVO (73\%).

Von den zuvor mittels Mikroarray als überexprimiert identifizierten Genen (67) konnte für 45 (67\%) per qRT-PCR gezeigt werden, dass sie auch in den 25 Zelllinien hochreguliert sind. Diese Gene sind in Tabelle 9 aufgeführt.

\begin{tabular}{|c|c|c|c|c|}
\hline ABHD13 & CARS2 & GPR180 & NUPL1 & TUBGCP3 \\
\hline ADPRHL1 & CDX2 & GRTP1 & PAN3 & XPO4 \\
\hline AKAP11 & CENPJ & GTF2F2 & PCID2 & ZDHHC20 \\
\hline ATP11A & CKAP2 & IPF1 & POLR1D & ZMYM2 \\
\hline ATP7B & DCUN1D2 & ITR & POMP & ZNF198 \\
\hline BRCA2 & DIAPH3 & KLF5 & RFC3 & \\
\hline C13ORF18 & DIS3 & LNX2 & SLC7A1 & \\
\hline C13ORF23 & EBPL & MIPEP & SOX1 & \\
\hline C13ORF29 & EFNB2 & MYCBP2 & TBC1D4 & \\
\hline C13ORF3 & GPR12 & NEK3 & TMTC4 & \\
\hline
\end{tabular}

Tabelle 9: 45 Gene, die sowohl per Mikroarray in den Tumoren und Zelllinien, als auch per PCR in den 25 Zelllinien als überexprimiert gefunden wurden. 


\begin{tabular}{|c|c|c|c|c|c|c|c|c|c|c|c|c|c|c|c|c|c|c|c|c|c|c|c|c|c|c|c|c|}
\hline & $\begin{array}{l}\infty \\
+\infty \\
+\infty \\
+\infty \\
\infty\end{array}$ & 今ે & 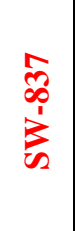 & $\stackrel{\theta}{\underline{U}}$ & $\bar{a}$ & 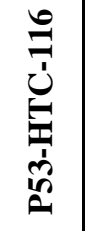 & 京 & 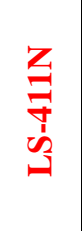 & 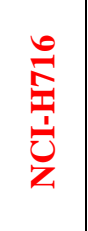 & 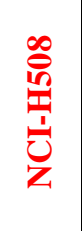 & 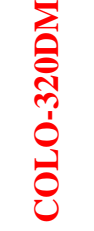 & $\begin{array}{l}\mathbb{Z} \\
\infty \\
\text { 崩 }\end{array}$ & 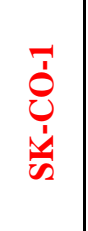 & 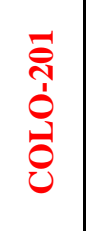 & 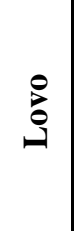 & 仓ુ & 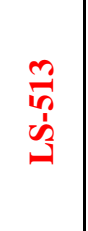 & $\frac{0}{3}$ & $\begin{array}{l}\text { בี } \\
\text { בี่ }\end{array}$ & 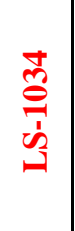 & 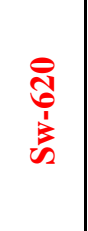 & 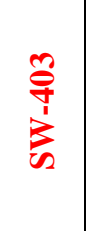 & $\frac{\substack{0 \\
+}}{\sum_{n}^{\prime}}$ & 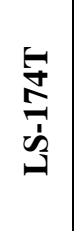 & $\stackrel{0}{\simeq}$ & 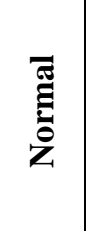 & 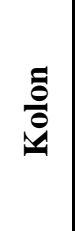 & 窇 \\
\hline ABHD13 & 2,17 & 1,63 & 2,47 & 2,19 & 2,89 & 1,66 & 5,34 & 5,59 & 7,19 & 7,46 & 5,50 & 2,19 & 4,13 & 3,32 & 2,15 & 2,42 & 12,32 & 1,75 & 3,07 & 2,96 & 3,37 & 7,13 & 4,79 & 3,17 & 2,20 & 2,71 & 0,18 & 1,00 \\
\hline ADPRHL1 & 4,32 & 3,37 & 0,62 & 10,22 & 5,33 & 5,59 & 1,95 & 1,58 & 1,63 & 9,92 & 11,88 & 0,16 & 1,19 & 0,06 & 1,30 & 0,95 & 1,78 & 1,19 & 2,09 & 1,38 & 3,90 & 10,01 & 1,60 & 4,39 & 0,99 & 0,99 & 0,63 & 1,00 \\
\hline ANKRD10 & 0,32 & 0,56 & 0,40 & 0,97 & 0,68 & 0,44 & 0,39 & 0,68 & 0,75 & 2,81 & 0,57 & 0,41 & 0,09 & 1,61 & 0,17 & 0,41 & 2,78 & 0,96 & 1,14 & 1,28 & 0,68 & 1,35 & 1,85 & 0,66 & 0,06 & 1,24 & 0,70 & 1,00 \\
\hline ATP11D & 7,41 & 11,82 & 8,65 & 8,13 & 6,98 & 6,84 & 12,27 & 20,30 & 7,05 & 19,84 & 10,63 & 5,62 & 11,45 & 31,63 & 8,09 & 15,28 & 20,30 & 16,60 & 14,59 & 8,48 & 11,03 & 22,52 & 10,63 & 5,87 & 7,16 & 4,29 & 0,66 & 1,00 \\
\hline BRCA2 & 22,47 & 13,39 & 3,21 & 2,43 & 11,66 & 4,12 & 6,13 & 41,45 & 20,21 & 8,69 & 10,63 & 8,28 & 3,29 & 21,61 & 9,96 & 9,08 & 24,14 & 14,45 & 16,41 & 8,42 & 7,08 & 11,90 & 4,63 & 7,23 & 3,94 & 0,78 & 0,11 & 1,00 \\
\hline C13ORF29 & 0,66 & 2,35 & 8,71 & 8,19 & 0,52 & 1,65 & 1,32 & 7,33 & 22,58 & 0,15 & 15,24 & 1,36 & 1,40 & 9,40 & 1,82 & 0,33 & 8,59 & 1,99 & 2,12 & 3,35 & 0,91 & 0,36 & 0,81 & 3,10 & 8,17 & 0,77 & 2,70 & 1,00 \\
\hline CARS2 & 0,47 & 0,32 & 0,44 & 0,38 & 0,80 & 0,52 & 0,77 & 2,91 & 0,65 & 1,82 & 0,55 & 0,65 & 0,62 & 0,88 & 1,67 & 0,29 & 2,49 & 0,78 & 0,49 & 0,88 & 1,04 & 2,91 & 0,84 & 0,73 & 0,76 & 0,70 & 0,62 & 1,00 \\
\hline CDC16 & 1,16 & 1,25 & 0,58 & 1,53 & 1,46 & 1,09 & 1,25 & 1,86 & 1,16 & 3,20 & 1,48 & 0,48 & 0,09 & 0,24 & 0,71 & 1,16 & 2,89 & 0,69 & 1,16 & 1,14 & 1,84 & 2,52 & 1,92 & 0,84 & 1,01 & 0,97 & 0,83 & 1,00 \\
\hline CDX2 & 0,09 & 0,53 & 1,40 & 0,20 & 1,82 & 0,11 & 0,89 & 1,58 & 0,38 & 3,29 & 20,97 & 2,28 & 2,26 & 0,00 & 0,84 & 0,95 & 1,49 & 4,51 & 0,29 & 2,27 & 0,11 & 0,30 & 1,39 & 1,55 & 0,14 & 1,20 & 0,97 & 1,00 \\
\hline CHR13ORF16 & 0,21 & 1,48 & 0,54 & 2,09 & 2,87 & 0,69 & 1,65 & 1,32 & 0,65 & 0,41 & 1,23 & 0,23 & 0,83 & 0,47 & 0,26 & 0,78 & 0,37 & 0,36 & 0,66 & 1,04 & 1,04 & 0,43 & 1,80 & 1,13 & 0,54 & 1,78 & 1,31 & 1,00 \\
\hline COL4A1 & 0,03 & 0,08 & 0,20 & $X$ & 0,17 & $\mathrm{X}$ & 0,00 & $\mathrm{X}$ & $\mathrm{X}$ & 0,00 & 0,97 & 0,00 & 0,00 & 0,00 & 0,00 & 0,09 & 0,16 & 0,17 & 0,00 & 0,85 & 0,00 & 0,40 & 0,04 & $\mathrm{X}$ & $\mathrm{X}$ & 19,43 & 3,02 & 1,00 \\
\hline COL4A2 & 0,07 & 0,00 & 0,00 & $x$ & 0,01 & $\mathrm{X}$ & 0,00 & $\mathrm{X}$ & 0,01 & $\mathrm{X}$ & 1,04 & $\mathrm{X}$ & $X$ & $\mathrm{X}$ & $x$ & 0,00 & $\mathrm{X}$ & $x$ & $\mathrm{X}$ & 0,00 & 0,01 & 0,00 & $\mathrm{X}$ & $\mathrm{X}$ & $\mathrm{X}$ & 10,13 & 3,93 & 1,00 \\
\hline DLEU2 & 11,16 & 4,70 & 1,82 & 12,85 & 6,56 & 15,60 & 6,26 & 8,19 & 12,01 & 6,59 & 6,77 & 5,06 & 2,69 & 10,43 & 7,24 & 3,47 & 6,33 & 5,40 & 6,76 & 4,15 & 7,64 & 7,53 & 4,23 & 2,19 & 4,69 & 3,94 & 0,34 & 1,00 \\
\hline EFNB2 & 0,03 & 0,42 & 0,05 & 0,33 & 0,53 & 0,38 & 1,10 & 0,90 & 0,38 & 3,16 & 0,32 & 0,44 & 1,85 & 2,66 & 0,72 & 0,60 & 1,18 & 0,46 & 0,31 & 0,78 & 1,32 & 0,76 & 0,25 & 0,39 & 1,37 & 0,30 & 0,34 & 1,00 \\
\hline FLJ10769 & 0,93 & 1,00 & 0,34 & 1,15 & 0,90 & 0,49 & 0,87 & 1,37 & 1,48 & 2,33 & 0,89 & 0,34 & 0,87 & 1,23 & 0,48 & 0,74 & 1,71 & 0,73 & 0,94 & 0,83 & 1,18 & 2,59 & 1,16 & 0,57 & 0,54 & 1,12 & 0,91 & 1,00 \\
\hline GAS6 & 1,77 & 0,63 & 0,31 & 0,42 & 1,28 & 0,68 & 0,67 & 2,40 & 0,00 & 0,65 & 0,00 & 0,28 & 0,46 & 0,40 & 0,63 & 0,44 & 4,90 & 1,35 & 1,33 & 1,33 & 0,84 & 3,61 & 1,77 & 0,72 & 0,25 & 1,99 & 0,44 & 1,00 \\
\hline GPC5 & $\mathrm{X}$ & $X$ & 0,32 & $\mathrm{X}$ & $X$ & 0,17 & 0,10 & $X$ & 20,63 & $\mathrm{X}$ & 4,56 & $\mathrm{X}$ & $\mathrm{X}$ & $\mathrm{X}$ & 1,71 & 2,59 & $\mathrm{X}$ & $X$ & $x$ & 0,15 & 0,10 & $X$ & 0,15 & $X$ & $\mathrm{X}$. & 5,06 & 2,76 & 1,00 \\
\hline GPR12 & 0,23 & 0,25 & 8,53 & 0,75 & 0,24 & 0,22 & 2,61 & 7,48 & 50,10 & $X$ & 14,12 & 1,07 & 0,08 & 0,32 & 0,25 & 0,04 & 8,13 & 0,07 & 2,26 & 0,50 & $X$ & $X$ & $\begin{array}{l}0,04 \\
0,\end{array}$ & 0,09 & 1,13 & 0,23 & 1,48 & 1,00 \\
\hline GRK1 & $X$ & $X$ & $\mathrm{X}$ & 12,94 & $X$ & 11,26 & $x$ & $\mathrm{X}$ & $\mathrm{X}$ & $\mathrm{X}$ & $\mathrm{X}$ & $X$ & $\mathrm{X}$. & $\mathrm{X}$ & $\mathrm{X}$ & $X$ & $X$ & $X$ & 9,89 & $X$ & $x$ & $\mathrm{X}$ & $x$ & $X$ & 17,03 & $\mathrm{X}$ & $\mathrm{X}$ & 1,00 \\
\hline ING1 & 1,66 & 1,39 & 0,75 & 1,86 & 1,46 & 1,35 & 1,05 & 2,50 & 2,42 & 1,71 & 1,84 & 0,73 & 0,17 & 1,51 & 1,57 & 0,58 & 2,70 & 0,83 & 1,33 & 1,23 & 1,14 & 2,26 & 2,43 & 0,82 & 0,57 & 1,71 & 1,37 & 1,00 \\
\hline IPF1 & 1,57 & 2,35 & 3,79 & 0,63 & 5,83 & 1,10 & 3,26 & 8,13 & 57,95 & 4,35 & 209,38 & 1,79 & 7,00 & 5,33 & 2,07 & 1,66 & 9,40 & 8,02 & 2,41 & 0,50 & 0,74 & 11,82 & 6,77 & 3,64 & 1,73 & 0,14 & 0,55 & 1,00 \\
\hline IRS2 & 5,35 & $\begin{array}{l}1,25 \\
0.4\end{array}$ & 1,42 & 1,31 & 0,31 & 0,63 & 1,77 & 2,52 & 2,92 & 2,64 & 9,13 & 0,73 & 0,20 & 5,55 & 1,98 & 0,64 & 4,97 & 5,36 & 2,69 & 1,86 & 5,59 & 3,30 & 3,63 & 4,83 & 0,63 & 4,66 & 0,37 & 1,00 \\
\hline
\end{tabular}




\begin{tabular}{|c|c|c|c|c|c|c|c|c|c|c|c|c|c|c|c|c|c|c|c|c|c|c|c|c|c|c|c|c|}
\hline KLF5 & 0,11 & 0,44 & 0,28 & 0,17 & 0,31 & 0,16 & 0,68 & 0,52 & 0,52 & 1,06 & 0,04 & 0,41 & 0,74 & 0,18 & 0,75 & 0,17 & 0,79 & 0,48 & 0,18 & 0,37 & 0,36 & 0,78 & 0,42 & 0,56 & 0,00 & 0,31 & 0,67 & 1,00 \\
\hline LAMP1 & 0,84 & 1,19 & 0,55 & 1,22 & 0,58 & 0,73 & 1,68 & 1,81 & 1,32 & 2,85 & 0,87 & 0,96 & 2,11 & 0,21 & 0,62 & 1,15 & 3,21 & 1,15 & 1,28 & 1,19 & 0,72 & 3,51 & 1,89 & 0,94 & 1,34 & 1,64 &, 11 & 1,00 \\
\hline LIG4 & 0,77 & 0,48 & 0,25 & 0,98 & 1,04 & 0,86 & 0,31 & 0,52 & 1,20 & 1,27 & 1,07 & 0,41 & 0,96 & 1,30 & 0,56 & 0,80 & 1,51 & 0,40 & 0,83 & 0,48 & 0,58 & 1,64 & 0,61 & 0,40 & 1,11 & 0,68 & 0,65 & 1,00 \\
\hline LNX2 & 0,98 & 0,93 & 0,97 & 0,92 & 1,18 & 0,50 & 0,80 & 3,26 & 1,90 & 2,95 & 0,72 & 0,96 & 0,04 & 1,53 & 0,89 & 1,22 & 2,13 & 2,33 & 1,19 & 1,43 & 0,54 & 1,19 & 2,55 & 1,09 & 0,42 & 0,86 & 0,52 & 1,00 \\
\hline MTIF & 1,18 & 1,61 & 0,68 & 1,42 & 2,38 & 0,49 & 1,00 & 2,78 & 1,89 & 2,77 & 1,72 & 1,01 & 1,19 & 2,02 & 0,83 & 0,82 & 3,19 & 1,34 & 1,38 & 1,14 & 0,46 & 1,45 & 1,99 & 1,55 & 0,95 & 1,20 & 0,33 & 1,00 \\
\hline MYCBP2 & 1,42 & 1,07 & 0,94 & 1,82 & 1,52 & 1,00 & 2,65 & 2,40 & 1,76 & 2,30 & 3,76 & 0,97 & 0,83 & 1,63 & 1,22 & 0,68 & 2,50 & 1,03 & 1,82 & 1,06 & 2,72 & 2,40 & 1,93 & 0,97 & 1,84 & 1,96 & 0,69 & 1,00 \\
\hline NUPL1 & 2,28 & 2,08 & 0,83 & 3,06 & 2,98 & 2,96 & 2,11 & 5,83 & 3,52 & 2,60 & 1,64 & 1,08 & 1,21 & 3,74 & 1,97 & 1,19 & 3,49 & 1,70 & 1,76 & 1,42 & 1,07 & 2,22 & 1,68 & 1,04 & 2,46 & 0,69 & 0,41 & 1,00 \\
\hline PAN3 & 1,56 & 1,43 & 0,77 & 1,37 & 1,05 & 0,47 & 1,37 & 2,65 & 2,01 & 2,19 & 2,13 & 0,97 & 1,50 & 2,24 & 1,43 & 0,93 & 1,88 & 3,02 & 1,98 & 1,77 & 0,68 & 1,57 & 2,79 & 0,95 & 0,84 & 1,27 & 0,42 & 1,00 \\
\hline PCID2 & 1,88 & 1,55 & 1,57 & 2,22 & 1,63 & 1,78 & 2,17 & 4,12 & 2,93 & 3,73 & 3,34 & 1,17 & 1,63 & 0,30 & 1,45 & 1,66 & 3,04 & 1,66 & 1,22 & 1,46 & 3,39 & 3,17 & 3,46 & 1,66 & 1,69 & 1,22 & 0,49 & 1,00 \\
\hline POLR1D & 1,67 & 2,40 & 1,4 & 3,64 & 2,4 & 2,02 & 2,67 & 6,74 & 2,7 & 5,17 & 7,67 & 1,15 & 65 & 09 & 3,57 & 2,16 & 4,57 & 5,36 & 1,80 & 3,21 &, 79 & 1,66 & 6,50 & 1,38 & 3,53 & 1,39 & 0,50 & 1,00 \\
\hline POLR1D B & 1,46 & 6,25 & 3,35 & 2,80 & 5,44 & 1,30 & 4,13 & 15,07 & 5,34 & 7,78 & 6,28 & 3,46 & 5,34 & 9,54 & 5,23 & 0,99 & 7,08 & 11,58 & 4,75 & 8,19 & 1,29 & 2,87 & 6,77 & 6,79 & 1,21 & 4,06 & 0,39 & 1,00 \\
\hline POMP & 5,43 & 4,24 & 1,53 & 2,72 & 4,70 & 3,69 & 1,69 & 5,79 & 5,97 & 8,63 & 2,66 & 2,39 & 2,73 & 5,51 & 2,29 & 2,26 & 7,53 & 4,42 & 3,62 & 3,10 & 1,14 & 3,08 & 2,53 & 2,70 & 3,39 & 2,50 & 0,33 & 1,00 \\
\hline RAS11A & 0,09 & 0,28 & 0,18 & 0,08 & 0,13 & 0,11 & 0,09 & 3,82 & 0,12 & 1,04 & 0,01 & 0,27 & 0,16 & 0,01 & 0,41 & 0,28 & 0,22 & 2,52 & 0,32 & 0,22 & 0,02 & 0,03 & 1,39 & 0,26 & 0,04 & 1,07 & 28 & 1,00 \\
\hline SLC46A3 & 0,49 & 0,13 & 0,51 & 0,10 & 0,29 & 0,03 & 0,43 & 0,64 & 0,02 & 1,91 & 0,09 & 0,22 & 0,01 & 0,88 & 0,50 & 0,14 & 1,25 & 0,92 & 0,31 & 0,04 & 0,11 & 1,30 & 1,13 & 0,26 & 0,05 & 3,23 & 0,66 & 1,00 \\
\hline TFDP1 & 2,16 & 2,63 & 0,78 & 1,41 & 2,56 & 1,92 & 2,42 & 3,77 & 3,07 & 3,73 & 2,00 & 1,35 & 1,86 & 0,56 & 2,28 & 1,06 & 4,24 & 1,42 & 2,12 & 1,55 & 1,64 & 4,09 & 2,11 & 1,71 & 1,13 & 0,59 & 1,23 & 1,00 \\
\hline TUBGCP3 & 7,31 & 7,38 & 2,40 & 6,74 & 5,44 & 7,13 & 7,98 & 10,43 & 5,05 & 10,78 & 8,51 & 3,14 & 7,05 & 11,74 & 5,23 & 5,79 & 11,50 & 4,36 & 6,13 & 5,55 & 11,34 & 10,58 & 6,82 & 4,33 & 5,31 & 2,89 & 0,19 & 1,00 \\
\hline USP12 & 0,93 & 0,58 & 0,54 & 1,00 & 0,70 & 0,85 & 0,53 & 3,61 & 1,55 & 1,49 & 0,58 & 0,72 & 1,21 & 0,67 & 0,58 & 0,48 & 1,05 & 2,40 & 0,67 & 0,71 & 0,31 & 0,19 & 1,05 & 0,37 & 0,52 & 0,79 & 1,32 & 1,00 \\
\hline
\end{tabular}

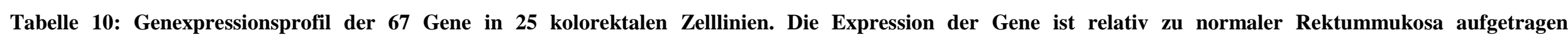
(„Foldchange“). Aneuploide Zelllinien sind rot markiert, diploide schwarz. Per qRT-PCR nicht detektierbare Expressionen sind mit einem „X“ gekennzeichnet. 


\begin{tabular}{|c|c|c|c|c|c|c|c|c|c|c|c|c|c|c|c|c|c|c|c|c|c|c|c|c|c|c|c|c|}
\hline & 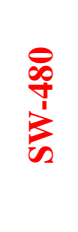 & 突 & 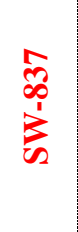 & $\stackrel{0}{\underline{\theta}}$ & $\overrightarrow{\hat{B}}$ & 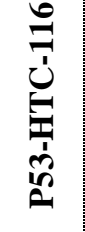 & $\begin{array}{l}\stackrel{\infty}{1} \\
\overbrace{\infty}^{1}\end{array}$ & $\begin{array}{l}Z \\
\exists \\
7 \\
\vdots \\
3 \\
3\end{array}$ & 䆓 & 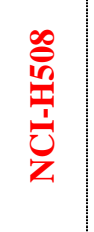 & 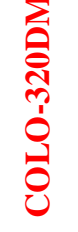 & $\begin{array}{l}\underset{+}{+} \\
\stackrel{1}{i}\end{array}$ & $\begin{array}{l}\overrightarrow{0} \\
\dot{y} \\
\dot{y}\end{array}$ & $\begin{array}{l}\overline{\widehat{T}} \\
\text { o } \\
0 \\
0\end{array}$ & 总 & ঠ̃ & 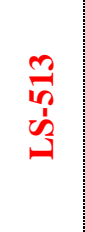 & 竞 & ָี & 岕 & $\begin{array}{l}\text { त్ర్రి } \\
\text { ⿳亠丷厂 }\end{array}$ & 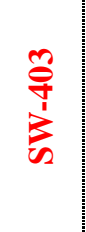 & $\mid \begin{array}{c}0 \\
0 \\
\frac{1}{2} \\
\frac{1}{2}\end{array}$ & $\begin{array}{l}5 \\
\frac{5}{5} \\
\end{array}$ & $\begin{array}{l}0 \\
\approx\end{array}$ & $\begin{array}{l}\overline{\mathbb{E}} \\
\bar{\Xi} \\
\bar{Z}\end{array}$ & $\frac{\tilde{0}}{0}$ & 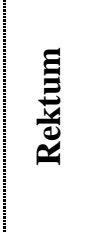 \\
\hline ABHD13 & 0,88 & 0,66 & 13,83 & 12,30 & 1,17 & 9,32 & 29,93 & 31,34 & 40,32 & 3,02 & 2,23 & 12,27 & 1,67 & 18,64 & 0,87 & 13,55 & 69,07 & 0,71 & 17,19 & 16,56 & 18,90 & 39,95 & 1,94 & 1,28 & 12,35 & 15,2 & 1,00 & 0,41 \\
\hline ANKRD10 & 0,82 & 1,42 & 0,57 & 1,39 & 1,72 & 0,63 & \begin{tabular}{|l|}
$.0,56$ \\
\end{tabular} & 0,97 & 1,07 & 7,09 & 1,44 & 0,59 & 0,22 & 2,30 & 0,44 & 0,59 & 3,97 & 2,43 & 1,63 & 1,83 & 0,98 & 1,93 & \begin{tabular}{|l|}
4,68 \\
\end{tabular} & 1,66 & 0,08 & 1,77 & 1,00 & 2,53 \\
\hline ATP11D & 0,86 & 1,37 & 13,18 & 12,38 & 0,81 & 10,41 & 18,68 & 30,91 & 10,73 & 2,29 & 1,23 & 8,55 & 1,32 & 48,17 & 0,94 & 23,26 & 30,91 & 1,92 & 22,21 & 12,91 & 16,80 & 34,30 & 1,23 & 0,68 & 10,90 & 6,53 & 1,00 & 0,12 \\
\hline BRCA2 & 7,00 & 4,17 & 30,27 & 22,94 & 3,63 & 38,85 & 57,81 & 391 & 190 & 2,71 & 3,31 & 78,07 & 1,02 & 204 & 3,10 & 85,63 & 228 & 4,50 & 155 & 79,34 & 66,72 & 112 & 1,44 & 2,25 & 37,19 & 7,40 & 1,00 & 0,31 \\
\hline C13ORF29 & 0,08 & 0,27 & 3,23 & 3,03 & 0,06 & 0,61 & 0,49 & 2,71 & 8,36 & 0,02 & 1,75 & 0,50 & 0,16 & 3,48 & 0,21 & 0,12 & 3,18 & 0,23 & 0,79 & 1,24 & 0,34 & 0,13 & 0,09 & 0,36 & 3,02 & 0,28 & 1,00 & 0,11 \\
\hline CARS2 & 1,07 & 0,72 & 0,72 & 0,61 & 1,82 & 0,84 & 1,24 & 4,72 & 1,05 & 4,10 & 1,25 & 1,05 & 1,41 & 1,42 & 3,77 & 0,47 & 4,03 & 1,77 & 0,79 & 1,43 & 1,68 & 4,72 & 1,89 & 1,65 & 1,24 & 1,14 & 1,00 & 2,26 \\
\hline CDC16 & 2,01 & 2,16 & 0,70 & 1,85 & 2,51 & 1,32 & 1,51 & 2,25 & 1,41 & 5,53 & 2,56 & 0,58 & 0,15 & 0,29 & 1,23 & 1,40 & 3,51 & 1,19 & 1,41 & 1,39 & 2,23 & 3,05 & 3,31 & 1,45 & 1,23 & 1,17 & 1,00 & 1,73 \\
\hline CDX2 & 0,06 & 0,38 & 1,44 & 0,20 & 1,30 & 0,11 & 0,92 & 1,64 & 0,40 & 2,36 & 15,00 & 2,36 & 1,62 & 0,00 & 0,60 & 0,98 & 1,54 & 3,23 & 0,30 & 2,35 & 0,12 & 0,31 & 1,00 & 1,11 & 0,15 & 1,24 & 1,00 & $\begin{array}{l}0,72 \\
\end{array}$ \\
\hline CHR13ORF16 & 0,39 & 2,71 & 0,41 & 1,59 & 5,28 & 0,53 & 1,26 & 1,01 & 0,49 & 0,75 & 2,26 & 0,17 & 1,52 & 0,36 & 0,47 & 0,59 & 0,28 & 0,66 & 0,50 & 0,79 & 0,79 & 0,33 & 3,31 & 2,07 & \begin{tabular}{|l|} 
\\
\end{tabular} & 1,35 & 1,00 & 1,84 \\
\hline COL4A1 & 0,14 & 0,41 & 0,07 & $X$ & 0,85 & $\mathrm{x}$ & 0,00 & $\mathrm{X}$ & $\mathrm{X}$ & 0,00 & 4,91 & 0,00 & 0,02 & 0,00 & 0,01 & 0,03 & 0,05 & 0,88 & 0,00 & 0,28 & 0,00 & 0,13 & 0,20 & $x$ & $x$ & 6,44 & 1,00 & 5,09 \\
\hline COL4A2 & 21,96 & 0,59 & 0,00 & $x$ & 1,80 & $\mathrm{X}$ & 0,00 & $\mathrm{X}$ & 0,00 & $\mathrm{x}$ & 327 & $\mathrm{X}$ & $X$ & $\mathrm{x}$ & $x$ & 0,00 & $x$ & $\mathrm{X}$ & $\mathrm{X}$ & 0,00 & 0,00 & 0,00 & $x$ & $\mathrm{x}$ & $x$ & 2,58 & 1,00 & 316 \\
\hline DLEU2 & 6,13 & 2,58 & 5,43 & 38,32 & 3,61 & 46,53 & 18,68 & 24,42 & 35,84 & 3,62 & 3,72 & 15,10 & 1,48 & 31,12 & 3,98 & 10,34 & 18,90 & 2,97 & 20,16 & 12,38 & 22,78 & 22,47 & 2,32 & 1,21 & 13,99 & 11,7 & 1,00 & 0,55 \\
\hline EFNB2 & 0,59 & 8,06 & 0,15 & \begin{tabular}{|l|}
0,97 \\
\end{tabular} & 10,27 & 1,11 & 3,23 & 2,66 & 1,13 & 60,83 & 6,22 & 1,28 & 35,59 & 7,84 & 13,77 & 1,77 & 3,48 & 8,88 & 0,90 & 2,30 & 3,89 & 2,25 & 4,78 & 7,57 & 4,02 & 0,89 & 1,00 & 19,25 \\
\hline FLJ10769 & 2,74 & 2,95 & 0,37 & 1,27 & 2,66 & 0,54 & 0,96 & 1,51 & 1,63 & 6,85 & 2,61 & 0,38 & 2,57 & 1,35 & 1,42 & 0,81 & 1,88 & 2,14 & 1,03 & 0,91 & 1,30 & 2,85 & 3,40 & 1,68 & 0,59 & 1,23 & 1,00 & 2,94 \\
\hline GAS6 & 5,60 & 2,00 & 0,72 & 0,96 & 4,06 & 1,56 & 1,53 & 5,46 & 0,00 & 2,07 & 0,00 & 0,63 & 1,45 & 0,91 & 1,99 & 0,99 & 11,16 & 4,29 & 3,04 & 3,03 & 1,92 & 8,22 & 5,60 & 2,28 & 0,57 & 4,52 & 1,00 & 3,17 \\
\hline GPC5 & $\mathrm{X}$ & $\mathrm{X}$ & 0,12 & $X$ & $X$ & 0,06 & 0,03 & $x$ & 7,48 & $\mathrm{x}$ & 14,19 & $X$ & $\mathrm{X}$ & $x$ & 5,33 & 0,94 & $X$ & $x$ & $x$ & 0,05 & 0,03 & $\mathrm{X}$ & 0,48 & $x$ & $x$ & 1,84 & 1,00 & 3,11 \\
\hline GPR12 & 0,03 & 0,03 & 5,78 & 0,51 & 0,03 & 0,15 & 1,77 & 5,06 & 33,90 & $\mathrm{x}$ & 1,65 & 0,73 & 0,01 & 0,22 & 0,03 & 0,03 & 5,50 & 0,01 & 1,53 & 0,34 & $\mathrm{x}$ & $\mathrm{X}$ & 0,00 & 0,01 & 0,76 & 0,16 & 1,00 & 0,12 \\
\hline GRK1 & $x$ & $\mathrm{X}$ & $\mathrm{X}$ & 14,42 & $X$ & 12,55 & $x$ & $x$ & $\mathrm{x}$ & $x$ & $\mathrm{X}$ & $\mathrm{X}$ & $\mathrm{X}$ & $x$ & $x$ & $\mathrm{X}$ & $x$ & $x$ & 11,03 & $x$ & $x$ & $X$ & $\mathrm{X}$ & $\mathrm{X}$ & 18,98 & $x$ & $x$ & $\mathrm{X}$ \\
\hline ING1 & 2,20 & 1,84 & 0,55 & 1,36 & 1,93 & 0,99 & 0,76 & 1,83 & 1,77 & 2,26 & 2,44 & 0,53 & 0,22 & 1,10 & 2,08 & 0,42 & 1,97 & 1,09 & 0,97 & 0,90 & 0,84 & 1,65 & 3,22 & 1,09 & \begin{tabular}{|l|} 
\\
\end{tabular} & 1,25 & 1,00 & 1,33 \\
\hline IPF1 & 0,41 & 0,62 & 6,87 & 1,13 & 1,54 & 1,99 & 5,91 & 14,72 & 104,93 & 1,15 & 55,20 & 3,24 & 1,84 & 9,65 & 0,54 & 3,01 & 17,03 & 2,11 & 4,36 & 0,90 & 1,34 & 21,41 & 1,79 & 0,96 & 3,13 & 0,25 & 1,00 & 0,26 \\
\hline IRS2 & 3,78 & 0,88 & 3,81 & $|3,53|$ & 0,22 & 1,71 & 4,77 & 6,77 & 7,85 & 1,86 & 6,44 & 1,95 & 0,14 & 14,93 & 1,40 & 1,73 & 13,36 & 3,78 & 7,23 & 4,99 & 15,03 & 8,88 & $\mid 2,56$ & 3,41 & 1,70 & 12,5 & $\mid 1,00$ & $\begin{array}{lll} \\
\end{array}$ \\
\hline
\end{tabular}




\begin{tabular}{|c|c|c|c|c|c|c|c|c|c|c|c|c|c|c|c|c|c|c|c|c|c|c|c|c|c|c|c|c|}
\hline KI & 1 & 66 & 2 & 26 & 1 & 4 & 2 & 77 & 0,78 & 3,75 & 5 & 2 & 1 & 0 & 5 & 6 & 8 & 1 & 7 & 5 & 4 & 16 & 49 & 1,97 & 1 & 47 &, 00 & 3,55 \\
\hline MP1 & & 16 & 0 & 99 & 5 & 66 & 1 & 62 & & 16 & 0 & 36 & 32 & 9 & 12 & 04 & 39 & 08 & 15 & 07 & 65 & 16 & ,43 & 1,71 &, 20 & 47 & ,00 & 1,81 \\
\hline & & & & 2 & & & 0,48 & & & & & & & & & & & & 8 & & & 53 & 47 & 1,62 & 1 & 5 & 00 & 1,05 \\
\hline LNX2 & & & 50 & 78 & 22 & & 56 & 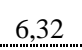 & 3,69 & 305 & 0,1 & 1,86 & 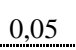 & 1 & 0,92 & 2,36 & 14 & 2,41 & 2,32 & 2,77 & 04 & 2,31 & 2,63 & 1,13 & 82 &, 68 & 1,00 &, 03 \\
\hline & & 36 & 24 & 26 & 55 & & (2) & & 5,67 & 07 & 53 & .05 & 76 & 06 & .23 &, 46 & 58 &, 97 & 15 &, 41 & 38 & 35 & 2,92 & 2,28 & 86 & 60 & 1,00 & 1,47 \\
\hline & & & 36 & 64 & 1,62 & 45 & 3,85 & & & $\begin{array}{ll}40 \\
*\end{array}$ & 4,02 & 1,40 & 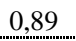 & 80 & 1,30 & 98 & 63 & 1,10 &, 65 & 1,54 & 94 &, 48 & 2,07 & 1,04 & 67 & 84 & 1,00 &, 07 \\
\hline & & 50 & 204 & 752 & 250 & & & & & 212 & 1,97 & 2,65 & 1,46 & 9,19 & 2,37 & 2,93 & 8,57 & 2,04 & 4,33 & 3,48 & 4 & 6 & 02 & 1,26 & 5 & 9 & 1,00 & 20 \\
\hline $\mathbf{P}$ & 02 & 35 & 84 & 3,27 & 1,37 & 12 & 28 & 32 & 4,80 & 2,84 & 2,76 & 2,32 & 1,95 & 5,35 & 1,86 & 2,22 & .50 & 3,92 & 4,73 & 23 & 64 & 3,76 & 3,62 & 1,23 & 01 &, 02 & 1,00 & 1,30 \\
\hline & & & 3 & 56 & 4 & & $\begin{array}{l}4,45 \\
4,35 x\end{array}$ & & $\begin{array}{l}6,01 \\
6,01\end{array}$ & 027 & 2 & 2,41 & 4 & 2 & 2 & 41 & 3 & 06 & 50 & 9 & 6 & 50 & 20 & 1,06 & 17 & .51 & 1,00 & 64 \\
\hline $\mathbf{P}$ & 115 & 165 & 2,93 & 731 & 67 & 406 & $\begin{array}{l}5,36 \\
3,36\end{array}$ & 355 & 5,48 & 355 & 5,27 & 2,31 & 1,82 & 4,20 & 2,45 & 4,35 & 9,19 & 3,68 & 3,61 & 6,45 & 3,61 & 34 & 4,46 & 95 & 7,09 & 8 & 0 & 69 \\
\hline & 4 & 37 & 8,69 & 7,26 & 1,62 & 36 &, 73 & 12 & 38 &, 32 & 1,87 & 8,98 & 1,59 & 4,76 & 1,56 & 2,57 & 8,38 & 3,46 & 2,32 & 21,26 & 3,34 & 7,46 & 2,02 & 2,03 & 3,15 & 10,53 & 1,00 &, 30 \\
\hline & SN: & 11 & 4,59 & 8,17 & 0,07 & 11,08 & 07 & 17,39 & 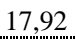 & 20,04 & 1,74 & 7,19 & 1,78 & , & 1,50 & 6,77 & 2,63 & 9 & 88 & 9,32 & & 5 & 65 & 1,77 & 17 & 50 &, 00 &, 65 \\
\hline R & & 156 & 0,14 & 77 & 15 & 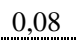 & 0,07 & 00 & 0,09 & 580 & 0,05 & 0 & 0,89 & 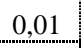 & 2,32 & 0,22 & 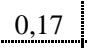 & 14,12 & 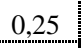 & 0,17 & 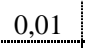 & 0,02 & 7,82 & 1,45 & 33 & 84 & 1,00 & 5,60 \\
\hline & 96 & 24 & 71 & 0,15 & 0,56 & D. & 66 & 91 & & 12 & 0,18 & 0,34 & 0,03 & 4 & 0,97 & 0,20 & 1,89 & 1,80 & 0,46 & 0,06 & 0,16 & 1,97 & 2,21 & 0,50 &, 08 & 1,88 & 1,00 & 1,95 \\
\hline & 76 & 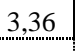 & 0,64 & 1,15 & 3,27 & & & & & 26) & 2,56 & 1,10 & 2,38 & 0,46 & 2,91 & 0,86 & 3,46 & 1,82 & 1,73 & 1,27 & 1,34 & 4 & 2,71 & 19 & 0,92 & 8 & 1,00 & 28 \\
\hline & 55 & 77 & 82 & 36,00 & 27 & 05 & 62 & 72 & ㄴong & 4,49 & .55 & 5,76 & 93 & 88 &, 18 & 0,91 & 1,39 , & 82 & 2,75 & 9,65 & 0,55 & 6,49 & 2,84 & 1,80 & 8,38 & 5,42 & 1,00 & 0,42 \\
\hline USP12 & 1,71 & 1,06 & 0,68 & 1,27 & 1,29 & 07 & 67 & 4,56 & 1,96 & 2,76 & 1,08 & 0,91 & 2,24 & 0,84 & 1,07 & 0,61 & 1,33 & 4,44 & 0,85 & 0,90 & 0,39 & 0,23 & 1,94 & 0,69 & 0,66 & 1,67 & 1,00 & 1,85 \\
\hline
\end{tabular}

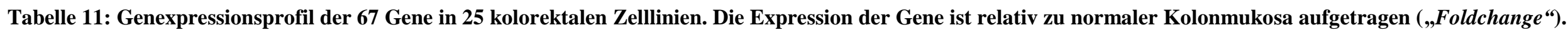
Aneuploide Zelllinien sind rot markiert, diploide schwarz. Per qRT-PCR nicht detektierbare Expressionen sind mit einem „, ${ }^{“}$ gekennzeichnet. 


\begin{tabular}{|c|c|c|c|c|c|c|c|c|c|c|c|c|c|c|c|c|c|c|c|c|c|c|c|c|c|c|c|c|}
\hline & 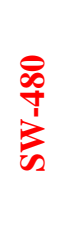 & 今ે & $\begin{array}{l}\hat{n} \\
\infty \\
\dot{\infty} \\
\vec{n}\end{array}$ & $\stackrel{\varrho}{ٍ}$ & ڤ̄ & 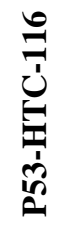 & $\frac{\infty}{\dot{y}}$ & 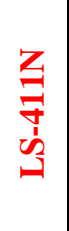 & $\begin{array}{l}\frac{0}{1} \\
\frac{1}{1} \\
\frac{1}{z}\end{array}$ & 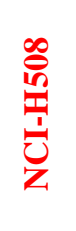 & 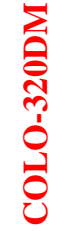 & $\begin{array}{l}\mathbb{Z} \\
\infty \\
\end{array}$ & $\begin{array}{l}7 \\
0 \\
\dot{1} \\
\dot{u} \\
\tilde{U}\end{array}$ & 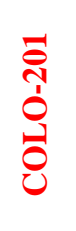 & $\stackrel{0}{\stackrel{2}{2}}$ & 仓ુ & 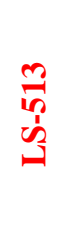 & ${ }^{0}$ & 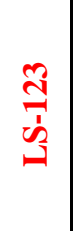 & 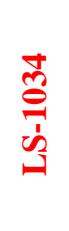 & 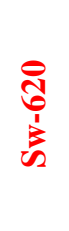 & 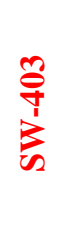 & $\begin{array}{c}m \\
\dot{b} \\
\frac{1}{1} \\
\dot{3}\end{array}$ & 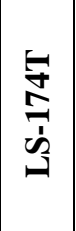 & $\stackrel{0}{2}$ & 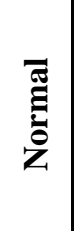 & 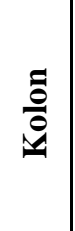 & $\underset{\Xi}{E}$ \\
\hline ADPRHL1 & 4,38 & 3,42 & 0,63 & 10 & 5 & 6 & 1,98 & 1,61 & 1,65 & 10 & 12 & 0,16 & 1,20 & 0,06 & 1,32 & 0,97 & 1,81 & 1,21 & 2,12 & 1,40 & 3,95 & 10 & 1,62 & 4,45 & 1,00 & 1,00 & 0,64 & 1,01 \\
\hline ANKRD10 & 0,26 & 0,45 & 0,32 & 0,79 & 0,55 & 0,35 & 0,32 & 0,55 & 0,61 & 2,27 & 0,46 & 0,33 & 0,07 & 1,30 & 0,14 & 0,33 & 2,24 & 0,78 & 0,92 & 1,03 & 0,55 & 1,09 & 1,49 & 0,53 & 0,05 & 1,00 & 0,56 & 0,81 \\
\hline ATP11D & 1,73 & 2,76 & 2,02 & 1,90 & 1,63 & 1,59 & 2,86 & 5 & 1,64 & 5 & 2,48 & 1,31 & 2,67 & 7 & 1,89 & 3,56 & 5 & 3,87 & 3,40 & 1,98 & 2,57 & 5 & 2,48 & 1,37 & 1,67 & 1,00 & 0,15 & 0,23 \\
\hline BRCA2 & 29 & 17 & 4,09 & 3,10 & 15 & 5 & 8 & 53 & 26 & 11 & 14 & 11 & 4,19 & 28 & 13 & 12 & 31 & 18 & 21 & 11 & 9 & 15 & 6 & 9 & 5 & 1,00 & 0,14 & 1,27 \\
\hline C13ORF29 & 0,85 & 3,06 & 11 & 11 & 0,67 & 2,15 & 1,71 & 10 & 29 & 0,19 & 20 & 1,77 & 1,82 & 12 & 2,37 & 0,43 & 11 & 2,59 & 2,76 & 4,36 & 1,18 & 0,46 & 1,06 & 4,04 & 11 & 1,00 & 3,51 & 1,30 \\
\hline CARS2 & 0,67 & 0,45 & 0,63 & 0,54 & 1,14 & 0,73 & 1,09 & 4,15 & 0,92 & 2,58 & 0,78 & 0,92 & 0,89 & 1,25 & 2,37 & 0,41 & 3,54 & 1,11 & 0,70 & 1,26 & 1,48 & 4,15 & 1,19 & 1,04 & 1,09 & 1,00 & 0,88 & 1,42 \\
\hline CDC16 & 1,21 & 1,30 & 0,60 & 1,58 & 1,51 & 1,13 & 1,29 & 1,92 & 1,20 & 3,32 & 1,54 & 0,50 & 0,09 & 0,25 & 0,74 & 1,20 & 3,00 & 0,71 & 1,20 & 1,18 & 1,91 & 2,61 & 1,99 & 0,87 & 1,05 & 1,00 & 0,85 & 1,04 \\
\hline CDX2 & 0,07 & 0,44 & 1,17 & 0,16 & 1,52 & 0,09 & 0,74 & 1,32 & 0,32 & 2,75 & 18 & 1,91 & 1,89 & 0,00 & 0,71 & 0,79 & 1,24 & 3,77 & 0,24 & 1,90 & 0,10 & 0,25 & 1,16 & 1,30 & 0,12 & 1,00 & 0,81 & 0,84 \\
\hline CHR13ORF16 & 0,12 & 0,83 & 0,31 & 1,18 & 1,62 & 0,39 & 0,93 & 0,74 & 0,37 & 0,23 & 0,69 & 0,13 & 0,47 & 0,26 & 0,14 & 0,44 & 0,21 & 0,20 & 0,37 & 0,58 & 0,58 & 0,24 & 1,01 & 0,63 & 0,30 & 1,00 & 0,74 & 0,56 \\
\hline COL4A1 & 0,00 & 0,00 & 0,01 & $\mathrm{X}$ & 0,01 & $X$ & 0,00 & $\mathrm{X}$ & $\mathrm{X}$ & 0,00 & 0,05 & 0,00 & 0,00 & 0,00 & 0,00 & 0,00 & 0,01 & 0,01 & 0,00 & 0,04 & 0,00 & 0,02 & 0,00 & $\mathrm{X}$ & $x$ & 1,00 & 0,16 & 0,05 \\
\hline COL4A2 & 0,01 & 0,00 & 0,00 & $\mathrm{X}$ & 0,00 & $X$ & 0,00 & $X$ & 0,00 & $x$ & 0,10 & $X$ & $X$ & $X$ & $X$ & 0,00 & $\mathrm{X}$ & $X$ & $\mathrm{X}$ & 0,00 & 0,00 & 0,00 & $X$ & $x$ & $x$ & 1,00 & 0,39 & 0,10 \\
\hline DLEU2 & 2,83 & 1,19 & 0,46 & 3,26 & 1,66 & 3,95 & 1,59 & 2,08 & 3,05 & 1,67 & 1,72 & 1,28 & 0,68 & 2,65 & 1,84 & 0,88 & 1,61 & 1,37 & 1,71 & 1,05 & 1,94 & 1,91 & 1,07 & 0,56 & 1,19 & 1,00 & 0,08 & 0,25 \\
\hline EFNB2 & 0,10 & 1,39 & 0,17 & 1,09 & 1,77 & 1,25 & 3,65 & 3,00 & 1,27 & 10 & 1,07 & 1,44 & 6 & 9 & 2,37 & 1,99 & 3,93 & 1,53 & 1,02 & 2,59 & 4,39 & 2,54 & 0,82 & 1,30 & 5 & 1,00 & 1,13 & 3,32 \\
\hline FLJ10769 & 0,84 & 0,90 & 0,30 & 1,03 & 0,81 & 0,44 & 0,78 & 1,23 & 1,33 & 2,08 & 0,80 & 0,31 & 0,78 & 1,10 & 0,43 & 0,66 & 1,53 & 0,65 & 0,84 & 0,74 & 1,06 & 2,32 & 1,04 & 0,51 & 0,48 & 1,00 & 0,81 & 0,90 \\
\hline GAS6 & 0,89 & 0,32 & 0,16 & 0,21 & 0,64 & 0,34 & 0,34 & 1,21 & 0,00 & 0,33 & 0,00 & 0,14 & 0,23 & 0,20 & 0,32 & 0,22 & 2,47 & 0,68 & 0,67 & 0,67 & 0,42 & 1,82 & 0,89 & 0,36 & 0,13 & 1,00 & 0,22 & 0,50 \\
\hline GPC5 & $X$ & $\mathrm{X}$ & 0,06 & $\mathrm{X}$ & $\mathrm{X}$ & 0,03 & 0,02 & $\mathrm{X}$ & 4,07 & $X$ & 0,90 & $X$ & $\mathrm{X}$ & $X$ & 0,34 & 0,51 & $\mathrm{X}$ & $X$ & $\mathrm{X}$ & 0,03 & 0,02 & $\mathrm{X}$ & 0,03 & $X$ & $X$ & 1,00 & 0,54 & 0,20 \\
\hline GPR12 & 0,99 & 1,04 & 36 & 3,21 & 1,00 & 0,95 & 11 & 32 & 213 & $X$ & 60 & 5 & 0,35 & 1,37 & 1,08 & 0,16 & 35 & 0,29 & 10 & 2,12 & $X$ & $\mathrm{X}$ & 0,17 & 0,38 & 5 & 1,00 & 6 & 4,26 \\
\hline GRK1 & $X$ & $X$ & $X$ & 10 & $X$ & 9 & $X$ & $\mathrm{X}$ & $\mathrm{X}$ & $X$ & $\mathrm{X}$ & $\mathrm{X}$ & $X$ & $\mathrm{X}$ & $X$ & $X$ & $\mathrm{X}$ & $X$ & 7 & $X$ & $x$ & $\mathrm{X}$ & $X$ & $X$ & 13 & $\mathrm{X}$ & $X$ & $X$ \\
\hline ING1 & 0,97 & 0,81 & 0,44 & 1,09 & 0,85 & 0,79 & 0,61 & 1,47 & 1,42 & 1,00 & 1,08 & 0,43 & 0,10 & 0,88 & 0,92 & 0,34 & 1,58 & 0,48 & 0,78 & 0,72 & 0,67 & 1,32 & 1,42 & 0,48 & 0,33 & 1,00 & 0,80 & 0,59 \\
\hline IPF1 & 12 & 17 & 28 & 5 & 43 & 8 & 24 & 60 & 427 & 32 & 1541 & 13 & 52 & 39 & 15 & 12 & 69 & 59 & 18 & 3,66 & 5 & 87 & 50 & 27 & 13 & 1,00 & 4,07 & 7 \\
\hline IRS2 & 1,15 & 0,27 & 0,30 & 0,28 & 0,07 & 0,14 & 0,38 & 0,54 & 0,63 & 0,57 & 1,96 & 0,16 & 0,04 & 1,19 & 0,43 & 0,14 & 1,07 & 1,15 & 0,58 & 0,40 & 1,20 & 0,71 & 0,78 & 1,04 & 0,14 & 1,00 & 0,08 & 0,21 \\
\hline
\end{tabular}




\begin{tabular}{|c|c|c|c|c|c|c|c|c|c|c|c|c|c|c|c|c|c|c|c|c|c|c|c|c|c|c|c|c|}
\hline KLF5 & 0,37 & 1,41 & 0,90 & 0,55 & 1,00 & 0,52 & 2,18 & 1,65 & 1,67 & 3,39 & 0,14 & 1,33 & 2,36 & 0,58 & 2,39 & 0,56 & 2,54 & 1,54 & 0,58 & 1,18 & 1,16 & 2,50 & 1,35 & 1,78 & 0,01 & 1,00 & 2,15 & 3,20 \\
\hline LAMP1 & 0,51 & 0,73 & 0,34 & 0,74 & 0,35 & 0,45 & 1,03 & 1,10 & 0,80 & 1,74 & 0,53 & 0,59 & 1,29 & 0,13 & 0,38 & 0,70 & 1,96 & 0,70 & 0,78 & 0,73 & 0,44 & 2,15 & 1,16 & 0,58 & 0,82 & 1,00 & 0,68 & 0,61 \\
\hline LIG4 & 1,13 & 0,70 & 0,36 & 1,44 & 1,53 & 1,26 & 0,45 & 0,76 & 1,76 & 1,85 & 1,57 & 0,61 & 1,40 & 1,90 & 0,82 & 1,18 & 2,21 & 0,58 & 1,21 & 0,71 & 0,84 & 2,40 & 0,90 & 0,59 & 1,62 & 1,00 & 0,95 & 1,46 \\
\hline LNX2 & 1,13 & 1,07 & 1,12 & 1,06 & 1,37 & 0,58 & 0,93 & 3,77 & 2,20 & 3,41 & 0,84 & 1,11 & 0,05 & 1,77 & 1,03 & 1,41 & 2,47 & 2,70 & 1,38 & 1,65 & 0,62 & 1,38 & 2,95 & 1,26 & 0,49 & 1,00 & 0,60 & 1,16 \\
\hline MTIF & 0,99 & 1,34 & 0,57 & 1,18 & 1,99 & 0,41 & 0,83 & 2,32 & 1,58 & 2,31 & 1,43 & 0,85 & 1,00 & 1,69 & 0,70 & 0,68 & 2,66 & 1,12 & 1,15 & 0,95 & 0,38 & 1,21 & 1,66 & 1,30 & 0,80 & 1,00 & 0,28 & 0,84 \\
\hline MYCBP2 & 0,73 & 0,55 & 0,48 & 0,93 & 0,78 & 0,51 & 1,35 & 1,23 & 0,90 & 1,17 & 1,92 & 0,49 & 0,43 & 0,83 & 0,62 & 0,34 & 1,28 & 0,53 & 0,93 & 0,54 & 1,39 & 1,23 & 0,99 & 0,49 & 0,94 & 1,00 & 0,35 & 0,51 \\
\hline NUPL1 & 3,32 & 3,02 & 1,21 & 4,45 & 4,33 & $\begin{array}{l}4,30 \\
3,30\end{array}$ & 3,07 & 8 & 5 & 3,78 & 2,38 & 1,57 & 1,76 & 5 & 2,86 & 1,73 & 5 & 2,47 & 2,56 & 2,06 & 1,56 & 3,23 & 2,45 & 1,52 & 3,58 & 1,00 & 0,59 & 1,45 \\
\hline PAN3 & 1,23 & 1,13 & 0,61 & 1,08 & 0,83 & 0,37 & 1,08 & 2,09 & 1,59 & 1,73 & 1,68 & 0,77 & 1,19 & 1,77 & 1,13 & 0,73 & 1,49 & 2,38 & 1,57 & 1,40 & 0,54 & 1,24 & 2,20 & 0,75 & 0,66 & 1,00 & $0,33$. & 0,79 \\
\hline PCID2 & 1,54 & 1,27 & 1,29 & 1,82 & 1,33 & 1,46 & 1,77 & 3,37 & 2,40 & 3,05 & 2,73 & 0,96 & 1,33 & 0,25 & 1,19 & 1,36 & 2,49 & 1,36 & 1,00 & 1,19 & 2,78 & 2,59 & 2,83 & 1,36 & 1,39 & 1,00 & 0,40 & 0,82 \\
\hline POLR1D A & 1,21 & 1,73 & 1,05 & 2,63 & 1,76 & 1,46 & 1,93 & 5 & 1,97 & 3,73 & 6 & 0,83 & 1,91 & 1,51 & 2,58 & 1,56 & 3,30 & 3,87 & 1,30 & 2,32 & 1,30 & 1,20 & 5 & 1,00 & 2,55 & 1,00 & 0,36 & 0,72 \\
\hline POLR1D B & 0,36 & 1,54 & 0,83 & 0,69 & 1,34 & 0,32 & 1,02 & 3,71 & 1,32 & 1,92 & 1,55 & 0,85 & 1,32 & 2,35 & 1,29 & 0,24 & 1,75 & 2,85 & 1,17 & 2,02 & 0,32 & 0,71 & 1,67 & 1,67 & 0,30 & 1,00 & 0,09 & 0,25 \\
\hline POMP & 2,17 & 1,70 & 0,61 & 1,09 & 1,88 & 1,48 & 0,68 & 2,32 & 2,39 & 3,46 & 1,06 & 0,96 & 1,09 & 2,21 & 0,92 & 0,90 & 3,02 & 1,77 & 1,45 & 1,24 & 0,46 & 1,23 & 1,01 & 1,08 & 1,36 & 1,00 & 0,13 & 0,40 \\
\hline RAS11A & 0,08 & 0,26 & 0,17 & 0,08 & 0,12 & 0,10 & 0,09 & 3,56 & 0,11 & 0,97 & 0,01 & 0,25 & 0,15 & 0,01 & 0,39 & 0,26 & 0,20 & 2,35 & 0,30 & 0,20 & 0,02 & 0,03 & 1,30 & 0,24 & 0,04 & 1,00 & 1,19 & 0,93 \\
\hline SLC46A3 & 0,15 & 0,04 & 0,16 & 0,03 & 0,09 & 0,01 & 0,13 & 0,20 & 0,00 & 0,59 & 0,03 & 0,07 & 0,00 & 0,27 & 0,15 & 0,04 & 0,39 & 0,29 & 0,10 & 0,01 & 0,03 & 0,40 & 0,35 & 0,08 & 0,02 & 1,00 & 0,20 & 0,31 \\
\hline TFDP1 & 3,66 & 4,45 & 1,32 & 2,38 & 4,33 & 3,26 & 4,10 & 6 & 5 & 6 & 3,39 & 2,28 & 3,15 & 0,95 & 3,85 & 1,79 & 7 & 2,40 & 3,60 & 2,63 & 2,78 & 7 & 3,58 & 2,89 & 1,91 & 1,00 & 2,08 & 1,69 \\
\hline TUBGCP3 & 2,53 & 2,56 & 0,83 & 2,33 & 1,88 & 2,47 & 2,76 & 3,61 & 1,75 & 3,73 & 2,95 & 1,09 & 2,44 & 4,07 & 1,81 & 2,00 & 3,98 & 1,51 & 2,12 & 1,92 & 3,93 & 3,66 & 2,36 & 1,50 & 1,84 & 1,00 & 0,06 & 0,35 \\
\hline USP12 & 0,70 & 0,44 & 0,41 & 0,76 & 0,53 & 0,64 & 0,40 & 2,74 & 1,18 & 1,13 & 0,44 & 0,54 & 0,92 & 0,50 & 0,44 & 0,37 & 0,80 & 1,82 & 0,51 & 0,54 & 0,24 & 0,14 & 0,80 & 0,28 & 0,40 & 0,60 & 0,76 & 1,00 \\
\hline
\end{tabular}

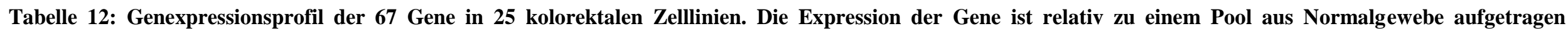
(,Foldchange “). Aneuploide Zelllinien sind rot markiert, diploide schwarz. Per qRT-PCR nicht detektierbare Expressionen sind mit einem „X“ gekennzeichnet. 


\section{Kolorektale Karzinomzelllinien}

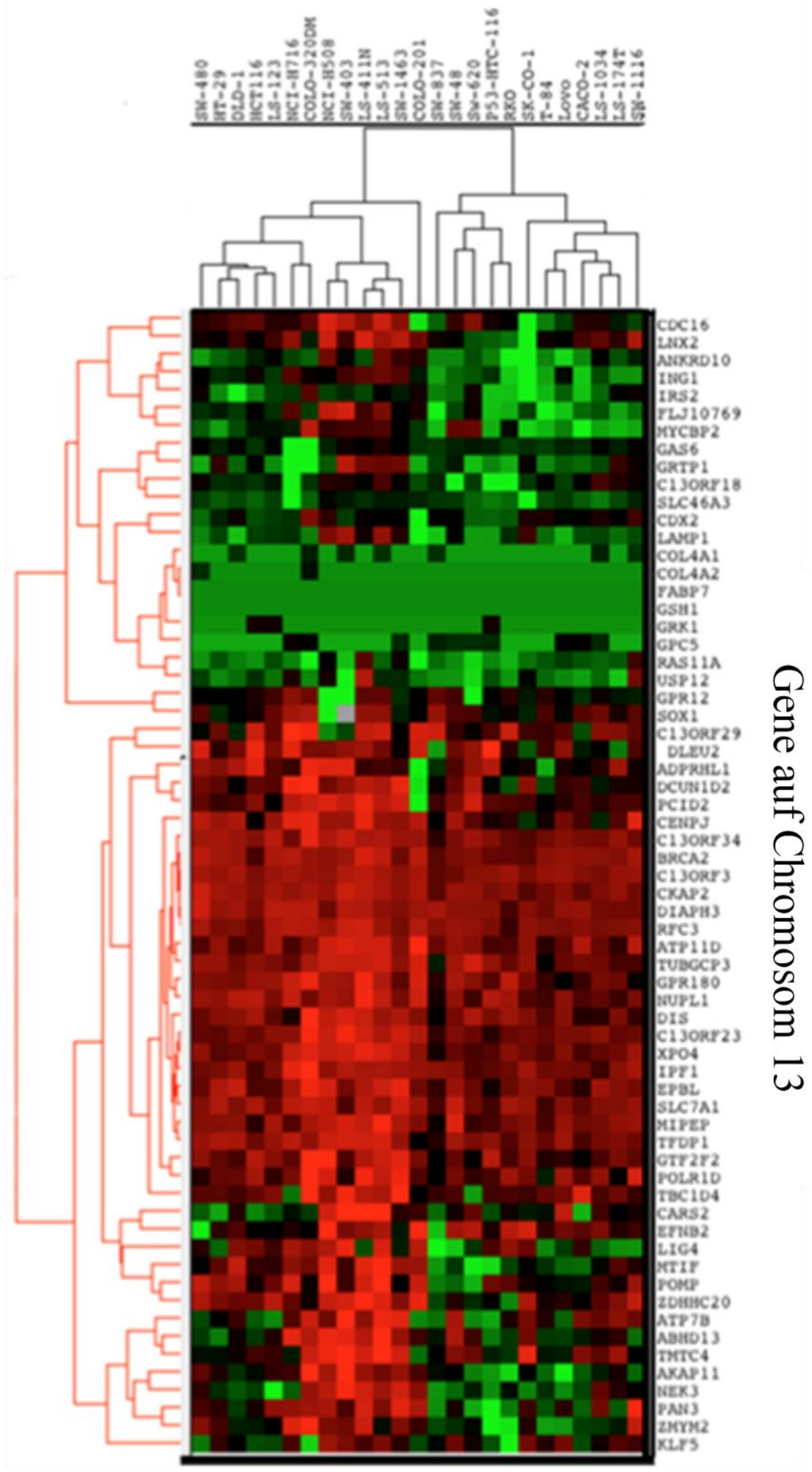

Abbildung 17: Heatmap der per qRT-PCR gemessenen Genexpression in 25 kolorektalen Zellinien, relativ zu einem Normal-Gewebe-Pool. Hochregulierte Gene sind in Rot dargestellt, herunterregulierte in Grün. 


\section{4 siRNA-vermittelte Genderegulation}

Nachdem Gene gefunden worden waren, die in kolorektalen Primärtumoren und Zelllinien überrepräsentiert waren und sowohl in Tumoren als auch in Zelllinien hochreguliert sind, sollte der Einfluss dieser Gene auf die Überlebensfähigkeit von Tumorzellen getestet werden. Dazu wurden die 44 Gene in der Zelllinie SW480, einer kolorektalen Zelllinie, welche die typischen chromosomalen Aberrationen kolorektaler Karzinome zeigt, jeweils durch zwei verschiedene siRNAs ausgeschaltet. Anschließend wurde die verbleibende Viabilität der Zellen im Verhältnis zu einer Kontroll-siRNA (siNEG) bestimmt. Mit qRT-PCR wurde die Menge an mRNA bestimmt, die nach siRNA-Transfektion noch vorhanden war, um sicherzustellen, dass die entsprechenden siRNAs auch das entsprechende Zielgen dereguliert hatten.

\subsubsection{SiRNA-Transfektion}

Der Erfolg der siRNA-Transfektion wurde durch eine Positivkontrolle überprüft. Der „Allstar Mega Killer siRNA mix“ (siMEGA) (Qiagen) löst bei erfolgreicher Transfektion ein Sterben der Zellen aus, welches mit einem absoluten Viabilitätsverlust einhergeht. Daher ist die Viabilitätsreduktion bei der Transfektion mit siMEGA ein indirekter Marker für die Transfektionseffizienz. Im Mittel wurde nach $72 \mathrm{~h}$ eine Viabilitätsreduktion um $90 \%$ erreicht, nach 96 um $94 \%$.

\subsubsection{Viabilitätsassay und Knockdown-Validierung}

48h nach Transfektion wurde RNA isoliert, in cDNA umgeschrieben und per qRT-PCR die verbleibende Menge an mRNA eines Gens bestimmt. Nach 72h und 96h wurde die verbleibende Viabilität der Zellen untersucht. Jeder Versuch wurde in drei Replikaten durchgeführt.

Zur Bestimmung der Toxizität des Transfektionsreagenz (Oligofectamin ${ }^{\circledR}$ ) wurden auf jeder Platte unbehandelte Zellen sowie nur mit Oligofectamin ${ }^{\circledR}$ versetzte Zellen mitgeführt. Mit Transfektionsreagenz versetzte Zellen verloren im Mittel 16\% Viabilität im Vergleich zu unbehandelten Zellen. Um den Einfluss einer Transfektion mit einer siRNA und deren Prozessierung auf die Viabilität von Zellen zu testen, wurde eine siRNA transfiziert, die keine bekannte Zielsequenz im humanen Genom hat (siNEG). Die Transfektion mit siNEG führte im Mittel zu einer Viabilitätsreduktion von 20\%. In den Abbildungen 18, 19, 20 und 21 sind 
die Viabilitätswerte der Zellen $72 \mathrm{~h}$ und 96h nach Transfektion mit einer siRNA, relativ zur Transfektion mit siNEG dargestellt. Zusätzlich ist die nach $48 \mathrm{~h}$ in den Zellen verbleibende mRNA-Expression des jeweiligen Zielgens, relativ zu mit siNEG transfizierten Zellen abgebildet.

19 siRNAs, entsprechend 16 Genen, führten nach $72 \mathrm{~h} \mathrm{zu}$ einer Viabilitätsreduktion von >10\%, 9 siRNAs, entsprechend 7 Genen, führen nach 72h zu einer Viabilitätsreduktion von $>20 \%$. Nach 96h hat sich der Effekt der meisten siRNAs noch verstärkt, 20 siRNAs, entsprechend 17 Genen, führen zu einer Viabilitätsreduktion von >10\%, 15 entsprechend 13 Genen zu einem Verlust $>20 \%$.

Zwei Gene gewinnen, nach einem Verlust $>10 \%$ Viabilität zum Zeitpunkt $72 \mathrm{~h}$, nach $96 \mathrm{~h}$ wieder an Viabilität hinzu: MIPEP und TUBGCP3.

Tabelle 13 zeigt die 15 siRNAs, entsprechend 13 Genen, durch die die stärkste Viabilitätsreduktion herbeigeführt wird.

\begin{tabular}{|c|c|c|c|c|}
\hline siRNA & Gensymbol & RNA 48h & Viabilität 72h & Viabilität 96h \\
\hline ATP7B_1 & ATP7B & $75 \%$ & $46 \%$ & $31 \%$ \\
\hline C13ORF12_2 & POMP & $61 \%$ & $66 \%$ & $36 \%$ \\
\hline RFC3_6 & RFC3 & $62 \%$ & $65 \%$ & $49 \%$ \\
\hline NUPL1_1 & NUPL1 & $19 \%$ & $59 \%$ & $51 \%$ \\
\hline NUPL1_3 & NUPL1 & $13 \%$ & $79 \%$ & $56 \%$ \\
\hline CDX2_8 & CDX2 & $43 \%$ & $73 \%$ & $58 \%$ \\
\hline KIAA1008_2 & DIS3 & $92 \%$ & $67 \%$ & $59 \%$ \\
\hline LNX2_5 & LNX2 & $23 \%$ & $83 \%$ & $67 \%$ \\
\hline CKAP2_5 & CKAP2 & $15 \%$ & $76 \%$ & $71 \%$ \\
\hline SLC7A1_4 & SLC7A1 & $25 \%$ & $83 \%$ & $73 \%$ \\
\hline POLR1D_1 & POLR1D & $24 \%$ & $84 \%$ & $77 \%$ \\
\hline CDX2_1 & CDX2 & $30 \%$ & $80 \%$ & $77 \%$ \\
\hline ZNF198_1 & ZNF198 & $56 \%$ & $87 \%$ & $77 \%$ \\
\hline FLJ25952_3 & ZDHHC20 & $10 \%$ & $88 \%$ & $80 \%$ \\
\hline CENPJ_2 & CENPJ & $93 \%$ & $88 \%$ & $80 \%$ \\
\hline
\end{tabular}

Tabelle 13: Liste der siRNAs mit dem stärksten Einfluss auf die Viabilität. Dargestellt sind die verbleibende Menge an mRNA nach 48h sowie die verbleibende Viabilität nach $72 \mathrm{~h}$ und 96h. 


\section{Viabilität 72h A}

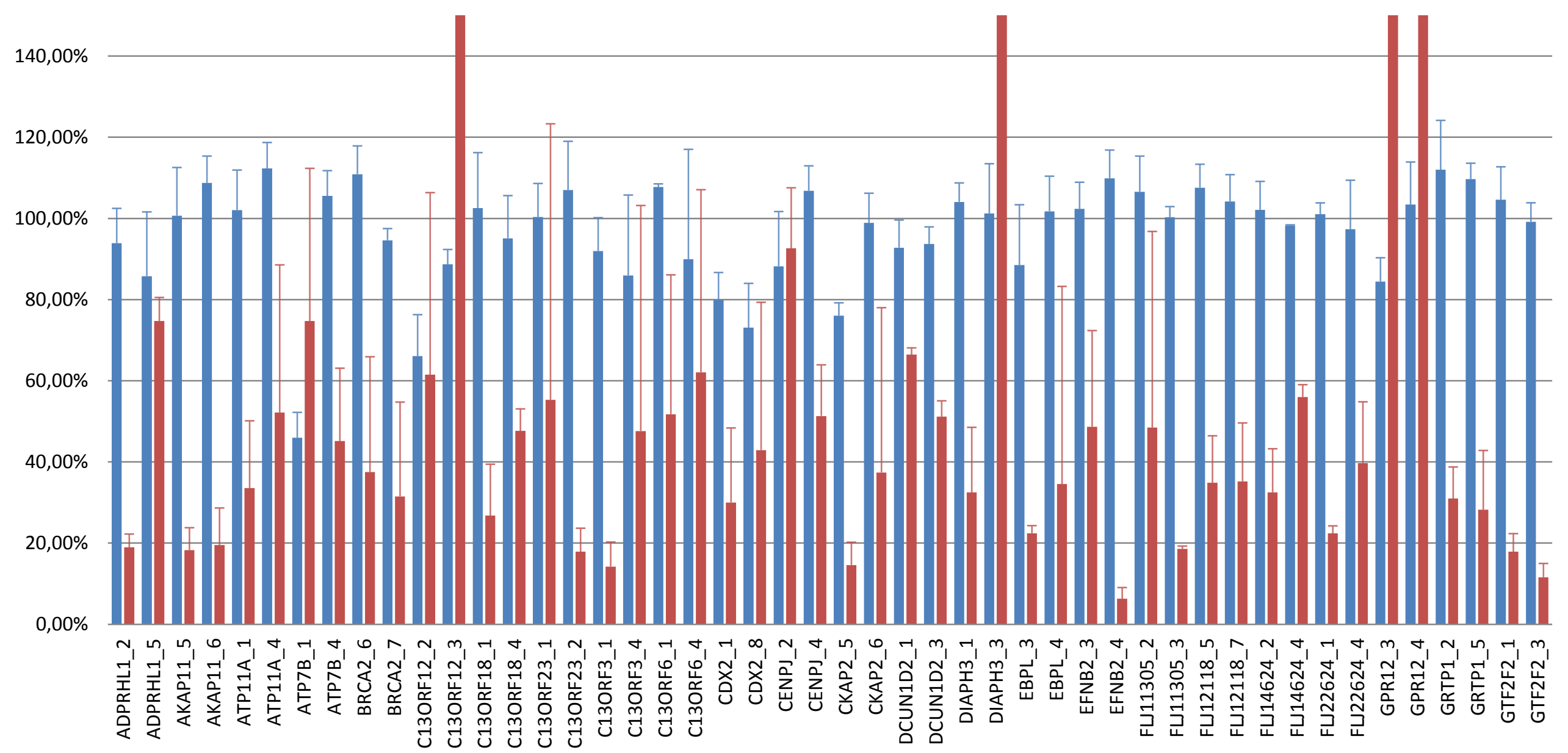

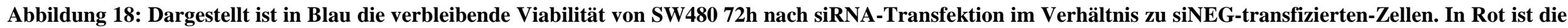
verbleibende mRNA-Expression des siRNA-Target-Gens 48h nach Transfektion abgebildet, ebenfalls im Verhältnis zu siNEG-transfizierten-Zellen. 


\section{Viabilität 72h B}

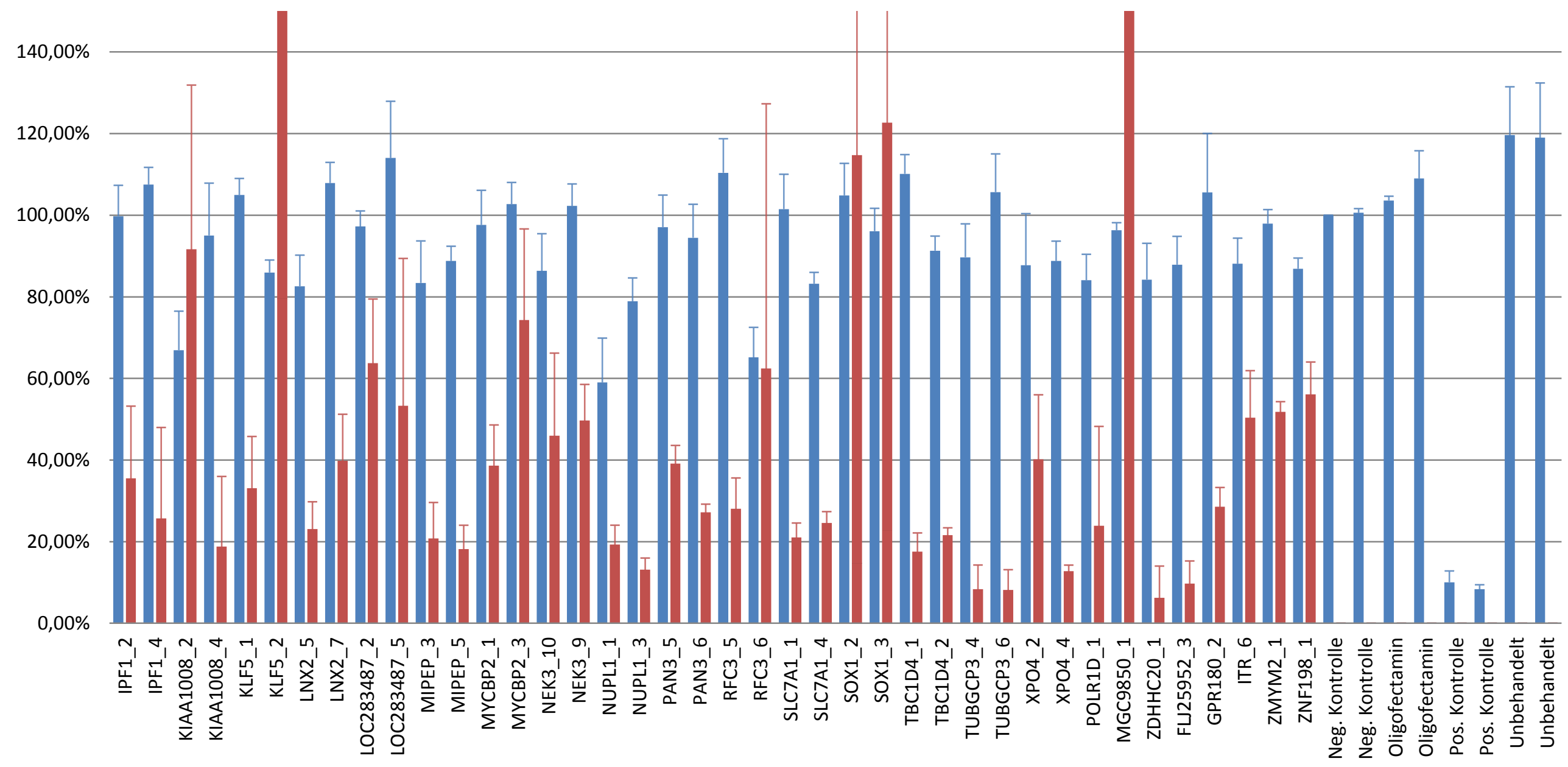

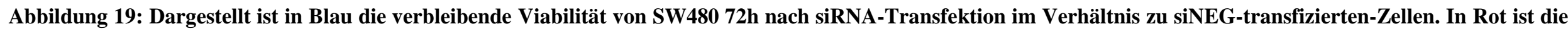
verbleibende mRNA-Expression des siRNA-Target-Gens 48h nach Transfektion abgebildet, ebenfalls im Verhältnis zu siNEG-transfizierten-Zellen. 


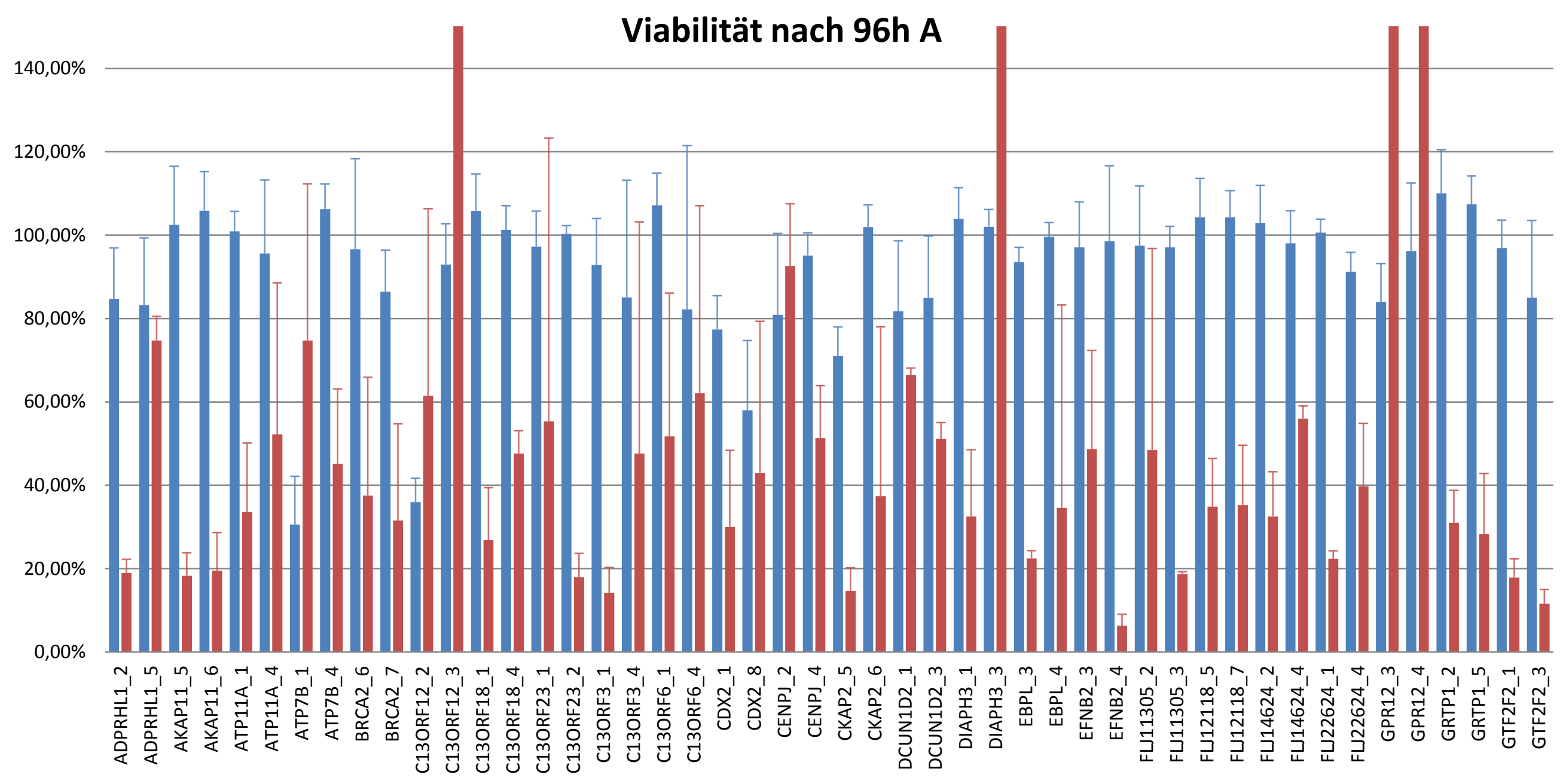

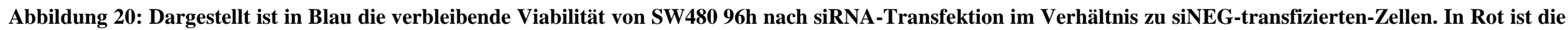
verbleibende mRNA-Expression des siRNA-Target-Gens $48 \mathrm{~h}$ nach Transfektion abgebildet, ebenfalls im Verhältnis zu siNEG-transfizierten-Zellen. 


\section{Viabilität nach 96h B}

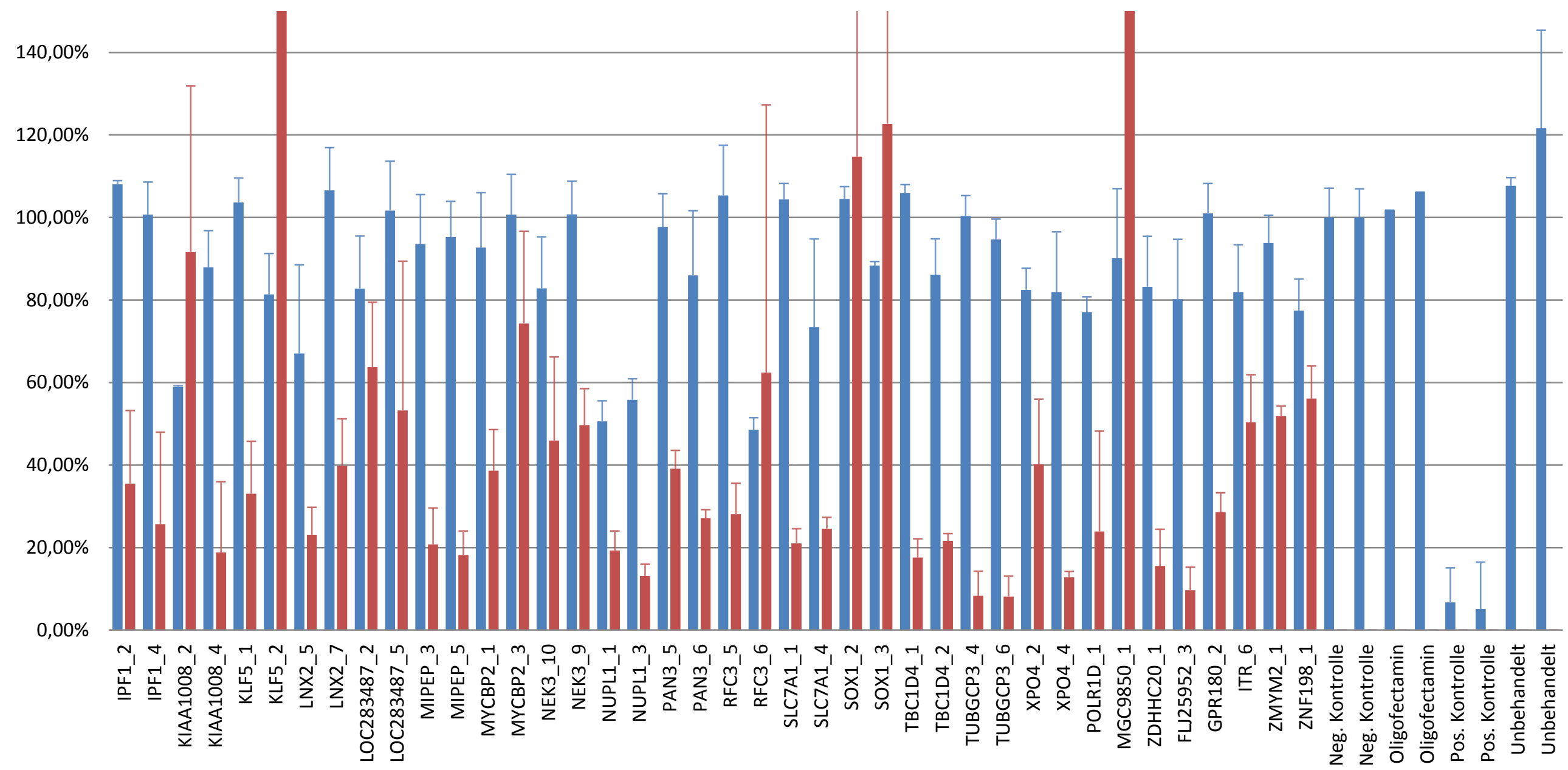

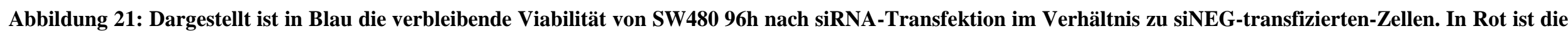
verbleibende mRNA-Expression des siRNA-Target-Gens 48h nach Transfektion abgebildet, ebenfalls im Verhältnis zu siNEG-transfizierten-Zellen. 
35 der 88 siRNAs, entsprechend 27 Genen, führten zu einem Knockdown ihres Zielgens von $>70 \%, 25$ siRNAs reduzierten das Expressionsniveau ihrer Ziel-RNA um >50\%. Weitere 17 siRNAs reduzierten die Expression ihres Zielgens um 20-50\%. Die restlichen siRNAs führten zu keiner Verringerung der Ziel-mRNA.

Bei den Genen NUPL1 (RNA Reduktion 80\% für siRNA_1 und 17\% für siRNA_3) und CDX2 (RNA Reduktion 57\% für siRNA_8 und 70\% für siRNA_1) führten beide siRNAs zu einer Viabilitätsreduktion von größer $20 \%$ nach $72 \mathrm{~h}$, diese Reduktion war nach $96 \mathrm{~h}$ sogar noch ausgeprägter.

Die Expression von LNX2 wurde durch die Transfektion mit siLNX2_5 um 77\% reduziert, die Viabilität ging auf $82 \%$ nach $72 \mathrm{~h}$ und auf $67 \%$ nach $96 \mathrm{~h}$ zurück. Die zweite siRNA (siLNX2_7) reduzierte die RNA-Expression nur um 40\%, es kam zu keiner Viabilitätsänderung. Durch siCKAP2_5 (RNA-Reduktion 85\%) kam es zu einer Reduktion der Viabilität von 24\% nach 72h und 29\% nach 96h. siCKAP2_6 (RNA Reduktion 60\%) führte zu keiner Änderung der Viabilität. Die Expression von SLC7A1 wurde von siRNA_4 auf $25 \%$ gesenkt, dies führte zu einem Verlust an Viabilität von $17 \%$ nach $72 \mathrm{~h}$, der nach $96 \mathrm{~h}$ noch ausgeprägter war (27\%). Durch die siRNA_1 kam es zu einer Reduktion der RNA von 80\%, dies hatte aber keinen Einfluss auf die Viabilität. POLRID knockdown durch siRNA_1 (RNA Reduktion um 76\%) führte zu einem Viabilitätsverlust von $16 \%$ nach $72 \mathrm{~h}$ und $23 \%$ nach 96h. Die zweite siRNA (siMGC9850_1) gegen POLR1D führte zu keiner messbaren Reduktion des mRNA Spiegels, allerdings reduzierte sie die Viabilität um 20\% nach $96 \mathrm{~h}$.

Die Expression von C13orf 12 wurde von der siC13orf12_2 auf 60\% gesenkt, es kam zu einer Viabilitätsreduktion von $34 \%$ nach $72 \mathrm{~h}$ und $65 \%$ nach $96 \mathrm{~h}$. siC13orf12_3 senkte das RNANiveau nicht, es kam nur zu einer Viabilitätsreduktion von $20 \%$.

siATP7B_1 führte zu einer mRNA Reduktion von 25\% und zu einer Viabilitätsreduktion von 54\% nach 72 und 69\% nach 96h. Die zweite siRNA gegen $A T P 7 B$, siATP7B_4 reduzierte die Ziel mRNA zwar bis auf 45\%, allerdings war die Viabilität nach $72 \mathrm{~h}$ und $96 \mathrm{~h}$ unverändert. siRFC3_6 reduzierte die mRNA Menge um 38\% und führte zu einer Viabilitätsreduktion von $35 \%$ nach $72 \mathrm{~h}$ und 52\% nach 96h. siRFC3_5 hingegen reduzierte die Ziel-RNA auf 35\% führte aber zu keiner Viabilitätsreduktion. 


\subsection{Zusammenfassung der Ergebnisse}

In einer erneuten Auswertung der ArrayCGH-Daten primärer kolorektaler Karzinome und 15 kolorektaler Zelllinien (In-Silico-Analyse) konnten im Bereich der Chromosomenbanden 13q12.1q12.3 und 13q34 zwei Regionen identifiziert werden, welche regelmäßige Zugewinne zeigten. Genexpressionsanalysen dieser Tumoren und Zelllinien zeigten, dass von den 72 annotierten Genen in diesen Regionen 48 überexprimiert sind. Die Expressionsmuster dieser 48 Gene sowie weiterer 19 Gene (ebenfalls hochreguliert auf 13q, aber außerhalb der Regionen liegend) wurden per PCR in 25 kolorektalen Karzinomzelllinien bestimmt. Diese Bestimmung diente sowohl der Validierung der Mikroarray-Ergebnisse mit einer unabhängigen Methode als auch der Analyse weiterer 10 Zelllinien. 44 der 67 Gene wurden sowohl per Mikroarray als auch per qRT-PCR in Tumoren und Zelllinien als überexprimiert gefunden. In einem „Loss-of-function-Screen“ wurde die mRNA dieser Gene durch siRNAs dereguliert. Für 13 Gene führte der siRNA-vermittelte Knockdown zu einem Viabilitätsverlust von $>20 \%$. 


\section{Diskussion}

In dieser Arbeit wird die Identifikation neuer potentieller Onkogene sowie möglicher therapeutischer Zielgene auf Chromosom 13q beschrieben. Das kolorektale Karzinom zeigt ein spezifisches Muster an chromosomalen Aberrationen, welche im Verlauf der Karzinogenese akkumulieren. Typischerweise finden sich Zugewinne der Chromosomen 1, 7, 8q, 13 und 20 sowie Verluste der Chromosomen 4, 8p und 18q (Ried et al. 1996; ParedesZaglul et al. 1998; Hermsen et al. 2002). Für die meisten dieser Aberrationen konnten bereits Zielgene identifiziert werden, beispielsweise liegt das MYC-Onkogen auf dem Chromosomenarm 8q, welcher eine hohe Rate an chromosomalen Zugewinnen beim kolorektalen Karzinom zeigt (Grade et al. 2007). Für den Zugewinn von Chromosom 13q konnten bisher allerdings noch keine solche Zielgene gefunden werden. Zuerst sollten daher durch die erneute Auswertung von ArrayCGH-Daten Regionen auf 13q identifiziert werden, welche regelmäßige Zugewinne bei kolorektalen Tumoren zeigten. Da der chromosomale Zugewinn von Bereichen der DNA zumeist mit einer Überexpression der in diesen Bereichen liegenden Gene einhergeht (Monni et al. 2001; Pollack et al. 2002), wurden anschließend mikroarraybasierte Genexpressionsanalysen und ArrayCGH-Daten der selben Tumoren integriert, um diejenigen Gene aufzudecken, welche in diesen Regionen liegen und auf RNAEbene im Vergleich zu normaler Mukosa überexprimiert sind. Per PCR konnte für einen Teil dieser Gene gezeigt werden, dass sie auch in einem Panel von 25 kolorektalen Zelllinien hochreguliert sind.

Nach der Identifikation von Genen, welche sowohl in Tumoren als auch Zelllinien auf DNA und Transkriptomebene Zugewinne aufwiesen, sollten sie als nächstes auf ihre funktionelle Relevanz für die Tumorzelle überprüft werden. Mithilfe eines RNAi basierten „Loss-offunction"-Screens und anschließender Messung der zellulären Viabilität kann die Relevanz einzelner Gene für die proliferative Aktivität von Tumorzellen oder deren Überleben getestet werden. In ähnlichen Screens konnten bereits mehrere mögliche Onkogene sowie therapeutische Zielgene gefunden werden (Bol und Ebner 2006; Ngo et al. 2006; Schlabach et al. 2008; Luo et al. 2009; Grade et al. 2011). Dementsprechend wurden die gefundenen, in zugewonnenen Regionen liegenden und in Tumoren und Zelllinien hochregulierten Gene per siRNA ausgeschaltet und die Auswirkungen des Expressionsverlustes der einzelnen Gene 
untersucht. Nachfolgend sollen die einzelnen experimentellen Schritte sowie die gefundenen Gene diskutiert werden.

\subsection{Interpretation der experimentellen Ergebnisse}

\subsubsection{Identifikation zweier Regionen auf 13q mit regelmäßigen Zugewinnen}

Der Zugewinn von Chromosom $13 q$ ist ein typisches, wenn auch spätes Ereignis der kolorektalen Karzinogenese (Paredes-Zaglul et al. 1998). Diverse Studien beschreiben einen Zugewinn von Chromosom 13q bei dem kolorektalen Karzinom (Ried et al. 1996; Hermsen et al. 2002; Ghadimi et al. 2003). In unserem Kollektiv zeigte sich ein ähnliches Bild: Von den 31 primären Kolontumoren zeigten 61\% Zugewinne von Teilen des Chromosomenarmes 13q, bei den kolorektalen Zelllinien waren es $60 \%$. Diese Daten wurden bereits teilweise von Camps et al. publiziert (Camps et al. 2008; Camps et al. 2009).

Der regelmäßige Zugewinn von Teilen des Chromosoms 13 ist umso erstaunlicher, da in anderen Tumorentitäten Verluste beschrieben werden, so ist ein Verlust oder die Mutation des RB1-Tumorsupressorgenes auf 13q14.2 Auslöser des Retinoblastoms (Corson et al. 2007). Ebenso kommt es zu chromosomalen Verlusten in der Karzinogenese des malignen Melanoms, des Nierenzellkarzinoms sowie des Osteosarkoms (Ozaki et al. 2002; Arai et al. 2008; Pryor et al. 2011). Yokota et al. beschreiben, dass sie sowohl beim Lungenkarzinom, als auch in einigen Fällen beim kolorektalen Karzinom Verluste von Teilen des Chromosom 13 in Metastasen der Tumoren fanden (Yokota et al. 1991). Scheinbar ist daher nicht der Zugewinn des gesamten Chromosomenarmes 13q entscheidend, sondern der Zugewinn einzelner Regionen. Die ArrayCGH ermöglicht es, durch ihre hohe Auflösung, genau die Bereiche auf 13q einzugrenzen, die in einer Mehrheit der Tumore Zugewinne oder sogar Amplifikationen hatten, aber in keinem Tumor Verluste aufweisen. In der Summation aller ArrayCGH-Daten zeigten sich zwei Regionen, nämlich 13q12.1-13q12.3 und 13q34 welche genau diesen Kriterien entsprachen, siehe Abbildung 11 (Summationsplot).

Neklason et al. fanden in ihrer Studie bei einer Familie der Utah Population Database mit einem erhöhten Vorkommen von kolorektalen Karzinomen eine Verbindung zwischen kolorektalen Adenomen und Karzinomen und Zugewinnen der Region 13q22.1-13q37.3 (Neklason et al. 2010). Douglas et al. entdeckten in Ihrer Untersuchung an 9 kolorektalen Karzinomzelllinien per ArrayCGH die Region 13q12.13-13q12.2, welche regelmäßig Amplifikationen aufwies, was damit unsere Daten bestätigt (Douglas et al. 2004). Die Autoren vermuteten, dass zwei in diesem Amplikon liegende Gene FLT3 und FLT1 die 
Zielgene dieser Aberration sein könnten und möglicherweise von funktioneller Bedeutung für die Entstehung des kolorektalen Karzinoms seien könnten. Unsere Expressionsdaten der Primärtumoren zeigten allerdings keine signifikante Überexpression dieser beiden Gene (siehe unten), aber trotzdem bestätigen diese beiden Studien die Wichtigkeit von Zugewinnen auf Chromosom 13q. Eine weitere Studie beschreibt ein Amplikon bei 13q12.13-13q12.2, also in direkter Nachbarschaft zu dem von uns gefundenen (Firestein et al. 2008). Diese Studie wird weiter unten genauer diskutiert.

\subsection{2 Überexprimierte Gene in den beiden Regionen}

Da chromosomale Zugewinne zumeist mit einer vermehrten Expression der auf dieser Region liegenden Gene einhergehen (Tsafrir et al. 2006; Myllykangas et al. 2007) wurden bereits erstellte Genexpressionsarrays erneut mit der Zielsetzung ausgewertet, in diesen beiden Regionen überexprimierte Gene zu finden. In dieser Studie konnten diverse zwischen den Tumoren und der normalen Mukosa differentiell exprimierte Gene gefunden werden. Auf Chromosom 13 waren insgesamt 597 Proben des Arrays signifikant dereguliert ( $>>0,0001)$ und damit mehr als bei der geringen Gendichte auf Chromosom $13 \mathrm{zu}$ erwarten gewesen wären (Dunham et al. 2004). Dies weist auf die Bedeutung von Chromosom 13 für die Entstehung des kolorektalen Karzinoms hin.

\subsubsection{Genexpressionsprofil der Zelllinien und Mikroarray-Validierung}

Mithilfe der semiquantitativen Real-Time-PCR wurden die Expressionsmuster der 48 in den Primärtumoren überexprimierten Gene im Bereich von 13q12.1q12.3 und 13q34 sowie weiterer 19 interessanter, hochregulierter Gene auf Chromosom 13q, welche aber außerhalb der beiden Regionen liegen, in 25 kolorektalen Zelllinien bestimmt.

Genexpressionsarrays ermöglichen es, von einer großen Anzahl Gene die Expressionslevel zu bestimmen und so Zielgene $\mathrm{zu}$ identifizieren, die zwischen Tumor und normalem Vergleichsgewebe differentiell exprimiert sind. Die große Menge an untersuchten Genen in Mikroarray-Experimenten führt allerdings dazu, dass die Anzahl an potentiell falsch positiven Zielgenen steigt. Deshalb ist, neben einer strengen statistisch-/mathematischen Auswertung der Arrayergebnisse, die Validierung der per Array gemessenen Expressionsunterschiede mit einer unabhängigen Methode entscheidend. Eine Methode zur Validierung von differentiellen mRNA-Werten bietet die semiquantitative Real-Time-PCR (Rajeevan et al. 2001a).

Die PCR-Primer zur Validierung der Mikroarrays wurden so gewählt, dass sie nach Möglichkeit in einem anderen Exon des Zielgens als die entsprechende Probe des 
Mikroarrays lagen. Darüber hinaus wurde darauf geachtet, dass die Primer alle SpleißVarianten eines Genes abdecken. War dies nicht möglich, wurden mehrere Primerpaare verwendet (siehe POLRD1). Im Gegensatz dazu deckten einige der Mikroarray-Proben nicht alle Varianten eines Gens ab.

Dieses experimentelle Design wurde absichtlich gewählt, auch wenn es zu einer schlechteren Korrelation zwischen Array und PCR Daten (66\%) als in anderen Studien (Rajeevan et al. 2001b) führte. Dies ist darauf zurückzuführen, dass bei dem verwendeten Design unterschiedliche Sequenzen desselben Gens gemessen wurden und nicht, wie in anderen Studien, exakt die durch den Array vorgegebene Sequenz. Rajeevan et al. zum Beispiel achteten darauf, dass die von den PCR-Primern amplifizierte Region mit den Proben des Genexpressionsarrays übereinstimmt. Dadurch können sie bis zu 71\% ihrer per Array identifizierten Gene validieren. Da es das Ziel der vorliegenden Arbeit war, Gene zu identifizieren, welche in den Primärtumoren und in den Zelllinien hochreguliert sind, war es entscheidend sicher zu stellen, dass ein Gen in all seinen Spleiß-Varianten in den Tumoren hochreguliert ist. Dies war von Nöten, da die siRNAs, welche später zur Genderegulation verwendet wurden, nicht zwangsläufig die durch den Array detektierten Varianten deregulieren. Auch wenn die Möglichkeit besteht, dass auf diese Weise einige interessante Gene oder einzelne Spleiß-Varianten fälschlicherweise aussortiert wurden, ermöglichte die Doppelbestimmung per PCR und Array eine weitere Reduktion der Zielgene und erhöhte die Wahrscheinlichkeit, relevant deregulierte Gene zu finden. In unserem Fall, reduzierte sich die Zahl der Gene von Initial 67 per Array als überexprimiert gefundenen auf 44 auch per PCR validierte. Neben der Auswahl der Zielsequenzen trug ebenfalls die Erhöhung der Anzahl an untersuchten Zelllinien zur Reduktion der Gene bei.

\subsubsection{Viabilitätsscreen}

Differentiell zwischen Tumor und Mukosa exprimierte Gene können an der Karzinogenese beteiligt sein. Aufgrund der hohen Anzahl an Zielgenen, die in einer arraybasierten Analyse gefunden werden, muss vor einer tiefgreifenden Analyse ihrer Funktion eine Vorauswahl getroffen werden und die Menge der Gene auf die vielversprechendsten reduziert werden. Unter der Annahme, dass die Überexpression eines Gens mit onkogenem Potential zu einer verstärkten Viabilität, das heißt zu verlängertem Überleben, schneller Proliferation und Wachstum sowie zu Apoptoseresistenz führt, wurden die in den Array-Untersuchungen gefundenen Gene in einem ,loss-of-function-Screen“ in einem Zelllinienmodell ausgeschaltet. Da die einzelne Messung all dieser Parameter in einer Screen-Analyse sehr aufwendig wäre, 
wurde zur Selektion der Kandidaten-Gene lediglich die Stoffwechselrate der Zellen gemessen. Diese sank bei verminderter Proliferation sowie Verlust von Zellen, als indirekter Marker für Apoptose und Wachstumsinhibierung. Unter Anwendung dieser Strategie konnte unsere Arbeitsgruppe bereits zwei Gene identifizieren, die potentiell die Entstehung des kolorektalen Karzinoms begünstigen (Grade et al. 2011).

Ähnliche Screens wurden schon häufiger angewendet. Ngo et al. schalteten mit einem RNAibasierten System in B-Zell-Lymphomzelllinien 2500 Gene aus und maßen die verbleibende Viabilität in einer Durchflusszytometrie-Analyse. Auf diese Weise konnten sie die Bedeutung des NF-kB Signalweges für das B-Zelllymphom aufdecken (Ngo et al. 2006). Schlabach et al. nutzten eine ähnliche Methode, auch sie transfizierten Zellen mit shRNAs und konnten eine Viabilitätssenkung für bestimmte Gene beobachten. Allerdings wurden in diesem Screen nicht nur eine shRNA pro Gen verwendet, sondern mehrere. Dadurch erhofften sich die Autoren weniger unspezifische Effekte (Schlabach et al. 2008).

Auf diese Weise können große Bereiche des humanen Transkriptoms untersucht werden. Der Nachteil dieser Screeningmethoden allerdings ist, dass sehr viele einzelne Experimente mit sehr vielen RNAi-Konstrukten durchgeführt werden müssen, Schlabach et al. verwendeten in ihrer Analyse zum Beispiel 42000 shRNAs. Für die Analyse des gesamten Transkriptoms mit je drei RNAi-Konstrukten pro Gen würden daher $>100000$ Konstrukte benötigt. Durch die Integration der ArrayCGH-Daten mit Genexpressionsdaten gelang es uns, interessante Bereiche auf DNA und Transkriptomebene einzugrenzen. Durch diese Vorauswahl mussten in unser Studie nur 44 vielversprechende Gene untersucht werden, die Menge an Experimenten konnte auf diese Weise sehr stark gesenkt werden.

Bei 13 der 44 Gene kam es zu einem Viabilitätsverlust der Zellen von größer als 20\%. Dies ist ein Hinweis auf die funktionelle Relevanz des Genes in einer Tumorzelle. Die Gene werden im Einzelnen weiter unten diskutiert.

\subsubsection{Bestimmung der verbleibenden mRNA-Menge}

Zur Bestimmung des mRNA-Niveaus eines Zielgens wurde 48h nach der siRNA-Transfektion RNA aus den Zellen isoliert und eine qRT-PCR durchgeführt. Leider sind die Ergebnisse nicht immer schlüssig. So wird das Expressionsniveau von ATP7B durch siRNA_1 um 20\% gesenkt, siRNA_4 senkt das mRNA Niveau um 50\%. Trotzdem verursacht nur siRNA_1 einen Viabilitätsverlust, siRNA_4 nicht. Ähnliches kann auch bei RFC3, CDX2 und KLF5 beobachtet werden: Eine stärkere gemessene mRNA-Reduktion geht nicht zwangsweise mit 
einem ausgeprägteren Phänotyp einher. Eine Korrelation zwischen mRNA-Niveau und Phänotyp zeigt sich hingegen bei $L N X 2, C K A P 2$ und C13ORF12.

Eine Möglichkeit für die schlechte Korrelation könnte ein suboptimales experimentelles Design sein. Die zu messenden Genexpressionsunterscheide waren nicht sehr groß und die Detektion daher sehr fehleranfällig. Dazu kommt, dass es erhebliche Schwankungen zwischen den einzelnen Replikaten gab, teilweise von größer 40 \%. Damit waren die Schwankungen zwischen den drei Replikaten (unterschiedliche Transfektionen derselben siRNA) sehr groß. In dem hier verwendeten Setup wurden auf einer PCR-Platte die Ct-Werte eines einzelnen Gens bestimmt. Dazu wurde ein Mastermix erstellt, der neben den PCR-Reagenzien und dem Sybr-Green-Farbstoff ein Primer-Paar enthielt. Dieser Mastermix wurde auf einer 96-WellPlatte verteilt und zu jedem Well eine cDNA Probe zugegeben. Dies führte dazu, dass neben der unterschiedlichen Expression der Gene in den einzelnen cDNA Proben, ebenfalls der Pipettierfehler bei der Zugabe der cDNA das Ergebnis beeinflusste.

Um diese Probleme zu umgehen, wurde im Rahmen dieser Studie ein neues Design für die Validierung einer Genderegulation per PCR entwickelt und erprobt. Die cDNA wurde anstelle der Primer in den Mastermix gegeben. Durch das größere Volumen konnte sichergestellt werden, dass in jedem Well die gleiche Menge an cDNA war, und somit „Housekeeping“Gen und Zielgen mit derselben cDNA-Konzentration gemessen werden konnten. So konnten eventuelle Ungenauigkeiten normalisiert werden.

Anschließend wurden die Primer zugegeben, da diese im Überschuss in eine PCR-Reaktion eingesetzt werden, haben Abweichungen im Volumen keinen Einfluss auf das Ergebnis der Reaktion. Im Ergebnis zeigte sich, dass die Standardfehler stark gesenkt und genauere Bestimmungen der mRNA-Veränderungen gemacht werden konnten. Abbildung 22 zeigt ein nach dieser Studie durchgeführtes Experiment, in dem das neue Setup angewendet wurde. Es kam zu einer viel geringeren Standardabweichung und die Genderegulation konnte genauer und reproduzierbarer gemessen werden. 


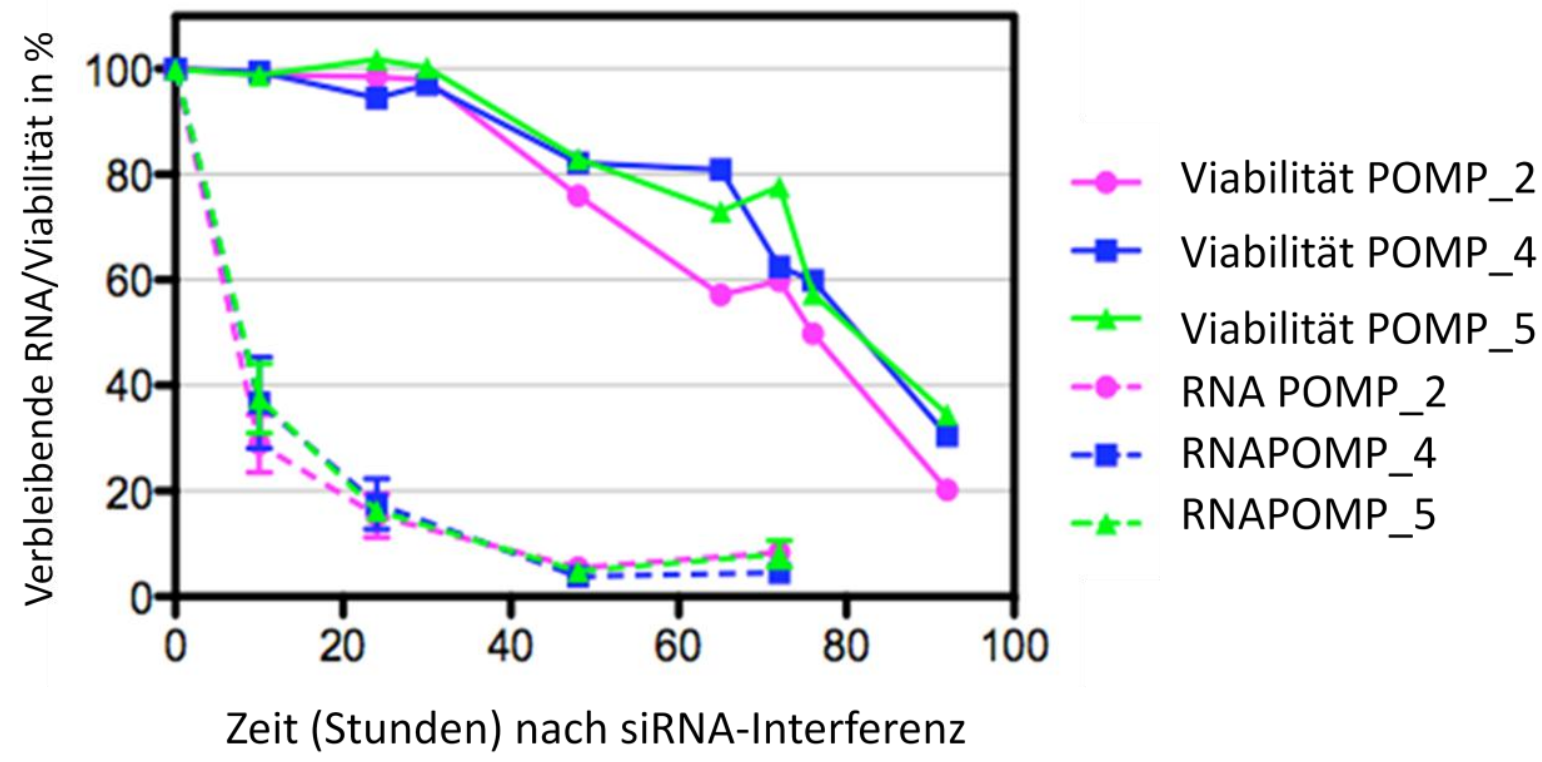

Abbildung 22: Veränderung des mRNA-Expressionsniveaus von POMP nach siRNA-Interferenz. Diese wurden mit dem im Laufe dieser Arbeit entwickelten PCR-Setup gemessen.

\subsubsection{Vergleich mit anderen Studien}

Firestein et al. (2008) versuchten ebenfalls neue Onkogene zu identifizieren. Sie wollten Gene finden, welche sowohl die Aktivität von ß-Catenin als auch die Proliferationsrate von kolorektalen Zelllinien beeinflussen. Zunächst klonierten sie einen Reporter (TOPFlash/FOP-Flash) in die kolorektale Zelllinie DLD1, welcher die transkriptionelle Aktivität des ß-Catenin-Komplexes anzeigt. Anschließend führten sie einen ersten Screen durch und schalteten per RNAi 1000 Gene in den DLD1-Reporterzellen aus. Dabei konnten sie 34 Gene identifizieren, deren Ausschalten die Aktivität von ß-Catenin reduzierte. In einem zweiten Screen, der dem unseren im Prinzip sehr ähnlich ist, schalteten sie die 1000 Gene per RNAi in HCT116 aus und fahndeten nach Genen, deren Deregulation zu einer Hemmung der Proliferation von Tumorzellen führte. Insgesamt fanden sie 9 Gene, deren Expression sowohl Einfluss auf die $\beta$-Catenin-Aktivität als auch auf die Proliferation von Kolontumorzellen hatte. Eines dieser 9 Gene war die Kinase CDK8. In einem nachfolgenden ArrayCGHExperiment konnten sie zeigen, dass CDK8 in einem Amplikon auf 13q liegt, welches in ihrer Untersuchung in $61 \%$ der Tumore Zugewinne zeigte. Dieses Amplikon überschneidet sich teilweise mit der ersten von uns gefundenen Region (13q12.1-13q12.3), in dem gemeinsamen Bereich liegen 11 Gene. Die Gene USP12, RPL21, RAS11A, MTIF3, IPF1, GSH1, FLT3 und GPR12 wurden sowohl von Firestone et al. als auch von uns in der zugewonnenen Region als hochreguliert gefunden. CDX2, LNX2 und POLR1D wurden ebenfalls in beiden Studien gefunden und aufgrund des Viabilitätsverlustes nach Ausschaltung in unserem Screen als 
potentielle Onkogene identifiziert. Die Kinase $C D K 8$, welche von Firestone et al. weiteruntersucht wurde, lag direkt neben dem von uns beschriebenen Amplikon, und wir konnten keine signifikante Hochregulation in der Gesamtheit der Primärtumoren feststellen. Eine mögliche Erklärung könnte sein, dass von Firestone et al. zwei Mikrosatelliten-instabileZelllinien für die Identifikation von Zielgenen verwendet wurden, während die meisten kolorektalen Tumoren Mikrosatelliten-stabil sind. Firestone et al. schlussfolgern, dass CDK8 das Zielgen des Zugewinnes von 13q12.13-13q12.2 ist, den anderen Genen in diesem Bereich wurde keine Bedeutung zugemessen. Allerdings zeigen unsere Daten, dass weitere Gene zusätzlich zu CDK8 eine wichtige Rolle für den Tumor spielen. LNX2 zum Beispiel liegt in unmittelbarer Nähe von $C D K 8$ (in beiden Studien im Bereich der regelmäßigen Zugewinne), ist auf Transkriptomebene überexprimiert, und seine Ausschaltung führt zu einem starken Viabilitätsverlust. Die Studie von Firestone et al. zeigt die wichtige Rolle von Chromosom 13q beim kolorektalen Karzinom und sie bestätigt ebenfalls, dass die Region um Chromosom $13 q 12.1$ sehr interessant ist.

\subsection{Diskussion der potentiellen neuen Onkogene}

\subsubsection{ATP7B (,ATPase, $\mathrm{Cu}^{2+}$ transporting, beta polypeptide ${ }^{6}$ )}

Das Gen der „B-Peptid der $\mathrm{Cu}^{2+}$ transportierenden ATPase“ (ATP7B) liegt nicht in einer der beiden Regionen auf Chromosom 13q, sondern auf 13q14.3. In den Primärtumoren war es durchschnittlich 3-fach überexprimiert, allerdings in der Gesamtheit der Tumoren nicht signifikant $(\mathrm{p}=0,1625)$. Bei genauerer Betrachtung zeigte sich, dass einzelne Tumoren eine starke Überexpression, andere keine oder sogar einen Herrunterregulation zeigten. In den Zelllinien zeigten ebenfalls nur SW48, COLO320DM, SW403 und SW1463 eine sehr ausgeprägte (>5-fach) Überexpression. Trotz der nicht signifikanten Überexpression über die Gesamtheit der Tumoren wurde $A T P 7 B$ aufgrund der sehr hohen Überexpression in einer Subgruppe der Tumoren und Zelllinien in den weiteren Screen aufgenommen. Eine siRNAvermittelte mRNA-Reduktion von nur $30 \%$ führte zur stärksten Viabilitätsreduktion dieser Untersuchung (70\%).

Physiologischerweise ist $A T P 7 B$, auch Morbus Wilson-Gen genannt, für die Aufrechterhaltung der Kupferhomöostase in Zellen verantwortlich. Aufgrund seiner Funktion als Kupfertransporter ist ATP7A ebenfalls für die Elimination platinbasierter Chemotherapeutika verantwortlich. Nakayama et al. konnten bei Patientinnen mit einem Ovarialkarzinom zeigen, dass hohe mRNA- und Protein-Level von ATP7B ein Marker für ein 
schlechtes klinisches Ergebnis einer Cisplatin basierten Chemotherapie sind (Nakayama et al. 2004). Chen et al. berichten, dass $A T P 7 B$ in Lungenkarzinomen ebenfalls überexprimiert ist und mit dem Ansprechen auf platinbasierte Chemotherapie korreliert (Chen HH et al. 2011). Für das kolorektale Karzinom konnten Martinez-Balibera et al. zeigen, dass hohe mRNA- und Proteinlevel von $A T P 7 B$ bei Patienten mit einem fortgeschrittenen Adenokarzinom unter Oxaliplatin/5-FU Therapie, zu einer kürzeren Zeit ohne Fortschreiten der Erkrankung führten (Martinez-Balibrea et al. 2009). In unserem Kollektiv scheint es ebenfalls Patienten und Zelllinien mit unterschiedlichen mRNA-Niveaus von $A T P 7 B \mathrm{zu}$ geben. Scheinbar ist für Tumorzellen die Aufrechterhaltung des Kupferstoffwechsels essentiell, da eine Deregulation von $A T P 7 B$ zu einem starken Viabilitätsverlust führte.

\subsubsection{POMP (,proteasome maturation protein")}

Das Proteasomreifungsprotein (POMP) liegt in der ersten Region auf Chromosom 13q und war in allen Zelllinien überexprimiert. Zudem fand sich in den Primärtumoren ebenfalls eine Hochregulation. Die siRNA-vermittelte mRNA-Reduktion um $40 \%$ führte zu einer starken Reduktion der Viabilität (65\%). In der Literatur ist eine Assoziation von POMP und Malignomen noch nicht beschrieben. Jedoch ist POMP als Untereinheit des 26s Proteasoms bekannt. Dieses Proteasom spielt eine entscheidende Rolle bei dem Abbau verschiedener intrazellulärer Proteine, darunter Zellzyklus- und Apoptoseregulatoren. Eine Deregulation des Proteasom-vermittelten Proteinabbaus scheint daher onkogenes Potential zu besitzen (Mani und Gelmann 2005). Der Wirkstoff Bortezomib inhibiert die Funktion des Proteasoms und wird momentan klinisch in der Zweitlinien-Therapie des Plasmozytoms eingesetzt (Richardson et al. 2005; Chen D et al. 2011). Erste präklinische Studien weisen auf eine Wirksamkeit von Proteasom-Inhibitoren auch beim kolorektalen Karzinom hin (O'Neil et al. 2010). Unsere Ergebnisse zeigen, dass die Deregulation eines einzelnen, in Tumorzellen überexprimierten Bestandteils des Proteasoms zu einer starken Viabilitätsreduktion führen. Eine genauere Evaluation des onkogenen Potenzials sowie der Funktion von POMP scheint, gerade im Hinblick auf die Entwicklung von Proteasominhibitoren, vielversprechend zu sein.

\subsubsection{RFC3 (,,replication factor C (activator 1) 3“)}

Der Replikationsfaktor C (Aktivator 1) 3 (RFC3) liegt auf 13q13.2 und kodiert für ein $38 \mathrm{k}$ großes Protein, das eine Untereinheit des Replikationsfaktor-C-Komplexes ist. Dieser Komplex ist essentiell für die DNA-Elongation durch die DNA-Polymerasen Delta und Epsilon (Majka et al. 2004). Kim et al. untersuchten Kolonkarzinome und fanden, dass 25\% 
der MSI-H eine inaktivierende Mutation von RFC3 aufwiesen, aber kein MSS Tumor. Darüber hinaus berichten sie, dass RFC3 in $65 \%$ der untersuchten Tumoren herunterreguliert war (Kim et al. 2010). Diese Daten wiedersprechen unseren Ergebnissen: Das Expressionsniveau von RFC3 lag in der Mehrheit der Primärtumoren weit über dem der Mukosa (durchschnittlich 5-fach höher) und auch in allen Zelllinien zeigte sich eine starke Überexpression. RNA-Interferenz führte in SW480 (RFC3 14-fach im Vergleich zu normaler Mukosa hochreguliert) zu einer Viabilitätsreduktion von 50\%, bei einer RNA Abnahme von 40\%. Koch et al. identifizierten RCF3 als ein c-MYC-assoziiertes Protein (Koch et al. 2007). Diese Interaktion mit einem bekannten Onkogen, die starke Überexpression in Tumoren und die Viabilitätsreduktion nach Ausschaltung weisen auf eine mögliche pro-onkogene Rolle von RFC3 für die kolorektale Tumorzelle hin.

\subsubsection{NUPL1 (,nucleoporin like $1^{\circ}$ )}

Über NUPL1 ist wenig bekannt, es ist dem Ratten-Nucleusporen-Protein p58 ähnlich und Teil des nukleären Poren-Komplexes. Alle Moleküle, die in oder aus dem Zellkern transportiert werden, passieren diesen Komplex (Hu und Gerace 1998). In unseren Analysen zeigte sich, dass die NUPL1-mRNA sowohl in den Primärtumoren als auch in den meisten Zelllinien hochreguliert ist. RNA-Interferenz führte für beide siRNAs zu einer Abnahme des NUPL1mRNA-Levels von mehr als 80\%. Dies führte zu einer 50\%igen Minderung der Viabilität von SW480 Zellen. NUPL1 scheint für kolorektale Zellen somit essentiell zu sein. Der starke Verlust an Viabilität und die hohe Überexpression könnten es als therapeutisches Ziel interessant machen. Allerdings müssen zunächst weitere Studien durchgeführt werden, um die der Viabilitätsreduktion zugrunde liegenden Signalwege aufzudecken. Desweiteren sollten die Auswirkungen einer Ausschaltung von NUPL1 in somatischen Zellen getestet werden, um einen Eindruck von möglichen Nebenwirkungen zu bekommen.

\subsubsection{CDX2 (,caudal type homeobox 2“)}

CDX2 liegt in unmittelbarer Nähe der Regionen auf Chromosom13q. Es zeigte eine 5-fache Überexpression in einigen der Primärtumoren $(\mathrm{p}<0,05)$ im Vergleich $\mathrm{zu}$ der korrespondierenden Mukosa. In den Zelllinien zeigten nur 9 der 25 Zelllinien eine Überexpression von $C D X 2,12$ von 25 hatten eine niedrigere Expression als das Referenzgewebe. SW480 hat eine 10-fach geringere Expression von CDX2 als normale Mukosa, trotzdem konnte per RNA-Interferenz das Expressionsniveau um weitere 50\% gesenkt werden, was zu einer Viabilitätsreduktion von $40 \%$ führte. 
Ee et al. konnten per Immunhistochemie in kolorektalen Adenomen und Karzinomen nachweisen, dass die Expression von CDX2 auf Proteinebene im Verlauf der kolorektalen Karzinogenese abnimmt (Ee et al. 1995). Hinoi et al. untersuchten kolorektale Zelllinien und fanden, dass einige Zelllinien eine reduzierte Expression von CDX2 zeigen (Hinoi et al. 2003). Ähnliches konnte auch in unseren Daten beobachtet werden, CDX2 war in 12 Zelllinien herunterreguliert. Kaimaketchiv et al. demonstrieren, dass die Expression von CDX2 in frühen Adenokarzinomen hochreguliert ist, aber mit Fortschreiten der Tumorgenese wieder verloren geht und somit als histologischer Marker für frühe Adenokarzinome verwendet werden kann (Kaimaktchiev et al. 2004). Daher scheint CDX2 trotz der Überexpression in einigen Tumoren kein universelles Ziel für einen Therapieansatz zu sein. Die hohe Viabilitätsreduktion lässt sich eventuell dadurch erklären, dass sehr geringe Expressionslevel von CDX2 essentiell für das Überleben von Zellen sind.

\subsubsection{DIS3 (,mitotic control homolog (S. cerevisiae) ${ }^{6)}$}

DIS3 liegt auf Chromosom 13q22.1 und war in 20 der 25 Zelllinien überexprimiert (1,5-fach erhöht). Die Zelllinie Colo320DM hat eine fokale Amplifikation und zeigte daher die höchste Expression von DIS3. Fast 50\% der untersuchten Primärtumore zeigte eine Überexpression von DIS3. Bei diesem Gen handelt es sich um eine Untereinheit des Exosoms, ein Komplex der in dem intrazellulären RNA-Stoffwechsel eine herausragende Rolle spielt. Interessanterweise scheint dieser Komplex eines der Ziele des Antimetaboliten 5-Fluoruracil zu sein, der in der Therapie des kolorektalen Karzinoms verwendet wird (Lum et al. 2004). Murakami et al. beschreiben in ihrer Studie, dass die Ribonuklease-Aktivität von DIS3 für das Fortschreiten der Mitose sowie die Formation des Kinetochor-Komplexes benötigt wird (Murakami et al. 2007). Diese Assoziation mit der Zellzyklusprogression spricht für die onkogene Funktion von DIS3. Liang et al. untersuchten die kolorektalen Zelllinien SW480 und SW620, die sich in dem Potential Metastasen bilden zu können, unterscheiden. Eines der Gene, welches mit hohem Metastasierungspotential einhergeht ist DIS3 (Liang et al. 2007). Chapman et al. entdeckten allerdings bei der Sequenzierung von 38 multiplen Myelomen in vier Fällen eine deaktivierende Mutation von DIS3. Dies widerspricht zumindest in dieser Entität einer Funktion als Onkogen (Chapman et al. 2011).

\subsubsection{LNX2 (,,ligand of numb-protein X 2")}

LNX2 liegt auf Chromosom 13q12.2 und damit im Bereich der Regionen mit regelmäßigen genomischen Zugewinnen in den Primärtumoren. Es war sowohl in den Tumoren als auch in 
den Zelllinien nur moderat überexprimiert. Durch RNA-Interferenz kam es in SW480 zu einem Viabilitätsverlust.

LNX2 kodiert ein Protein, welches als Ubiquitin-Ligase funktionieren kann. Hohe Level von LNX2 verursachen einen ubiqiquitinvermittelten proteasomischen Abbau von NUMB, dies führt zu einer Aktivierung des NOTCH-Signalweges (Nie et al. 2002). Eine Aktivierung des NOTCH Signalweges scheint für das onkogene Potential von kolorektalen Tumorzellen wichtig zu sein. So konnte in Kolon-Adenomen eine anormal hohe NOTCH-Aktivität gezeigt werden (Miyamoto und Rosenberg 2011). In APC-defekten Mäusen führt die Aktivierung des NOTCH-Signalweges zur Adenombildung. Van Es et al. zeigten, dass die Inhibition des NOTCH-Signalweges zu einer Differenzierung von Adenomzellen führte (van Es et al. 2005). Da sich in unseren Experimenten nach Ausschaltung von LNX2 in kolorektalen Zelllinien eine starke Viabilitätsreduktion zeigte, vermuten wir, dass LNX2 über den NOTCHSignalweg die Tumorzellen beeinflusst. Weitere Experimente müssen zeigen, ob es zu einer Veränderung von Genen des NOTCH-Signalwegs kommt und ob sich der von van Es et al. beschriebene Effekt der Ausdifferenzierung von Adenomzellen auch nach LNX2 Deregulation einstellt.

\subsubsection{CKAP2 (, , cytoskeleton associated protein 2") / TMAP (,cytoskeleton associated protein 2")}

Das mikrotubuli-assoziierte Protein CKAP2, auch tumor-assoziiertes mikrotubuli-assoziiertes Protein (TMAP) genannt, ist in den Primärtumoren 4,5-fach überexprimiert $(\mathrm{p}<0,05)$, ebenso war es in allen 25 Zelllinien stark hochreguliert, in SW480 sogar um das 18-fache im Vergleich zu normaler Mukosa. RNA-Interferenz gegen dieses Gen (85\% Herrunterregulation der mRNA) führte zu einer Viabilitätsreduktion von $30 \%$. Hong et al. berichten Ähnliches, nach siRNA-vermittelter mRNA-Deregulation in den murinen Zelllinien NIH3T3 und C2C12 sowie in humanen Fibroblasten und HeLa Zellen, beobachteten Sie eine reduzierte Zellviabilität aufgrund vermehrter fehlerhafter Segregation von Chromosomen, die zu einer verstärkten chromosomalen Instabilität führte (Hong et al. 2009). CKAP2 ist in mehreren Tumorentitäten hochreguliert, unter anderem in Magenkarzinomen sowie B- und TZelllymphomen (Bae et al. 2003; Maouche-Chretien et al. 1998; Eichmuller et al. 2001). Allerdings gibt es bis jetzt keine Daten zum kolorektalen Karzinom in der Literatur.

Seki und Fang (2007) beschreiben die Funktion von CKAP2. Physiologischerweise scheint CKAP2 ein Substrat des APC/C-Komplexes zu sein, das während des Mitoseendes degradiert wird. Eine künstliche Überexpression führte in HeLa-Zellen zu einem Zellzyklusarrest in der 
Mitose. Hiernach hätte CKAP2 eine tumorsuppressive Funktion. Allerdings scheint es aufgrund der regelmäßigen Überexpression von $C K A P 2$ in verschiedenen Tumorentitäten, wie auch in den von uns untersuchten Primärtumoren und Zelllinien sowie der starken Viabilitätsreduktion nach Ausschaltung wahrscheinlich, dass CKAP2 eine weitere onkogene Funktion hat, die noch nicht bekannt ist.

\subsubsection{SLC7A1 (,solute carrier family 7 (cationic amino acid transporter, $y+$ system), member 1")}

Die Expression von SLC7A1 ist in den Primärtumoren gegenüber normaler Kolonmukosa zweifach erhöht; alle 25 Zelllinien zeigen ebenfalls eine Hochregulation des Gens. Eine mRNA-Reduktion um 80\% führte zu einem Viabilitätsverlust von im Mittel 25\% (1 von 2 siRNAs). SLC7A1 kodiert für einen L-Arginin-Transporter. In humanen Brustkrebszellen (MCF-7) ist das Proteinprodukt von SCL7A1 (CAT-1) exprimiert und sorgt wahrscheinlich für eine ausreichende Versorgung der Zelllinie mit L-Arginin (Abdelmagid et al. 2011). Eine weitere Assoziation dieses Gens mit Neoplasien ist in der Literatur nicht beschrieben, allerdings könnte es aufgrund der starken Hochregulation sowohl in Tumoren als auch in Zelllinien eine wichtige Stoffwechselfunktion in der Tumorzelle haben oder auf eine andere, bisher unbekannte Weise, onkogenes Potential entfalten.

\subsubsection{POLR1D (,polymerase (RNA) I polypeptide $D^{“)}$}

Das Polymerase-(RNA)-I-Polypeptid-D-Gen (POLR1D) kodiert für einen Teil des RNAPolymerase I und III Komplexes. Der Komplex I hilft bei der Produktion von 18S, 5.8S und 28S, während die RNA Polymerase III kleine, essentielle RNAs, zum Beispiel tRNA, 5SrRNA und snRNAs synthetisiert (Martinez-Calvillo et al. 2007). Das POLR1D-Gen liegt im amplifizierten Bereich auf Chromosom 13q. Nur einige der primären Tumoren wiesen eine Überexpression des Gens auf. Allerdings zeigten $60 \%$ der Zelllinien eine Überexpression. Eine Herunterregulation des Gens um 60\% führte zu einem Viabilitätsverlust von 23\%. Ähnliches wird von Sheffer et al. beschrieben, sie fanden bei der Integration von ArrayCGH(Affymetrix-SNP-Arrays) und Genexpressionsdaten ebenfalls ein Amplikon auf Chromosom 13q und fanden POLRID in $42 \%$ der 50 von ihnen untersuchten Tumoren überexprimiert. Dabei korrelierte die Überexpression mit genomischen Zugewinnen (Sheffer et al. 2009). Der Zugewinn und die Überexpression von POLRD1 scheinen daher Tumorzellen einen Selektionsvorteil zu bieten. Auf welche Weise POLRD1 prokanzerogen wirkt muss in weiteren Studien geklärt werden. 


\subsubsection{ZNF198}

Das Zink-Finger-198-Gen (ZNF198) war in den Primärtumoren um das 2,96-fache hochreguliert sowie in 53\% der Zelllinien überexprimiert, eine Reduktion der Genexpression um $43 \%$ führte zu einer Verminderung der Viabilität um 20\%. Über die physiologische Funktion von ZNF198 ist noch nicht viel bekannt, es könnte sich um einen Transkriptionsfaktor (Baumann et al. 2003) handeln, ZNF198 könnte allerdings auch einen Teil des BHC-Deacetylase-Komplexes darstellen. ZNF198 kann bei einer Translokation von Chromosom 8 und 13 ein Fusionsgen mit dem Fibroblast-Growth-Faktor 1 (FGR1) bilden, dieses Fusionsgen aktiviert den NOTCH-Signalweg (Ren und Cowell 2011). Unsere Untersuchungen lassen vermuten, dass ZNF198 möglicherweise zum Tumorerhalt oder dessen Bildung auf eine bisher unbekannte Art beiträgt.

\subsection{Ausblick}

Im Rahmen dieser Arbeit wurden zwei Regionen auf Chromosom 13q identifiziert, die in kolorektalen Karzinomen Zugewinne zeigten. Durch Genexpressionsanalysen konnten Gene separiert werden, die in diesen Regionen liegen und die in Zelllinien und Tumoren überexprimiert waren. Per RNA-Interferenz wurden diese Gene ausgeschaltet um zu testen, ob sie für die Viabilität der Tumorzellen eine Rolle spielen. Einige wenige der 13 gefundenen Gene wurde bereits als potentiell krebsfördernd beschrieben, andere der Gene weisen interessante Assoziationen zu beim kolorektalen Karzinom deregulierten Signalwegen auf.

Im Anschluss an diese Studie wurden weitere Untersuchungen durchgeführt, um die Ergebnisse näher zu charakterisieren (diese sind allerdings nicht Gegenstand der vorliegenden Arbeit). Initial wurde der siRNA Screen in der kolorektalen Zelllinie DLD1 wiederholt. Anschließend wurden für die 17 vielversprechendsten Zielgene die Experimente mit weiteren 2 siRNAs sowie den 2 siRNAs aus dem Primärscreen in den Zelllinien SW480, HT29 und DLD1 wiederholt.

Insgesamt fanden sich 8 Gene, bei denen eine siRNA-vermittelte Deregulation zu starken Viabilitätsverlusten in den Zelllinien führte. 6 der 13 in dieser Arbeit beschriebenen Gene (NUPL1, DIS3, POMP, LNX2, SLC7A1 und POLRD1) waren darunter. Um die Funktion der Gene aufzuklären, wurden für die 8 Zielgene mikroarraybasierte Genexpressionsanalysen nach siRNA-Deregulation durchgeführt. Es zeigte sich, dass als Folge der Deregulation wichtige Signalwege der Zelle verändert wurden. RNAi gegen POMP und NUPL1 führte zu 
einer Veränderung der Zielgene von SMAD4. Das Ausschalten von LNX2 deregulierte Zielgene von TCF4 und, wie aus der Literatur antizipiert, NOTCH1 Zielgene.

Ein Manuskript, welches diese Ergebnisse zusammenfasst, befindet sich zum Zeitpunkt der Abgabe dieser Arbeit im Begutachtungsverfahren. Weitere Experimente sollen die der Viabilitätsreduktion zugrundeliegenden Signalwege genauer charakterisieren, momentan werden die Veränderungen im Transkriptom nach siRNA vermitteltem Gen-Silencing erneut mit Mikroarrays zu verschiedenen Zeitpunkten nach siRNA-Transfektion untersucht, um die zeitliche Abfolge der Veränderungen in der Zelle aufzudecken. Wir hoffen so die Funktion der von uns gefundenen Zielgene weiter zu verstehen, um einerseits aufzudecken, ob und wie sie zur Karzinogenese beitragen und andererseits, um sie auf ihre Eignung als therapeutisches Ziel hin zu untersuchen. 


\section{$5 \quad$ Zusammenfassung}

Kolorektale Karzinome sind durch ein spezifisches Muster chromosomaler Aberrationen charakterisiert, die im Verlauf der Tumorprogression akkumulieren. Obwohl die meisten Tumoren Sequenzgewinne oder Amplifikationen von Chromosom 13q aufweisen, sind die Zielgene dieser Aberration nach wie vor unbekannt.

Um potentielle Onkogene bzw. therapeutische Zielgene auf Chromosom 13q zu identifizieren, wurde eine hochauflösende Analyse dieser Region durchgeführt. Dazu wurden 25 primäre Kolonkarzinome (UICC-II/III) und 15 kolorektale Zelllinien mittels Array-CGH untersucht. Zusätzlich wurden die Genexpressionsprofile dieser Tumoren und Zelllinien mittels WholeGenome-Mikroarrays bestimmt.

67 Gene wiesen sowohl eine vermehrte Kopie-Anzahl als auch ein erhöhtes Expressionsniveau auf. Die Expressionsmuster dieser Gene wurden dann in 25 Kolonkarzinom-Zelllinien mittels Real-Time-PCR validiert, wobei 44 der 67 Gene eine deutliche Überexpression auch in den Zelllinien zeigten. Das Ausschalten von 13 dieser 44 Gene in der Kolonkarzinom-Zelllinie SW480 führte zu einer Reduktion der Zellviabilität von 20-60\%. Diese 13 Gene könnten somit potentielle Onkogene oder mögliche therapeutische Zielgene darstellen. In Folgeexperimenten versuchen wir daher, die der Viabilitätsreduktion zugrundeliegenden Signalwege zu entschlüsseln. 


\section{$6 \quad$ Literaturverzeichnis}

Abdelmagid SA, Rickard JA, McDonald WJ, Thomas LN, Too CK (2011): CAT-1-mediated arginine uptake and regulation of nitric oxide synthases for the survival of human breast cancer cell lines. J Cell Biochem 112, 1084-1092

Altschul SF, Madden TL, Schaffer AA, Zhang J, Zhang Z, Miller W, Lipman DJ (1997): Gapped BLAST and PSI-BLAST: a new generation of protein database search programs. Nucleic Acids Res 25, 3389-3402

Arai E, Ushijima S, Tsuda H, Fujimoto H, Hosoda F, Shibata T, Kondo T, Imoto I, Inazawa J, Hirohashi S, et al. (2008): Genetic clustering of clear cell renal cell carcinoma based on array-comparative genomic hybridization: its association with DNA methylation alteration and patient outcome. Clin Cancer Res $\underline{14}$, 5531-5539

Bae CD, Sung YS, Jeon SM, Suh Y, Yang HK, Kim YI, Park KH, Choi J, Ahn G, Park J, et al. (2003): Up-regulation of cytoskeletal-associated protein 2 in primary human gastric adenocarcinomas. J Cancer Res Clin Oncol 129, 621-630

Baker SJ, Preisinger AC, Jessup JM, Paraskeva C, Markowitz S, Willson JK, Hamilton S, Vogelstein B (1990): p53 gene mutations occur in combination with 17p allelic deletions as late events in colorectal tumorigenesis. Cancer Res $\underline{50}, 7717-7722$

Baumann H, Kunapuli P, Tracy E, Cowell JK (2003): The oncogenic fusion protein-tyrosine kinase ZNF198/fibroblast growth factor receptor-1 has signaling function comparable with interleukin-6 cytokine receptors. J Biol Chem $\underline{278}$, 16198-16208

Bol D, Ebner R (2006): Gene expression profiling in the discovery, optimization and development of novel drugs: one universal screening platform. Pharmacogenomics $\underline{7}$, 227-235 
Boland CR, Thibodeau SN, Hamilton SR, Sidransky D, Eshleman JR, Burt RW, Meltzer SJ, Rodriguez-Bigas MA, Fodde R, Ranzani GN, et al. (1998): A National Cancer Institute Workshop on Microsatellite Instability for cancer detection and familial predisposition: development of international criteria for the determination of microsatellite instability in colorectal cancer. Cancer Res $\underline{58}$, 5248-5257

Bolstad BM, Irizarry RA, Astrand M, Speed TP (2003): A comparison of normalization methods for high density oligonucleotide array data based on variance and bias. Bioinformatics $\underline{19}, 185-193$

Bunz F, Dutriaux A, Lengauer C, Waldman T, Zhou S, Brown JP, Sedivy JM, Kinzler KW, Vogelstein B (1998): Requirement for p53 and p21 to sustain G2 arrest after DNA damage. Science $\underline{282}, 1497-1501$

Bustin SA (2000): Absolute quantification of mRNA using real-time reverse transcription polymerase chain reaction assays. J Mol Endocrinol 25, 169-193

Bustin SA, Benes V, Garson JA, Hellemans J, Huggett J, Kubista M, Mueller R, Nolan T, Pfaffl MW, Shipley GL, et al. (2009): The MIQE guidelines: minimum information for publication of quantitative real-time PCR experiments. Clin Chem $\underline{55}$, 611-622

Cahill DP, Lengauer C, Yu J, Riggins GJ, Willson JK, Markowitz SD, Kinzler KW, Vogelstein B (1998): Mutations of mitotic checkpoint genes in human cancers. Nature $\underline{392}, 300-303$

Campbell SL, Khosravi-Far R, Rossman KL, Clark GJ, Der CJ (1998): Increasing complexity of Ras signaling. Oncogene $\underline{17}, 1395-1413$

Camps J, Grade M, Nguyen QT, Hormann P, Becker S, Hummon AB, Rodriguez V, Chandrasekharappa S, Chen Y, Difilippantonio MJ, et al. (2008): Chromosomal 
breakpoints in primary colon cancer cluster at sites of structural variants in the genome. Cancer Res $\underline{68}, 1284-1295$

Camps J, Nguyen QT, Padilla-Nash HM, Knutsen T, McNeil NE, Wangsa D, Hummon AB, Grade M, Ried T, Difilippantonio MJ (2009): Integrative genomics reveals mechanisms of copy number alterations responsible for transcriptional deregulation in colorectal cancer. Genes Chromosomes Cancer $\underline{48}$, 1002-1017

Caplen NJ, Mousses S (2003): Short interfering RNA (siRNA)-mediated RNA interference (RNAi) in human cells. Ann N Y Acad Sci 1002, 56-62

Chapman MA, Lawrence MS, Keats JJ, Cibulskis K, Sougnez C, Schinzel AC, Harview CL, Brunet JP, Ahmann GJ, Adli M, et al. (2011): Initial genome sequencing and analysis of multiple myeloma. Nature $\underline{471}, 467-472$

Chen D, Frezza M, Schmitt S, Kanwar J, Q PD (2011): Bortezomib as the first proteasome inhibitor anticancer drug: current status and future perspectives. Curr Cancer Drug Targets $\underline{11}, 239-253$

Chen HH, Yan JJ, Chen WC, Kuo MT, Lai YH, Lai WW, Liu HS, Su WC (2011): Predictive and prognostic value of human copper transporter 1 (hCtr1) in patients with stage III non-small-cell lung cancer receiving first-line platinum-based doublet chemotherapy. Lung Cancer (,Epub ahead of print“")

Chow E, Macrae F (2005): A review of juvenile polyposis syndrome. J Gastroenterol Hepatol $\underline{20}, 1634-1640$

Corson TW, Gallie BL (2007): One hit, two hits, three hits, more? Genomic changes in the development of retinoblastoma. Genes Chromosomes Cancer $\underline{46}, 617-634$

Day DW, Morson BC (1978): The adenoma-carcinoma sequence. Major Probl Pathol 10, 5871 
Deng Y, Chan SS, Chang S (2008): Telomere dysfunction and tumour suppression: the senescence connection. Nat Rev Cancer $\underline{8}, 450-458$

Douglas EJ, Fiegler H, Rowan A, Halford S, Bicknell DC, Bodmer W, Tomlinson IP, Carter NP (2004): Array comparative genomic hybridization analysis of colorectal cancer cell lines and primary carcinomas. Cancer Res $\underline{64}$, 4817-4825

Dunham A, Matthews LH, Burton J, Ashurst JL, Howe KL, Ashcroft KJ, Beare DM, Burford DC, Hunt SE, Griffiths-Jones S, et al. (2004): The DNA sequence and analysis of human chromosome 13 . Nature $\underline{428}, 522-528$

Eberl: Malignom; in: Lehratlas der Koloskopie, hrsg. v. Messelmann H; Thieme, Stuttgart $2004,81-88$

Ee HC, Erler T, Bhathal PS, Young GP, James RJ (1995): Cdx-2 homeodomain protein expression in human and rat colorectal adenoma and carcinoma. Am J Pathol $\underline{147}, 586-$ 592

Eichmuller S, Usener D, Dummer R, Stein A, Thiel D, Schadendorf D (2001): Serological detection of cutaneous T-cell lymphoma-associated antigens. Proc Natl Acad Sci U S A $\underline{98}, 629-634$

Fearon ER (2011): Molecular genetics of colorectal cancer. Annu Rev Pathol $\underline{6}, 479-507$

Fearon ER, Vogelstein B (1990): A genetic model for colorectal tumorigenesis. Cell $\underline{61}$, 759767

Fearon ER, Cho KR, Nigro JM, Kern SE, Simons JW, Ruppert JM, Hamilton SR, Preisinger AC, Thomas G, Kinzler KW, et al. (1990): Identification of a chromosome 18q gene that is altered in colorectal cancers. Science $247,49-56$ 
Firestein R, Bass AJ, Kim SY, Dunn IF, Silver SJ, Guney I, Freed E, Ligon AH, Vena N, Ogino S, et al. (2008): CDK8 is a colorectal cancer oncogene that regulates beta-catenin activity. Nature $\underline{455}, 547-551$

Gaedcke J, Grade M, Jung K, Schirmer M, Jo P, Obermeyer C, Wolff HA, Herrmann MK, Beissbarth T, Becker H, et al. (2010): KRAS and BRAF mutations in patients with rectal cancer treated with preoperative chemoradiotherapy. Radiother Oncol $\underline{94}$, 76-81

Galiatsatos P, Foulkes WD (2006): Familial adenomatous polyposis. Am J Gastroenterol 101, 385-398

Ganem NJ, Godinho SA, Pellman D (2009): A mechanism linking extra centrosomes to chromosomal instability. Nature $\underline{460}, 278-282$

Ghadimi BM, Sackett DL, Difilippantonio MJ, Schrock E, Neumann T, Jauho A, Auer G, Ried T (2000): Centrosome amplification and instability occurs exclusively in aneuploid, but not in diploid colorectal cancer cell lines, and correlates with numerical chromosomal aberrations. Genes Chromosomes Cancer 27, 183-190

Ghadimi BM, Grade M, Liersch T, Langer C, Siemer A, Fuzesi L, Becker H (2003): Gain of chromosome 8q23-24 is a predictive marker for lymph node positivity in colorectal cancer. Clin Cancer Res $\underline{9}, 1808-1814$

Goossens K, Van Poucke M, Van Soom A, Vandesompele J, Van Zeveren A, Peelman LJ (2005): Selection of reference genes for quantitative real-time PCR in bovine preimplantation embryos. BMC Dev Biol $\underline{5}, 27$

Grade M, Becker H, Liersch T, Ried T, Ghadimi BM (2006): Molecular cytogenetics: genomic imbalances in colorectal cancer and their clinical impact. Cell Oncol $\underline{28}, 71-84$ 
Grade M, Hormann P, Becker S, Hummon AB, Wangsa D, Varma S, Simon R, Liersch T, Becker H, Difilippantonio MJ, et al. (2007): Gene expression profiling reveals a massive, aneuploidy-dependent transcriptional deregulation and distinct differences between lymph node-negative and lymph node-positive colon carcinomas. Cancer Res $\underline{67}, 41-56$

Grade M, Hummon AB, Camps J, Emons G, Spitzner M, Gaedcke J, Hoermann P, Ebner R, Becker H, Difilippantonio MJ, et al. (2011): A genomic strategy for the functional validation of colorectal cancer genes identifies potential therapeutic targets. Int J Cancer $\underline{128}, 1069-1079$

Guimaraes DP, Hainaut P (2002): TP53: a key gene in human cancer. Biochimie $\underline{84}$, 83-93

Hajra KM, Fearon ER (2002): Cadherin and catenin alterations in human cancer. Genes Chromosomes Cancer $\underline{34}, 255-268$

Halazonetis TD, Gorgoulis VG, Bartek J (2008): An oncogene-induced DNA damage model for cancer development. Science $\underline{319}, 1352-1355$

Hanahan D, Weinberg RA (2000): The hallmarks of cancer. Cell $\underline{100}, 57-70$

Hanahan D, Weinberg RA (2011): Hallmarks of cancer: the next generation. Cell 144, 646674

Hanski C, Itzkowitz SH (2000): Translating the knowledge of molecular alterations that occur during colon carcinogenesis into clinically relevant solutions. Ann N Y Acad Sci 910, $1-9$

Hawkins NJ, Gorman P, Tomlinson IP, Bullpitt P, Ward RL (2000): Colorectal carcinomas arising in the hyperplastic polyposis syndrome progress through the chromosomal instability pathway. Am J Pathol 157, 385-392 
Hermsen M, Postma C, Baak J, Weiss M, Rapallo A, Sciutto A, Roemen G, Arends JW, Williams R, Giaretti W, et al. (2002): Colorectal adenoma to carcinoma progression follows multiple pathways of chromosomal instability. Gastroenterology $\underline{123}$, 11091119

Hinoi T, Loda M, Fearon ER (2003): Silencing of CDX2 expression in colon cancer via a dominant repression pathway. J Biol Chem $\underline{278}, 44608-44616$

Hong KU, Kim E, Bae CD, Park J (2009): TMAP/CKAP2 is essential for proper chromosome segregation. Cell Cycle $\underline{8}, 314-324$

$\mathrm{Hu}$ T, Gerace L (1998): cDNA cloning and analysis of the expression of nucleoporin p45. Gene $\underline{221}, 245-253$

Hughes S, Williams RD, Webb E, Houlston RS (2006): Meta-analysis and pooled re-analysis of copy number changes in colorectal cancer detected by comparative genomic hybridization. Anticancer Res $\underline{26}, 3439-3444$

Huppi K, Martin SE, Caplen NJ (2005): Defining and assaying RNAi in mammalian cells. Mol Cell $\underline{17}, 1-10$

Huxley RR, Ansary-Moghaddam A, Clifton P, Czernichow S, Parr CL, Woodward M (2009): The impact of dietary and lifestyle risk factors on risk of colorectal cancer: a quantitative overview of the epidemiological evidence. Int J Cancer $\underline{125}, 171-180$

Iacopetta B, Grieu F, Amanuel B (2010): Microsatellite instability in colorectal cancer. Asia Pac J Clin Oncol $\underline{6}, 260-269$

Imbeaud S, Graudens E, Boulanger V, Barlet X, Zaborski P, Eveno E, Mueller O, Schroeder A, Auffray C (2005): Towards standardization of RNA quality assessment using user- 
independent classifiers of microcapillary electrophoresis traces. Nucleic Acids Res $\underline{33}$, e56

Issa JP (2004): CpG island methylator phenotype in cancer. Nat Rev Cancer $\underline{4}$, 988-993.

Jaiswal AS, Narayan S (2001): Upstream stimulating factor-1 (USF1) and USF2 bind to and activate the promoter of the adenomatous polyposis coli (APC) tumor suppressor gene. J Cell Biochem $\underline{81}, 262-277$

Jass JR (2007): Classification of colorectal cancer based on correlation of clinical, morphological and molecular features. Histopathology $\underline{50}, 113-130$

Kaimaktchiev V, Terracciano L, Tornillo L, Spichtin H, Stoios D, Bundi M, Korcheva V, Mirlacher M, Loda M, Sauter G, et al. (2004): The homeobox intestinal differentiation factor CDX2 is selectively expressed in gastrointestinal adenocarcinomas. Mod Pathol $\underline{17}, 1392-1399$

Kim YR, Song SY, Kim SS, An CH, Lee SH, Yoo NJ (2010): Mutational and expressional analysis of RFC3, a clamp loader in DNA replication, in gastric and colorectal cancers. Hum Pathol $\underline{41}$, 1431-1437

Koch HB, Zhang R, Verdoodt B, Bailey A, Zhang CD, Yates JR, 3rd, Menssen A, Hermeking H (2007): Large-scale identification of c-MYC-associated proteins using a combined TAP/MudPIT approach. Cell Cycle $\underline{6}, 205-217$

Laird PW (2005): Cancer epigenetics. Hum Mol Genet 14 Spec No 1, R65-76

Leslie A, Pratt NR, Gillespie K, Sales M, Kernohan NM, Smith G, Wolf CR, Carey FA, Steele RJ (2003): Mutations of APC, K-ras, and p53 are associated with specific chromosomal aberrations in colorectal adenocarcinomas. Cancer Res $\underline{63}, 4656-4661$ 
Leslie A, Stewart A, Baty DU, Mechan D, McGreavey L, Smith G, Wolf CR, Sales M, Pratt NR, Steele RJ, et al. (2006): Chromosomal changes in colorectal adenomas: relationship to gene mutations and potential for clinical utility. Genes Chromosomes Cancer $\underline{45}$, 126-135

Liang L, Qu L, Ding Y (2007): Protein and mRNA characterization in human colorectal carcinoma cell lines with different metastatic potentials. Cancer Invest 25, 427-434

Lievre A, Bachet JB, Le Corre D, Boige V, Landi B, Emile JF, Cote JF, Tomasic G, Penna C, Ducreux, et al. (2006): KRAS mutation status is predictive of response to cetuximab therapy in colorectal cancer. Cancer Res $\underline{66}, 3992-3995$.

Lips EH, de Graaf EJ, Tollenaar RA, van Eijk R, Oosting J, Szuhai K, Karsten T, Nanya Y, Ogawa S, van de Velde CJ, et al. (2007): Single nucleotide polymorphism array analysis of chromosomal instability patterns discriminates rectal adenomas from carcinomas. J Pathol 212, 269-277

Lips EH, van Eijk R, de Graaf EJ, Doornebosch PG, de Miranda NF, Oosting J, Karsten T, Eilers PH, Tollenaar RA, van Wezel T, et al. (2008): Progression and tumor heterogeneity analysis in early rectal cancer. Clin Cancer Res $\underline{14}, 772-781$

Lum PY, Armour CD, Stepaniants SB, Cavet G, Wolf MK, Butler JS, Hinshaw JC, Garnier P, Prestwich GD, Leonardson A, et al. (2004): Discovering modes of action for therapeutic compounds using a genome-wide screen of yeast heterozygotes. Cell $\underline{116}, 121-137$

Luo J, Emanuele MJ, Li D, Creighton CJ, Schlabach MR, Westbrook TF, Wong KK, Elledge SJ (2009): A genome-wide RNAi screen identifies multiple synthetic lethal interactions with the Ras oncogene. Cell $\underline{137}, 835-848$

Majka J, Chung BY, Burgers PM (2004): Requirement for ATP by the DNA damage checkpoint clamp loader. J Biol Chem 279, 20921-20926 
Malumbres M, Barbacid M (2003): RAS oncogenes: the first 30 years. Nat Rev Cancer $\underline{3}$, $459-465$

Mani A, Gelmann EP (2005): The ubiquitin-proteasome pathway and its role in cancer. J Clin Oncol 23, 4776-4789

Maouche-Chretien L, Deleu N, Badoual C, Fraissignes P, Berger R, Gaulard P, Romeo PH, Leroy-Viard K (1998): Identification of a novel cDNA, encoding a cytoskeletal associated protein, differentially expressed in diffuse large B cell lymphomas. Oncogene 17, 1245-1251

Martin SE, Caplen NJ (2007): Applications of RNA interference in mammalian systems. Annu Rev Genomics Hum Genet $\underline{8}, 81-108$

Martinez-Balibrea E, Martinez-Cardus A, Musulen E, Gines A, Manzano JL, Aranda E, Plasencia C, Neamati N, Abad A (2009): Increased levels of copper efflux transporter ATP7B are associated with poor outcome in colorectal cancer patients receiving oxaliplatin-based chemotherapy. Int J Cancer 124, 2905-2910

Martinez-Calvillo S, Saxena A, Green A, Leland A, Myler PJ (2007): Characterization of the RNA polymerase II and III complexes in Leishmania major. Int J Parasitol 37, 491-502

Mazelin L, Bernet A, Bonod-Bidaud C, Pays L, Arnaud S, Gespach C, Bredesen DE, Scoazec JY, Mehlen P (2004): Netrin-1 controls colorectal tumorigenesis by regulating apoptosis. Nature $\underline{431}, 80-84$

Mehlen P, Mazelin L (2003): The dependence receptors DCC and UNC5H as a link between neuronal guidance and survival. Biol Cell $\underline{95}, 425-436$

Meijer GA, Hermsen MA, Baak JP, van Diest PJ, Meuwissen SG, Belien JA, Hoovers JM, Joenje H, Snijders PJ, Walboomers JM, et al. (1998): Progression from colorectal 
adenoma to carcinoma is associated with non-random chromosomal gains as detected by comparative genomic hybridisation. J Clin Pathol $\underline{51}, 901-909$

Miyamoto S, Rosenberg DW (2011): Role of Notch signaling in colon homeostasis and carcinogenesis. Cancer Sci 102, 1938-1942

Monni O, Barlund M, Mousses S, Kononen J, Sauter G, Heiskanen M, Paavola P, Avela K, Chen YD, Bittner ML, et al. (2001): Comprehensive copy number and gene expression profiling of the 17q23 amplicon in human breast cancer. Proc Natl Acad Sci U S A $\underline{98}$, $5711-5716$

Moss SF, Liu TC, Petrotos A, Hsu TM, Gold LI, Holt PR (1996): Inward growth of colonic adenomatous polyps. Gastroenterology $\underline{111}, 1425-1432$

Murakami H, Goto DB, Toda T, Chen ES, Grewal SI, Martienssen RA, Yanagida M (2007): Ribonuclease activity of Dis3 is required for mitotic progression and provides a possible link between heterochromatin and kinetochore function. PLoS One 2 , e317

Myllykangas S, Bohling T, Knuutila S (2007): Specificity, selection and significance of gene amplifications in cancer. Semin Cancer Biol 17, 42-55

Nakayama K, Kanzaki A, Terada K, Mutoh M, Ogawa K, Sugiyama T, Takenoshita S, Itoh K, Yaegashi N, Miyazaki K, et al. (2004): Prognostic value of the Cu-transporting ATPase in ovarian carcinoma patients receiving cisplatin-based chemotherapy. Clin Cancer Res $\underline{10}, 2804-2811$

Neklason DW, Tuohy TM, Stevens J, Otterud B, Baird L, Kerber RA, Samowitz WS, Kuwada SK, Leppert MF, Burt RW, (2010): Colorectal adenomas and cancer link to chromosome 13q22.1-13q31.3 in a large family with excess colorectal cancer. J Med Genet $\underline{47}, 692-699$ 
Ngo VN, Davis RE, Lamy L, Yu X, Zhao H, Lenz G, Lam LT, Dave S, Yang L, Powell J, et al. (2006): A loss-of-function RNA interference screen for molecular targets in cancer. Nature $\underline{441}, 106-110$

Nie J, McGill MA, Dermer M, Dho SE, Wolting CD, McGlade CJ (2002): LNX functions as a RING type E3 ubiquitin ligase that targets the cell fate determinant Numb for ubiquitin-dependent degradation. EMBO J 21, 93-102

O'Neil BH, Raftery L, Calvo BF, Chakravarthy AB, Ivanova A, Myers MO, Kim HJ, Chan E, Wise PE, Caskey LS, et al. (2010): A phase I study of bortezomib in combination with standard 5-fluorouracil and external-beam radiation therapy for the treatment of locally advanced or metastatic rectal cancer. Clin Colorectal Cancer $\underline{9}, 119-125$

Ozaki T, Schaefer KL, Wai D, Buerger H, Flege S, Lindner N, Kevric M, Diallo R, Bankfalvi A, Brinkschmidt C,et al. (2002): Genetic imbalances revealed by comparative genomic hybridization in osteosarcomas. Int J Cancer 102, 355-365

Paredes-Zaglul A, Kang JJ, Essig YP, Mao W, Irby R, Wloch M, Yeatman TJ (1998): Analysis of colorectal cancer by comparative genomic hybridization: evidence for induction of the metastatic phenotype by loss of tumor suppressor genes. Clin Cancer Res $\underline{4}, 879-886$

Park SJ, Rashid A, Lee JH, Kim SG, Hamilton SR, Wu TT (2003): Frequent CpG island methylation in serrated adenomas of the colorectum. Am J Pathol $\underline{162}, 815-822$

Pfaffl MW: Quantification Strategies in Real-Time PCR; in: A-Z of Quantitative PCR; hrsg. Bustin S, International University Line, La Jolla 2004, 87-112

Pino MS, Chung DC (2011): Microsatellite instability in the management of colorectal cancer. Expert Rev Gastroenterol Hepatol ㅁ, 385-399 
Polakis P (2007): The many ways of Wnt in cancer. Curr Opin Genet Dev $\underline{17}, 45-51$

Pollack JR, Sorlie T, Perou CM, Rees CA, Jeffrey SS, Lonning PE, Tibshirani R, Botstein D, Borresen-Dale AL, Brown PO (2002): Microarray analysis reveals a major direct role of DNA copy number alteration in the transcriptional program of human breast tumors. Proc Natl Acad Sci U S A 99, 12963-12968

Pryor JG, Brown-Kipphut BA, Iqbal A, Scott GA (2011): Microarray comparative genomic hybridization detection of copy number changes in desmoplastic melanoma and malignant peripheral nerve sheath tumor. Am J Dermatopathol $\underline{33}, 780-785$

Qiagen: TurboCapture ${ }^{\mathrm{TM}}$ mRNA Handbook; in: TurboCapture ${ }^{\mathrm{TM}}$ mRNA Handbook Second Edition, Qiagen, Hilden 2008, 8

Rajeevan MS, Ranamukhaarachchi DG, Vernon SD, Unger ER (2001a): Use of real-time quantitative PCR to validate the results of cDNA array and differential display PCR technologies. Methods $\underline{25}, 443-451$

Rajeevan MS, Vernon SD, Taysavang N, Unger ER (2001b): Validation of array-based gene expression profiles by real-time (kinetic) RT-PCR. J Mol Diagn $\underline{3}, 26-31$

Ramakers C, Ruijter JM, Deprez RH, Moorman AF (2003): Assumption-free analysis of quantitative real-time polymerase chain reaction (PCR) data. Neurosci Lett $\underline{339}, 62-66$

Ren M, Cowell JK (2011): Constitutive Notch pathway activation in murine ZMYM2FGFR1-induced T-cell lymphomas associated with atypical myeloproliferative disease. Blood 117, 6837-6847

Ribic CM, Sargent DJ, Moore MJ, Thibodeau SN, French AJ, Goldberg RM, Hamilton SR, Laurent-Puig P, Gryfe R, Shepherd LE, et al. (2003): Tumor microsatellite-instability 
status as a predictor of benefit from fluorouracil-based adjuvant chemotherapy for colon cancer. N Engl J Med $\underline{349}$, 247-257

Richardson PG, Sonneveld P, Schuster MW, Irwin D, Stadtmauer EA, Facon T, Harousseau JL, Ben-Yehuda D, Lonial S, Goldschmidt H, et al. (2005): Bortezomib or high-dose dexamethasone for relapsed multiple myeloma. N Engl J Med 352, 2487-2498

Ried T, Knutzen R, Steinbeck R, Blegen H, Schrock E, Heselmeyer K, du Manoir S, Auer G (1996): Comparative genomic hybridization reveals a specific pattern of chromosomal gains and losses during the genesis of colorectal tumors. Genes Chromosomes Cancer $\underline{15}, 234-245$

Robert-Koch-Institut: Darm; in: Krebs in Deutschland 2005/2006. Häufigkeiten und Trends ; hrsg. Robert Koch-Institut und Gesellschaft der epidemiologischen Krebsregister in Deutschland e. V., Berlin 2010, 36

Rozen S, Skaletsky H (2000): Primer3 on the WWW for general users and for biologist programmers. Methods Mol Biol 132, 365-386

Schlabach MR, Luo J, Solimini NL, Hu G, Xu Q, Li MZ, Zhao Z, Smogorzewska A, Sowa ME, Ang XL, et al. (2008): Cancer proliferation gene discovery through functional genomics. Science $\underline{319}, 620-624$

Schmiegel W, Reinacher-Schick A, Arnold D, Graeven U, Heinemann V, Porschen R, Riemann J, Rodel C, Sauer R, Wieser M, et al. (2008): Update S3-guideline "colorectal cancer" 2008. Z Gastroenterol $\underline{46}, 799-840$

Schmoll DA, A. Lang, U. Graeven (2007): "Kolorektales Karzinom." Abgerufen am 09.08.2010 von http://www.onkodin.de; hrsg. v. Link H; Kaiserslautern 2010

Schroeder A, Mueller O, Stocker S, Salowsky R, Leiber M, Gassmann M, Lightfoot S, Menzel W, Granzow M, Ragg T, et al. (2006): The RIN: an RNA integrity number for assigning integrity values to RNA measurements. BMC Mol Biol 7, 3 
Seiden-Long IM, Brown KR, Shih W, Wigle DA, Radulovich N, Jurisica I, Tsao MS (2006): Transcriptional targets of hepatocyte growth factor signaling and Ki-ras oncogene activation in colorectal cancer. Oncogene $\underline{25}, 91-102$

Seki A, Fang G (2007): CKAP2 is a spindle-associated protein degraded by APC/C-Cdh1 during mitotic exit. J Biol Chem $\underline{282}$, 15103-15113

Sheffer M, Bacolod MD, Zuk O, Giardina SF, Pincas H, Barany F, Paty PB, Gerald WL, Notterman DA, Domany E, et al. (2009): Association of survival and disease progression with chromosomal instability: a genomic exploration of colorectal cancer. Proc Natl Acad Sci U S A $\underline{106}, 7131-7136$

Sinicrope FA, Rego RL, Halling KC, Foster N, Sargent DJ, La Plant B, French AJ, Laurie JA, Goldberg RM, Thiboudeau SN, et al.(2006): Prognostic impact of microsatellite instability and DNA ploidy in human colon carcinoma patients. Gastroenterology $\underline{131}$, 729-737

Smyth G (2005). Limma: linear models for microarray data; in: Bioinformatics and Computational Biology Solutions using R and Bioconductor, hrsg. v. Gentleman R, Carey V, u.a.; Springer, New York 2005, 397-420

Stryker SJ, Wolff BG, Culp CE, Libbe SD, Ilstrup DM, MacCarty RL (1987): Natural history of untreated colonic polyps. Gastroenterology $\underline{93}$, 1009-1013

Teodoro JG, Evans SK, Green MR (2007): Inhibition of tumor angiogenesis by p53: a new role for the guardian of the genome. J Mol Med (Berl) $\underline{85}$, 1175-1186

Tsafrir D, Bacolod M, Selvanayagam Z, Tsafrir I, Shia J, Zeng Z, Liu H, Krier C, Stengel RF, Baraby F, et al. (2006): Relationship of gene expression and chromosomal abnormalities in colorectal cancer. Cancer Res $\underline{66}, 2129-2137$ 
U.S.-Preventive-Services-Task-Force (2008): Screening for colorectal cancer: U.S. Preventive Services Task Force recommendation statement. Ann Intern Med 149, 627-637

van der Velden VH, Hochhaus A, Cazzaniga G, Szczepanski T, Gabert J, van Dongen JJ (2003): Detection of minimal residual disease in hematologic malignancies by real-time quantitative PCR: principles, approaches, and laboratory aspects. Leukemia 17, 10131034

van Es JH, van Gijn ME, Riccio O, van den Born M, Vooijs M, Begthel H, Cozijnsen M, Robine S, Winton DJ, Radtke F, et al. (2005): Notch/gamma-secretase inhibition turns proliferative cells in intestinal crypts and adenomas into goblet cells. Nature $\underline{435}, 959$ 963

Vogelstein B, Fearon ER, Hamilton SR, Kern SE, Preisinger AC, Leppert M, Nakamura Y, White R, Smits AM, Bos JL (1988): Genetic alterations during colorectal-tumor development. N Engl J Med 319, 525-532

Vousden KH, Prives C (2009): Blinded by the Light: The Growing Complexity of p53. Cell $\underline{137}, 413-431$

Wang Z, Cummins JM, Shen D, Cahill DP, Jallepalli PV, Wang TL, Parsons DW, Traverso G, Awad M, Sillman N, et al. (2004): Three classes of genes mutated in colorectal cancers with chromosomal instability. Cancer Res $\underline{64}$, 2998-3001

Wittekind C (2010). TNM-Klassifikation maligner Tumoren, 7. Auflage, hrsg. v. Wittekind C und Bootz F; Wiley-Liss, Heidelberg/Berlin 2010, 66-70

Yokota J, Ookawa K, Nishikawa R, Sameshima Y (1991): Tumor suppressor genes involved in metastasis of lung and colorectal carcinomas. Princess Takamatsu Symp 22, 71-76 


\section{Abbildungsverzeichnis}

Abbildung 1: Verteilung und Lokalisation des kolorektalen Karzinoms 3

Abbildung 2: Genetisches Progressionsmodell der kolorektalen Karzinogenese 6

Abbildung 3: Chromosomales Progressionsmodell der kolorektalen Karzinogenese 12

Abbildung 4: Schematische Darstellung der RNA-Isolation und cDNA-Synthese in einer Capture Plate. 24

Abbildung 5: Prinzip des Sybr Green Assays

Abbildung 6: Zwei Schmelzkurvenanalysen, einmal mit einem spezifischen Produkt (A) und einmal mit zwei unspezifischen Produkten (B). Hier ist jeweils die erste Ableitung des emittierten Lichtes gegen die Temperatur dargestellt.

Abbildung 7: A: Schematischer Aufbau einer siRNA. Diese besteht aus einem 19 Nukleotid großen RNA-Duplex mit einem Überhang von 2 Basenpaaren (bp) pro Seite. B: Funktionsprinzip der siRNA vermittelten Genausschaltung. Eine synthetische siRNA wird in die Zelle gebracht, sie bindet an den RISC-Komplex. Der „Sense“-Strand wird degradiert, der Komplex aktiviert. Dieser kann nun an die Zielsequenz binden und diese denaturieren

Abbildung 8: Schematische Darstellung des siRNA-Screens. Je 7000 SW480 Zellen wurden transfiziert und nach $48 \mathrm{~h}$ wurde per qRT-PCR die Runterregulation der Zielsequenz bestimmt. Nach $72 \mathrm{~h}$ und $96 \mathrm{~h}$ wurde per „Cell-Titer-Blue-Assay“ die verbleibende Viabilität bestimmt. 36

Abbildung 9: Beispielhaftes Plate-Setup einer siRNA-Transfektion zur Viabilitätsmessung, mit Wildtyp (Wt)-Zellen, Toxizitätskontrolle (nur mit Oligofectamin behandelte 
Zellen), Negativkontrolle (siNEG), Positivkontrollen (siMEGA, siPLK1, siCaspase 8) und vier zu testenden siRNAs.

Abbildung 10: Schematischer Ablauf der Experimente.

Abbildung 11: Zusammenfassung der Array-CGH-Analyse von 31 Patienten für Chromosom 13q und der 15 Zelllinien. Verluste sind in Grün dargestellt, Zugewinne in Rot. Die Regionen 13q12.1q12.3 und 13q34 sind zusätzlich markiert.

Abbildung 12: Beispielhafte Darstellung zweier Array-CGH Experimente (Primärtumor und Zelllinie) Zugewinne hier rot, Verluste grün. Die Regionen mit regelmäßigen Zugewinnen/Amplifikationen sind markiert.

Abbildung 13: Expressionsmuster von 28 deregulierten Proben in der Region 13q12.1-12.3 im Vergleich zwischen Zelllinien und RNA-Referenz-Pool. Eine Expression von 1 bedeutet gleiche mRNA-Level in Zelllinie und Referenz.

Abbildung 14: Expressionsmuster von den ersten 34 deregulierten Proben in der Region 13q12.1-12.3 im Vergleich zwischen Zelllinien und RNA Referenz Pool. Eine Expression von 1 bedeutet gleiche mRNA-Expressions-Level in Zelllinie und Referenz.

Abbildung 15: Expressionsmuster von weiteren 34 deregulierten Proben in der Region 13q12.1-12.3 im Vergleich zwischen Zelllinien und RNA-Referenz-Pool. Eine Expression von 1 bedeutet gleiche mRNA-Level in Zelllinie und Referenz. 44

Abbildung 16: Gelelektrophorese der Produkte von 47 der 67 in dieser Arbeit verwendeten Primer. LNX2 und PAN3 wurden jeweils aus 2 Reaktionsreplikaten aufgetragen, um eine Reproduzierbarkeit zu zeigen. 45

Abbildung 17: Heatmap der per qRT-PCR gemessenen Genexpression in 25 kolorektalen Zelllinien relativ zu einem Normal-Gewebe-Pool. Hochregulierte Gene sind in Rot dargestellt, herunterregulierte in Grün 
Abbildung 18: Dargestellt ist in Blau die verbleibende Viabilität von SW480 72h nach siRNA-Transfektion im Verhältnis zu siNEG-transfizierten-Zellen. In Rot ist die verbleibende mRNA-Expression des siRNA-Target-Gens 48h nach Transfektion abgebildet, ebenfalls im Verhältnis zu siNEG-transfizierten-Zellen 56

Abbildung 19: Dargestellt ist in Blau die verbleibende Viabilität von SW480 72h nach siRNA-Transfektion im Verhältnis zu siNEG-transfizierten-Zellen. In Rot ist die verbleibende mRNA-Expression des siRNA-Target-Gens 48h nach Transfektion abgebildet, ebenfalls im Verhältnis zu siNEG-transfizierten-Zellen 57

Abbildung 20: Dargestellt ist in Blau die verbleibende Viabilität von SW480 96h nach siRNA-Transfektion im Verhältnis zu siNEG-transfizierten-Zellen. In Rot ist die verbleibende mRNA-Expression des siRNA-Target-Gens 48h nach Transfektion abgebildet, ebenfalls im Verhältnis zu siNEG-transfizierten-Zellen 58

Abbildung 21: Dargestellt ist in Blau die verbleibende Viabilität von SW480 96h nach siRNA-Transfektion im Verhältnis zu siNEG-transfizierten-Zellen. In Rot ist die verbleibende mRNA-Expression des siRNA-Target-Gens 48h nach Transfektion abgebildet, ebenfalls im Verhältnis zu siNEG-transfizierten-Zellen 59

Abbildung 22: Veränderung des mRNA-Expressionsniveaus von POMP nach siRNAInterferenz. Diese wurden mit dem im Laufe dieser Arbeit entwickelten PCR-Setup gemessen .68 


\section{Tabellenverzeichnis}

Tabelle 1: TNM-Klassifikation des kolorektalen Karzinoms 2

Tabelle 2: Stadieneinteilung des kolorektalen Karzinoms nach der UICC 2

Tabelle 3: Auflistung aller verwendeten Zelllinien mit Angaben über Wachstumsbedürfnisse und Herkunft 17

Tabelle 4: Liste aller Primer dieser Arbeit, unter Angabe ihrer Ziel-Referenz-SequenzNummer und der Anzahl an Spleiß-Varianten des Ziel Gens. Zusätzlich sind die Primersequenzen der Paare sowie ihre Lokalisation im Transkript aufgeführt. Die eingesetzte Primerkonzentration ist ebenfalls aufgeführt 28

Tabelle 5: PCR-Mastermix 29

Tabelle 6: Beispiel eines Platesetups im Zelllinienscreen zur Bestimmung des Expressionsmusters eines Gens. Jede Reaktion wurde in Triplikaten durchgeführt, um eventuelle Ausreißer zu vermeiden. Zusätzlich zu den 25 Zelllinien sind eine Wasserkontrolle (NTC), 3 verschiedene Normalgewebepoole (Kolon, Normal, Rektum) und ein Referenz-cDNA-Pool mitgeführt worden.

Tabelle 7: PCR Protokoll, die ersten beiden Schritte wurden jeweils ein Mal durchgeführt, nach Schritt 5 wurde zu Schritt 3 zurückgegangen und dieser insgesamt 40x wiederholt.

Tabelle 8: Liste aller verwendeten siRNAs, jeweils zwei pro Targetgen sowie der Kontrollen. Dabei ist zu beachten, dass einige siRNAs, obwohl gegen dasselbe Targetgen gerichtet, unterschiedliche Namen tragen. 38 
Tabelle 9: 45 Gene, die sowohl per Mikroarray in den Tumoren und Zelllinien, als auch per PCR in den 25 Zelllinien als überexpremiert gefunden wurden. 46

Tabelle 10: Genexpressionsprofil der 67 Gene in 25 kolorektalen Zelllinien. Die Expression der Gene ist relativ zu normaler Rektummukosa aufgetragen („Fold change“). Aneuploide Zelllinien sind rot markiert, diploide schwarz. Per qRT-PCR nicht detektierbare Expressionen sind mit einem „X“ gekennzeichnet 48

Tabelle 11: Genexpressionsprofil der 67 Gene in 25 kolorektalen Zelllinien. Die Expression der Gene ist relativ zu normaler Kolonmukosa aufgetragen („Fold change“). Aneuploide Zelllinien sind rot markiert, diploide schwarz. Per qRT-PCR nicht detektierbare Expressionen sind mit einem „X“ gekennzeichnet 50

Tabelle 12: Genexpressionsprofil der 67 Gene in 25 kolorektalen Zelllinien. Die Expression der Gene ist relativ zu einem Pool aus Normalgewebe aufgetragen (,Fold change ${ }^{6)}$. Aneuploide Zelllinien sind rot markiert, diploide schwarz. Per qRT-PCR nicht detektierbare Expressionen sind mit einem „X“ gekennzeichnet. 52

Tabelle 13: Liste der siRNAs mit dem stärksten Einfluss auf die Viabilität. Dargestellt sind die verbleibende Menge an mRNA nach $48 \mathrm{~h}$ sowie die verbleibende Viabilität nach $72 \mathrm{~h}$ und $96 \mathrm{~h}$.... 


\section{Abkürzungsverzeichnis}

\begin{tabular}{|c|c|}
\hline ATP & Adenosintriphosphat \\
\hline $\mathrm{bp}$ & Basenpaar \\
\hline${ }^{\circ} \mathrm{C}$ & Grad Celsius \\
\hline ca. & circa \\
\hline cDNA & komplementäre DNA \\
\hline $\mathrm{CGH}$ & „Comparative Genomic Hybridisation" \\
\hline Chr & Chromosom \\
\hline CIMP & „CpG Island Methylator Pathway“ \\
\hline CIN & chromosomale Instabilität \\
\hline cRNA & komplementäre RNA \\
\hline $\mathrm{Ct}$ & „,cycle threshold" / „,crossing threshold" \\
\hline CTP & Cytidintriphosphat \\
\hline Cy3 & Cyanine 3-CTP \\
\hline Cy5 & Cyanine 5-CTP \\
\hline $\mathrm{Da}$ & Dalton \\
\hline DECP & Diethylpyrocarbonat \\
\hline DNA & Desoxyribonukleinsäure \\
\hline dsDNA & Doppelstrang-DNA \\
\hline DTP & Desoxyribonucleosidtriphosphat \\
\hline DTT & Dithiothreitol \\
\hline dUTP & Uridintriphosphat \\
\hline FAP & familiäre adenomatöse Polyposis \\
\hline FBS & Fetal Bovine Serum \\
\hline $5-\mathrm{FU}$ & 5-Fluoruracil \\
\hline GDP & Guanosindiphosphat \\
\hline GTP & Guanosintriphosphat \\
\hline $\mathrm{h}$ & Stunde \\
\hline HNPCC & hereditäres nichtpolypöses kolorektales Karzinom \\
\hline hrsg. v. & herausgegeben von \\
\hline $\mathrm{K}$ & Tausend \\
\hline $\log$ & Logarithmus \\
\hline $\mathrm{LOH}$ & „loss of heterozygosity“ \\
\hline $\mathrm{m}$ & Meter \\
\hline M & Molar \\
\hline $\min$ & Minute \\
\hline MIN & Mikrosatelliteninstabilität \\
\hline MIQE & "minimum information of quantitative real-time PCR experiments" \\
\hline miRNA & micro RNA \\
\hline MMR & „,mismatch repair system“ \\
\hline MOPS & 3- (N-Morpholino) Propansulfonsäure \\
\hline mRNA & Boten-RNA \\
\hline MSI-H & MSI-High \\
\hline
\end{tabular}




$\begin{array}{ll}\text { MSI-L } & \text { MSI-Low } \\ \mathrm{n} & \text { Anzahl } \\ \text { NCBI } & \text { National Center for Biotechnology Information } \\ \text { NCI } & \text { National Cancer Institute } \\ \text { NTC } & \text { "No-Template-Control" } \\ \text { NTP } & \text { Nukleosidtriphosphat } \\ \text { PBS } & \text { Phosphat-gepufferte Salzlösung } \\ \text { PCR } & \text { Polymerase-Kettenreaktion } \\ \text { pH } & \text { negativ dekadischer Logarithmus der H+-Ionen-Konzentration } \\ \text { Präfix d } & \text { desoxy- } \\ \text { qRT-PCR } & \text { semiquantitative Real-Time-Polymerase-Kettenreaktion } \\ \text { Ref. Seq. } & \text { „Reference Sequence“ } \\ \text { RIN } & \text { RNA-Integrität-Nummer } \\ \text { RISC } & \text { RNA-induced-silencing complex } \\ \text { RNA } & \text { Ribonukleinsäure } \\ \text { rRNA } & \text { ribosomale RNA } \\ \text { sek } & \text { Sekunde } \\ \text { siRNA } & \text {,short interfering RNA" } \\ \text { TTP } & \text { Thymidintriphosphat } \\ \text { U/min } & \text { Umdrehungen pro Minute } \\ \text { u.a. } & \text { unter anderem } \\ \text { UICC } & \text { "Union internationale contre le cancer" } \\ \text { UV } & \text { Ultraviolett } \\ \text { V } & \text { Volt } \\ \text { Wt } & \text { Wildtyp }\end{array}$

Vorsätze für

Maßeinheiten

d Dezi-

c Zenti-

m Milli-

$\mu \quad$ Mikro-

n Nano-

$\mathrm{p} \quad$ Piko-

si-Einheiten

$\begin{array}{ll}\mathrm{m} & \text { Meter } \\ \mathrm{g} & \text { Gramm } \\ \mathrm{s} & \text { Sekunde } \\ \mathrm{A} & \text { Ampere } \\ \mathrm{V} & \text { Volt } \\ \mathrm{K} & \text { Kelvin } \\ \mathrm{mol} & \text { Mol } \\ \mathrm{l} & \text { Liter }\end{array}$


